\title{
Die „Italia Pontificia“ und das Kreuzzugsgeschehen
}

\author{
Rudolf Hiestand
}

Italien ist nicht das Land des Kreuzzuges. Urban II., ein Franzose aus der Champagne, rief ihn in Clermont auf französischem Boden aus, und läßt man die alte Streitfrage offen, ob Gottfried von Bouillon ein Franzose oder ein Deutscher war, so waren in mittelalterlicher Sicht alle Anführer des ersten Kreuzzug Franzosen: Gottfrieds Brüder Balduin und Eustach, Robert von der Normandie, Robert von Flandern, die drei Angehörigen einer Königsfamilie Hugo von Vermandois, Bruder Philipps I., Robert von der Normandie, ältester Sohn Wilhelms des Eroberers, und sein Schwager Stephan von Blois, Raimund von St-Gilles und der päpstliche Legat Adhemar von Le Puy. Kein Angehöriger des Kardinalkollegiums oder des weiteren kurialen Personals, kein Erzbischof aus Italien zog mit, nur eher zweitrangige Bischöfe aus Adria, Ariano Irpino, Martirano, von denen letzterer in wenig rühmlicher Art hervortrat ${ }^{1}$. Franzosen waren auch die meisten Chronisten des ersten Kreuzzuges und in der Folge Bernhard von Clairvaux und Ludwig VII., Philipp II. Augustus und der letzte regierende abendländische Herrscher, der sich vor 1291 auf einen Kreuzzug begab, Ludwig IX. bzw. Saint Louis, wie wohl die Mehrzahl der im 12. und 13. Jahrhundert in den Osten aufbrechenden Kreuzfahrer und Pilger aus Frankreich $\mathrm{kam}^{2}$.

In Frankreich hatten ebenso alle Herrscher der Kreuzfahrerstaaten des 12. Jahrhunderts ihre familiären Wurzeln, die lothringischen Herrscher in Jerusalem, die Angevinen, die Lusignans, die tolosanische Dynastie in Tripolis und die

1 Siehe zu ihnen unten S. 645-647. Im Beitrag wurden folgende Abkürzungen verwendet: O 1-3 = Rudolf Hiestand: Papsturkunden für Templer und Johanniter, Göttingen 1972-1985 (Vorarbeiten zum Oriens Pontificius 1-3); RRH = Reinhold RöнRiснт: Regesta Regni Hierosolymitani 1097-1291, Innsbruck 1893; Ders., Additamentum, Innsbruck 1904.

2 Zur Geschichte der Kreuzzüge und der Kreuzfahrerstaaten sei hier aus der Überfülle an Gesamtdarstellungen der letzten Jahrzehnte generell verwiesen auf Hans Eberhard Mayer: Geschichte der Kreuzzüge, 10. Aufl., Stuttgart 2005 mit der Rezeption der aktuellen Forschung, A History of the Crusades, hg.v. Kenneth M. Setron, 6 Bde., Madison 1955-1989, die knappe Zusammenfassung bei Nikolas JASPERT: Geschichte der Kreuzzüge, 3. Aufl., Darmstadt 2006 (Geschichte kompakt), für die Kirchengeschichte auf Wilhelm Нотzецт: Kirchengeschichte Palästinas im Zeitalter der Kreuzzüge, Köln 1980 (Palästinahefte des deutschen Vereins vom heiligen Lande) und Bernard Hamilton: The Latin Church in the Crusader States. The Secular Church, London 1980. Auf die Aufführung von Einzelnachweisen wird bewusst verzichtet. 
Poitevins in Antiochia. Auch der erste lateinische Fürst von Antiochia, Bohemund, war ein nach Süditalien verpflanzter Normanne, der gleichsam zur Rückbindung im Jahre 1106 in das kapetingische Königshaus einheiratete ${ }^{3}$.

Dennoch war der Kreuzzug eine ,internationale“ Bewegung, die alle Teile des Abendlandes umfaßte und unter der führenden Rolle des Papsttums auch die Apenninenhalbinsel religiös, personell, politisch und logistisch einbezog. Und „international“ waren die mit Kreuzzugsidee und -geschehen existentiell verbundenen geistlichen Ritterorden mit den Templern und den Johannitern an erster Stelle. Daher stellt sich die Frage: Was tragen die Forschungen Paul Fridolin Kehrs in den Archiven und Bibliotheken Italiens und die „Italia Pontificia“ zur Geschichte der militärischen Unternehmen in den Osten, der Kreuzfahrerstaaten und der Kreuzfahrerkirche, und was trägt der lateinische Osten zur „Italia Pontificia“ bei? Welches Bild des Kreuzzugsgeschehens und des Anteils des Papsttums an ihm läßt sich aus der „Italia Pontificia“ gewinnen? Angedeutet ist damit schon, daß wir es mit drei, genauer gesagt vier Aspekten zu tun haben: den eigentlichen Kreuzzügen, den Kreuzfahrerstaaten und -kirchen, den Niederlassungen italienischer Seestädte im lateinischen Osten und den Ritterorden, und daß zu trennen ist zwischen der Rolle dieser Kreuzzugswelt in den Beziehungen der Päpste des 12. Jahrhunderts zu den Kirchen und politischen Kräften Italiens ${ }^{4}$ und den neuen Materialien für die Kreuzzugsgeschichte, die als Ergebnis der jahrzehntelangen Forschungen auf der Apenninenhalbinsel in Dutzenden von Berichten unter dem Titel „Papsturkunden in

3 Es ist vielleicht kein Zufall, daß es aus italienischer Sicht keine größere Gesamtdarstellung der Kreuzzüge gibt, die ,kanonischen' Charakter erhalten hätte.

4 IP 1-10; vgl. Paul Fridolin KeHR: Ueber den Plan einer kritischen Ausgabe der Papsturkunden bis Innocenz III., NGG 1896 S. $72-86$ (wieder abgedruckt in: Ders., Ausgewählte Schriften, Bd. 1, hg.v. Rudolf Hiestand, Göttingen 2005 [AAG, phil.hist. Kl., 3. Folge 250], S. 3-17); die Selbstanzeige von IP 1, in: GGN 168 (1906) S. 593-610 (wieder abgedruckt in: KeHR, Schriften [in dieser Anm.] S. 18-35), vgl. dazu auch den Band Hundert Jahre Papsturkundenforschung, Bilanz - Methoden Perspektiven, Akten eines Kolloquiums zum hundertjährigen Bestehen der Regesta Pontificum Romanorum vom 9.-11. Oktober 1996 in Göttingen, hg.v. Dems., Göttingen 2003 (AAG, phil.-hist. Kl., 3. Folge 261); mit dem einleitenden Beitrag: 100 Jahre Papsturkundenwerk, S. 11-44 und für die Italia Pontificia Ders.: Die Italia Pontificia, in: Das Deutsche historische Institut in Rom 1888-1988, hg.v. Reinhard Elze/Arnold Esch, Tübingen 1990 (Bibliothek des Deutschen Historischen Instituts in Rom 70), S. 167-189 und Ders.: Die unvollendete Italia Pontificia, in: Hundert Jahre Papsturkundenforschung (in dieser Anm.) S. 47-57. 
Italien" zusammengefaßt worden sind". Jene ist ein Ausschnitt aus der Geschichte des Papsttums und der Geschichte von Hunderten von Kirchen, Klöstern und politischen Gebilden auf der Apenninenhalbinsel, diese sind ein Teil der „Nachlese“ als erstem Schritt auf dem Weg zur Edition als Krönung des Ganzen und zur „urkundlichen Archivgeschichte“, die Kehr beim Erscheinen des ersten Bandes der „Italia Pontificia“ als das eigentliche Ziel des Unternehmens bezeichnete ${ }^{6}$. Wenn jene sich damit auf den Raum Italiens bezieht und die Kreuzzüge, erst recht die Kreuzfahrerstaaten und die Kreuzfahrerkirche in ihr eo ipso keinen Platz haben können, es sei denn durch Begleiterscheinungen auf italienischem Boden, sind diese ohne jede vorgegebene räumliche oder sachliche Einschränkung nur abhängig von der Überlieferung und hier interessant, soweit dabei aufgrund der streng archivalischen Vorgehensweise nebenbei Nicht-Italica zum Vorschein kamen, Stücke, die nicht Italien, sondern den lateinischen Osten betrafen.

Eine klare Trennung zwischen Italica und Nicht-Italica ist oft deswegen schwierig, weil viele transmarine Kirchen und Klöster und vor allem die großen Ritterorden auch Besitz in Italien hatten, andererseits die italienischen Seestädte und ihre Kirchen durch Niederlassungen im Osten präsent waren ${ }^{7}$. Unübersehbar besteht jedoch in dieser Reziprozität von Anfang an ein Ungleichgewicht, denn eine Nachlese im Osten, die nebenbei Italica zu Tage gefördert hätte, konnte es nicht geben, weil es Archive von lateinischen Kirchen und weltlichen Herrschaften auf dem Boden der einstigen syrischen Kreuzfahrerstaaten seit dem Fall von Akkon 1291 nicht mehr gab, auf Zypern solche spätestens 1571 restlos untergegangen waren. Doch einen gewissen Ausgleich schufen in den Westen gerettete Archive oder Archivtrümmer solcher Institutionen des lateinischen Ostens, was allerdings für unsere Fragestellung eine Reihe von schwierigen Problemen nach sich zieht, die im Vorgriff auf den Oriens Pontificius Latinus noch zu erörtern sein werden.

Wissenschaftsgeschichtlich entstand das Göttinger Papsturkundenwerk, dessen Zeitfenster dem ersten Jahrhundert der Kreuzzugsgeschichte bis zum Vorabend des vierten Kreuzzuges entsprach, als sich die Kreuzzugsforschung auf einem ersten Höhepunkt befand und eine Reihe wichtiger Arbeitsinstrumente geschaffen hatte, die für die "Italia Pontificia“ und die Nachlese nutzbar gemacht werden konnten. Drei Jahre vor Kehrs öffentlicher Vorstellung seines

5 Paul Fridolin KeHR: Papsturkunden in Italien. Reiseberichte zur Italia Pontificia 1-5, Città del Vaticano 1977 (Acta Romanorum pontificum 1-5), mit Registern von Raffaello Volpini in Bd. 6.

6 Ders.: Selbstanzeige (wie Anm. 4) S. 595-597 mehrfach (wieder abgedruckt in: KeHr, Schriften [wie Anm. 4] S. 20-22).

7 Vgl. auch die Zusammenstellung der Lemmata in Rudolf Hiestand: Initien- und Empfängerverzeichnis zu Italia Pontificia 1-10, München 1984 (Hilfsmittel der MGH 6). 
Planes veröffentlichte Reinhold Röhricht nach dem Muster der Regesta Imperii die „Regesta Regni Hierosolymitani“ über alle bisher bekannten Urkunden, die die Kreuzfahrerstaaten und die nach dem ersten Kreuzzug entstandene Kreuzfahrerkirche - nicht die Kreuzzüge und die Pilgerfahrten - betrafen ${ }^{8}$. Im gleichen Jahr erschien der erste Band der „Revue de l'Orient latin“, die sich die Aufgabe stellte, unbekannte erzählende und urkundliche Quellen zu publizieren?. Ein Jahre darauf legte Joseph Delaville le Roulx den ersten Band des monumentalen „Cartulaire général de l'Ordre des Hospitaliers de Saint-Jean-deJérusalem " vor, der in rascher Folge bis 1906 in vier Bänden über 5000 Urkunden für den Johanniterorden, darunter nicht wenige Papsturkunden, meist im Volltext, den Rest in Auszügen oder Regesten herausgab ${ }^{10}$, nachdem er Ende der 1870er Jahre in einer Art Wettlauf mit Hans Prutz die gewaltigen Schätze des Ordensarchivs auf Malta ins Bewußtsein zurückgerufen hatte ${ }^{11}$. Prutz veröffentlichte neben Johanniter- und Templerurkunden auch eine große Zahl von Papsturkunden für die Templer ${ }^{12}$, denen er im Jahre 1888 die erste wissenschaftliche Geschichte des Templerordens mit weiteren Papsturkunden ${ }^{13}$ und im Jahre 1908 eine Gesamtdarstellung der geistlichen Ritterorden folgen ließ ${ }^{14}$, die in ihrer umfassenden Sicht erst in jüngster Zeit durch die Bücher von Alan Forey und Alain Demurger überholt worden ist ${ }^{15}$.

Durch den 1841 begonnenen „Recueil des Historiens des Croisades“ der Académie des Inscriptions et Belles-Lettres, dessen letzter Band im gleichen Jahr 1906 erschien wie der erste Band der „Italia Pontificia“ und der letzte Band des "Cartulaire" von Delaville le Roux, der nun die Berichte Paul Fridolin Kehrs und Luigi Schiaparellis über ihre neuen Funde im Archiv auf Malta und in Palermo in einem Anhang zum ersten Band auswertete, standen die Chroniken des ersten Kreuzzuges Wilhelms von Tyrus und seiner Fortsetzungen zur Ver-

8 RRH (wie Anm. 1).

9 Revue de l'Orient latin 1 (1893)-12 (1911) als Fortsetzung der Archives de l'Orient latin 1 (1881)-2 (1884).

10 Joseph Delaville le Roulx: Cartulaire général de l'Ordre des Hospitaliers de SaintJean de Jérusalem, 4 Bde., Paris 1894-1906.

11 Ders.: Documents concernant les Templiers extraits des archives de Malte, Paris 1882; Ders. : Les archives, la bibliothèque et le trésor de l'Ordre de Saint-Jean de Jérusalem à Malte, Paris 1883. Zur Forschungsgeschichte vgl. auch O 1 S. 12-38.

12 Hans Prutz: Malteser Urkunden und Regesten zur Geschichte der Tempelherren und der Johanniter, München 1883.

13 Ders.: Entwicklung und Untergang des Templerordens, Berlin 1888.

14 Ders.: Die geistlichen Ritterorden, Berlin 1908.

15 Alain Forey: The Military Orders from the Twelfth to the Early Fourteenth Centuries, Basingbroke 1992 (New studies in medieval history) und Alain Demurger: Chevaliers du Christ. Les ordres religieux-militaires au Moyen Age. XI $-\mathrm{XVI}^{\mathrm{e}}$ siècle, Paris 2002. 
fügung ${ }^{16}$, während Röhricht 1898 eine nach dem Muster der "Jahrbücher des deutschen Reiches" mit enormem Fleiß zusammengestellte „Geschichte des Königreichs Jerusalem“ auf über tausend Seiten veröffentlichte, bis heute in der Fülle des Materials unübertroffen und oft zu Unrecht übergangen ${ }^{17}$.

Auch die Edition der Urkunden des lateinischen Ostens hatte rasche Fortschritte gemacht. Mit Ausnahme des "Cartulaire général de l'Ordre du Temple (1119?-1150)" des Marquis d'Albon, der die Papsturkunden bis zum Ende des Pontifikats Eugens III. (1145-1153) einschloß, lagen so 1896 schon fast alle großen Urkundenfonds für den lateinischen Osten, seien sie archivalisch oder in Chartularen überliefert, vor ${ }^{18}$. Die beiden Chartulare des Kapitels des Hl. Grabes in der vatikanischen Bibliothek mit 38 Papsturkunden bis 1198, davon neun feierliche Privilegien, in denen Besitz in Italien aufgezählt wird, hatte 1849 Eugène de Rozière herausgegeben ${ }^{19}$. Mit dem in Venedig liegenden Chartular der Kathedrale von Nikosia auf Zypern veröffentlichte wenig später Louis de Mas Latrie auch drei Papsturkunden des 12. Jahrhunderts, die jedoch außer ihrem Überlieferungsort keinen Bezug zu Italien besitzen ${ }^{20}$, Ernst Strehlke 1869 in den „Tabulae ordinis Theutonici“ aus dem Königsberger Archiv zwei Urkunden Clemens' III. und Coelestins III., die ebenfalls Italien nicht betrafen ${ }^{21}$, während das 1881 veröffentlichte Chartular der Lazariter in Turin keine

16 Recueil des Historiens des Croisades, 16 Bde., Paris 1841-1906. Übersicht in Repfont I 5-7. Die wichtigste Chronik des 12. Jahrhunderts Wilhelm von Tyrus jetzt Wilhelmi Tyrensis archiepiscopi chronicon, ed. Robert B. C. HuYgens, Turnhout 1986 (CChrCM 86 und 86A).

17 Vgl. Reinhold Röнricht: Geschichte des Königreich Jerusalem 1109-1291, Innsbruck 1898.

18 Paris 1913.

19 Cartulaire de l'église du Saint-Sépulcre de Jérusalem, Paris 1849; jetzt auch Geneviève Bresc-Bautier: Le cartulaire du chapitre de l'église du Saint-Sépulcre de Jérusalem, Paris 1986 (Documents relatifs à l'histoire des croisades 15), dazu Rudolf Hiestand in: Francia 16 (1989) S. 282-287, die Papsturkunden auch in O 3. Eine in den Chartularen nicht enthaltene Ausfertigung Lucius' III. von 1182 Juli 14 aus Barletta fügte 1886 Acta Pontificum Romanorum inedita, ed. Julius von Pflugk-Harttung, 3 Bde., Tübingen 1881-1886, hier 3 S. 293 Nr. 322, hinzu (auch O 3 S. 298 Nr. 125), siehe zu ihr unten S. 651 f. Feierliche Privilegien mit Nennung von Besitz in Süditalien sind O 3 Nr. 28, 37, 39, 47, 52, 62, 102, 172 aus den Chartularen und Nr. 125 aus Barletta. In IP 9 S. 302 werden unter Barletta in der Narratio die dortigen Besitzungen der Ritterorden und der Kirchen des Hl. Landes hervorgehoben, wie dann auch für den Deutschen Orden und die Johanniter eigene Lemmata (IP 9 S. 304 f.) folgen; für das Hl. Grab und die Kirche von Nazareth wird erwähnt, daß sie nach dem endgültigen Fall von Akkon um 1310 in Barletta Zuflucht fanden.

20 Histoire de l'Ile de Chypre sous le règne des princes de la maison de Lusignan, 3 Bde., Paris 1855-1861, hier 3 S. 599-606.

21 Tabulae ordinis Theutonici, Berlin 1869, S. 263-266. 
Papsturkunden enthält ${ }^{22}$. Aus den nach Sizilien geretteten Urkundenbeständen der Abteien im Tale Josaphat und S. Maria Latina wurden 1880 von HenriFrançois Delaborde für jene elf ${ }^{23}$, 1890 von Reinhold Röhricht für diese zwei Papsturkunden des 12. Jahrhunderts ediert ${ }^{24}$, die zum Teil auch italienischen Besitz aufführen. Schon als eine Art erster Summe erstellte Paul Riant eine Übersicht über die kleineren Überreste von Archiven und Archivtrümmern von Klöstern des Hl. Landes ${ }^{25}$, während Delaville le Roulx als Vorspann des „Cartulaire" in eine detaillierte Übersicht über die Archivbestände zur Geschichte der Johanniter auf über 200 Folioseiten, z. T. Aktenbündel um Aktenbündel auch die nach der Aufhebung des Templerordens in die Johanniterarchive integrierten Urkunden einbezog ${ }^{26}$.

Auf diese Vorarbeiten konnten sich Kehr und Schiaparelli stützen, als sie die „Nachlese" in Italien begannen ${ }^{27}$. Von 1896 an liefen die Kreuzzugsforschung und das Papsturkundenwerk parallel, doch zu einem wirklichen Austausch kam es nur ansatzweise. Zum ersten Mal wurde dies deutlich an der Jahrhundertwende, als Schiaparelli im Jahre 1899 im Auftrage Kehrs in Palermo Archive und Bibliotheken aufsuchte und in einer Handschrift des sizilischen Hofhistoriographen Antonino Amico (1586-1641) zwei unbekannte Urkunden Alexanders III. für die Abtei S. Maria im Tale Josaphat fand $^{28}$, während gleichzeitig, ohne Kenntnis vom Vorhaben des anderen, Charles Kohler aus Kopien, die Riant hatte erstellen lassen, eine Edition aller unbekannten Texte aus der gleichen Handschrift zum Teil im Volltext, zum Teil wie für die beiden gleichen Papsturkunden in Regestenform vorbereitete und im Jahre 1900 in der „Revue de l'Orient latin“"veröffentlichte ${ }^{29}$. Nicht zu ihrem Vorteil hat die

22 Comte de Marsy, Fragment d'un cartulaire de l'ordre de St-Lazare en Terre-Sainte, in: Archives de l'Orient latin IIB (1884) S. 121-157.

23 Chartes de la Terre Sainte provenant de l'abbaye de Notre-Dame de Josaphat, Paris 1880 (Bibliothèque des Écoles françaises d'Athènes et de Rome 19).

24 Reinhold Rӧнгіснт: Zur Geschichte der Kirche S. Maria Latina in Jerusalem, in: Neues Archiv 15 (1890) S. 203-206.

25 Comte Paul Riant: Les archives des établissements latins d'Orient. À propos d'une publication récente de l'École de Rome, in: Archives de l'Orient latin 1 (1881) S. $705-$ 710 (gemeint ist die Edition von Delaborde, vgl. Anm. 23).

26 Delaville le RoulX: Cartulaire (wie Anm. 10) 1 S. XI-CCXXX; vgl. jetzt auch für die Papsturkunden der beiden Ritterorden O 1 S. 41-200 und O 2 S. 15-64.

27 Siehe dazu unten S. 621-623.

28 Paul Fridolin Kenr: Ueber die Papsturkunden für S. Maria de Valle Josaphat, NGG 1899 S. 338-368, hier S. 366 Nr. 6 und 367 Nr. 7 (wieder abgedruckt in: Ders., Ausgewählte Schriften [wie Anm. 4] S. 318 f.) und O 3 S. 258 f. Nr. 99 f.

29 Charles Kohler, Chartes de l'abbaye de Notre-Dame de la vallée de Josaphat en Terre Sainte, in: Revue de l'Orient latin 7 (1900) S. 108-222, hier S. 141 Nr. 31 und S. 145 Nr. 35. Trotz der Ortsangabe Dat. Beneventi stellte Kohler die erste der beiden Urkunden zu 1159-1180 und erwähnte nur in einer Anmerkung, daß der Papst 1168 und 1169 in 
englisch- und französischsprachige Kreuzzugsforschung die Ergebnisse des Göttinger Papsturkundenwerkes erst sehr spät zu rezipieren begonnen.

II.

Beginnen wir mit der Nachlese und den Kreuzfahrerstaaten und der $\mathrm{Kreuzfahrerkirche.} \mathrm{In} \mathrm{einem} \mathrm{umfassenderen} \mathrm{Blick} \mathrm{konnte} \mathrm{man} \mathrm{sich} \mathrm{im}$ Jahre 1896 fragen, ob aus einer neuen Durchsicht von Archiven und Bibliotheken Italiens wie in allen anderen Teilen Europas noch Unbekanntes hervorgehen werde. Möglich schien dies höchstens in Beständen, die auf die eine oder andere Weise vor 1291 oder 1571 in den Westen gerettet worden waren, aber dem suchenden Auge der Kreuzzugshistoriker bisher entgangen waren. $\mathrm{Da}$ Chartulare des Hl. Grabes und eine vereinzelte Papsturkunde und Chartulare der Kathedrale von Nikosia und der Lazariter in italienischen Archiven lagen, Urkunden von S. Maria Latina und von S. Maria im Tale Josaphat und von S. Maria auf dem Sionsberg nach Messina, mindestens eine Königsurkunde des Templum Domini nach Apulien und dann nach Cava de' Tirreni, die Urkunden der Abtei auf dem Thabor in Galiläa schon 1256 mit dieser an die Johanniter gelangt waren und deren Archivgeschichte geteilt hatten, war bekannt $^{30}$. Dagegen waren weder vom Erzbistum Nazareth, das sich in Barletta neu konstituiert hatte, vom Erzbistum Tyrus, das mit Oristano auf Sardinien als neuem Sitz verbunden worden war $^{31}$, oder vom Patriarchat Antiochia, dessen Titular noch vor der Eroberung durch Baybars zuerst Limassol auf Zypern, dann Genua als Ausstattung erhielt und sehr wohl die Möglichkeit besessen hätte, Urkunden in Sicherheit zu bringen, ältere Papsturkunden in italienischen Archiven erhalten geblieben. Dies gilt auch für alle anderen Archive der Diözesanorganisation außer der Kopie einer Urkunde Innozenz' II. in einem genuesischen Kopialbuch. Neben Einträgen in den päpstlichen Registern mit der Erwähnung von Vorurkunden des 12. Jahrhunderts für die Diözesen Nazareth, Valenia, Tyrus und Tortosa haben wir für Bethlehem nur als Kopien, die vor dem Ende der Kreuzfahrerstaaten im Osten erstellt wurden, in Varazze in Ligurien und in Bologna feierliche Privilegien des 13. Jahrhunderts, die wiederum Vorurkunden des 12. Jahrhunderts erwähnen ${ }^{32}$. Zwar weiß man, daß St. Lazarus in Bethanien Besitz in der Diözese Agrigento hatte, die Zisterzienserabtei Belmont in der Diözese Tripolis ebensolchen auf Sizilien und daß zwischen S. Samuel auf dem Freudenberg und S. Samuel in Barletta vielleicht eine Ab-

Benevent geweilt habe, die zweite wegen des Abtes Petrus als Adressat zu 1164-1176, mit dem gleichen Hinweis auf das Itinerar.

30 Vgl. Riant: Les archives (wie Anm. 25) und O 3 S. 68-71 für Mons Thabor.

31 IP 10 S. 453.

32 Vgl. O 3 passim. 
hängigkeit bestand ${ }^{33}$, doch für sie alle sind keine Papsturkunden und vor allem keine feierlichen Privilegien der päpstlichen Kanzlei mit Besitzlisten weder des 12. noch des 13. Jahrhunderts erhalten.

$\mathrm{Zu}$ den für ihren heutigen Aufbewahrungsort ,fremden' Beständen aus dem lateinischen Osten, in der Regel dort, wo die einzelnen Kirchen und Klöster spätestens nach 1291 institutionell und personell einen Zufluchtsort fanden, konnten jedoch, wenn auch in einer oft nur schwer zu trennenden Gemengelage gerade Papsturkunden kommen, die trotz des anderen Anscheins als genuiner Besitz gelten müssen. Denn die Niederlassungen von Kirchen und Klöstern der Kreuzfahrerstaaten im Westen besaßen oft aus logistischen Gründen angesichts der großen Entfernung vom Mutterhaus eigene Papsturkunden für die der Institution zugestandenen Vergünstigungen, die dennoch, weil ihr Inhalt der ganzen Gemeinschaft zustand, weder in der Adresse noch im Kontext ihren nachgeordneten Empfänger angaben ${ }^{34}$, scheinbar also aus dem Osten stammten, in Wirklichkeit nie die Apenninenhalbinsel verlassen hatten.

Dementsprechend enthielten die bis 1896, dem Beginn der Nachlese für das Göttinger Unternehmen, bzw. 1906, dem Erscheinen des ersten Bandes der „Italia Pontificia“, von der Kreuzzugsforschung veröffentlichten Papsturkunden außer wenigen Stücken für die Ritterorden keine an einen italienischen Empfänger gerichteten Papsturkunden, die offenkundig zu einem Regest in ihr hätten führen müssen. Zudem ergaben nach dem von Kehr für die „Italia Pontificia" entwickelten Arbeitsprinzip die in Papsturkunden für Abteien und Kirchen im Hl. Land aufgeführten Besitzungen in Italien keine Regesten für die „Italia Pontificia“. Erst mit dem Fortschreiten der „Italia Pontificia“ wurde, wenn auch ganz unsystematisch, in den einleitenden Narrationes der einschlägigen Diözesen oder Orte wie etwa unter Barletta, Agira, Messina, Agrigento usw. ein knapper Hinweis auf solchen (Fremd-)Besitz und gegebenenfalls dort aufbewahrte Papsturkunden eingefügt.

Die Hoffnung, auf italienischem Boden weitere Reste der geistlichen Archive aus den Kreuzfahrerstaaten zu finden, die nach Hattin, in der Zeit Friedrichs II. oder beim Fall von Akkon 1291 in den Westen verbracht worden wären, erfüllte sich in der Tat nicht. Kehr hat keinen großen, bisher unbekannten Bestand mit Papsturkunden für die Kreuzzugsgeschichte ,entdeckt'.

33 Neben Riant: Les archives (wie Anm. 25) vgl. Lynn Townsend White jr.: Latin Monasticism in Norman Sicily, Cambridge/Mass. 1938, passim; Geneviève Bresc-BAUTIER: Les possessions des Églises de Terre-Sainte en Italie du Sud (Pouille, Calabre, Sicile), in: Roberto il Guiscardo e il suo tempo (Relazioni e comunicazioni nelle prime Giornate normanno-sueve), Rom 1975 (Fonti e studi del corpus membranarum italicarum 11), S. 13-24.

$34 \mathrm{Zu}$ den „cismarinen“ Archiven vgl. Riant: Les archives (wie Anm. 25), zur Überlieferung der Papsturkunden vgl. O 3 S. 19-83, für die Templer und Johanniter vgl. Anm. 26, für die Kanoniker des Heiligen Grabes vgl. vor allem O 3 S. 29-32. 
Solche Funde waren nach den intensiven vorangehenden Forschungen von Delaville, Prutz, Riant, Delaborde und Röhricht von vorneherein wenig wahrscheinlich. Erst Walther Holtzmann gelang bei der Vorbereitung der beiden letzten Bände der "Italia Pontificia“ in Agira, das Schiaparelli und Kehr nicht aufgesucht hatten, mit dem Archiv von S. Maria Latina ein solcher Fund ${ }^{35}$.

Dennoch war der Ertrag der Nachlese für die Kreuzfahrerkirche nicht unbedeutend. Vor allem auf Sizilien und Malta hat die nochmalige Durchsicht von Urkundenfonds und Handschriften die bisherigen Ergebnisse z.T. erheblich erweitert $^{36}$. Von den zwei Stücken Alexanders III. für S. Maria im Tale Josaphat aus den Handschriften Amicos in Palermo ist schon die Rede gewesen. Sie sicherten Ende der 1160er Jahre der jerusalemitanischen Abtei Schutz gegen Leistungsforderungen des Patriarchen von Jerusalem ${ }^{37}$ und erweiterten die einige Jahre zuvor vom Legaten Johannes von SS. Giovanni e Paolo als Dank für die Unterstützung Alexanders III. im Kampf gegen Viktor IV. verliehenen Rechte des Abtes auf die Pontifikalinsignien als die letzten Papsturkunden des 12. Jahrhunderts für die Abtei ${ }^{38}$. Zu ihnen und den von Delaborde und PflugkHarttung edierten Papsturkunden ${ }^{39}$ kamen nun im Staatsarchiv Palermo und im bisher nicht beachteten Museo Civico in Catania fünf weitere, darunter drei Spuria aus mehreren aufeinanderfolgenden Fälscheraktionen, die vermutlich wegen königlicher Revokationen im 13. Jahrhundert ausgedehnten Besitz in Sizilien und in Kalabrien sichern sollten und von Delaborde wohl bewußt beiseite gelassen worden waren ${ }^{40}$. Daneben bestätigten zwei neue Papsturkun-

35 Walther Holtzmann: Papst-, Kaiser- und Normannenurkunden aus Unteritalien 1, in: Quellen und Forschungen aus italienischen Archiven und Bibliotheken 35 (1955) S. 47 49. Genau genommen war ihm G. Pietro Sinopoli di Giunta: La badia regia di S. Maria Latina in Agira, Acireale 1913, und Ders.: Tabulario di S. Maria Latina di Agira, in: Archivio storico per la Sicilia orientale 22 (1926) S. 135-190, vorangegangen, doch erst durch Holtzmann kam das schwer zugängliche Archiv ins allgemeine Bewußtsein. Vollständig ist das Archiv freilich für den transmarinen Besitz nicht. Es fehlen alle Königsurkunden und fast völlig Privaturkunden. Drei Urkunden für Tripolis hat Jean Richard: Le chartrier de Sainte-Marie-Latine et l'établissement de Raymond de SaintGilles à Mont-Pèlerin, in: Mélanges de l'histoire du Moyen Âge dédiés à la mémoire de Louis Halphen, Paris 1951, S. 605-611, herausgegeben.

36 Als „neu“ galten im Sinne Kehrs die in Jaffés zweiter Auflage nicht verzeichneten Stücke.

37 O 3 S. 258 Nr. 99.

38 O 3 S. 259 Nr. 100.

$39 \mathrm{Zu}$ den zehn bei Delaborde, Chartes (wie Anm. 23) edierten Stücken kam noch JL $\dagger 8096$ bei Pflugk-Harttung, Acta (wie Anm. 19) 2 S. 312 Nr. 350 hinzu.

40 Sie wurden von Kehr in einem eigenen Bericht, der nicht in den Nachdruck von Volpini aufgenommen wurde, zusammen mit den vier anderen echten Urkunden ediert, KEHR, Papsturkunden (wie Anm. 28) S. 338-368 (wieder abgedruckt: Ders., Schriften [wie Anm. 4] S. 290-320). Die Frage ihrer Entstehungszeit und Intention ist freilich bis in die jüngste Zeit mehrfach kontrovers erörtert worden, vgl. zuletzt Theo Kölzer: Neues 
den, ein Original Innozenz' II. und die Kopie einer Urkunde Eugens III., beide aus Catania ${ }^{41}$, eine Kirche und Zehnten in Galiläa und Besitz in Paternò auf Sizilien als Sonderbesitz unter Zinspflicht an die päpstliche Kammer ${ }^{42}$. Sie betrafen damit sowohl den Westen als auch den Osten, gingen aber aus den genannten Verfahrensgrundsätzen nicht als Regesten in die "Italia Pontificia“ ein, wo sie unter Paternò wenigstens in der Narratio erwähnt wurden. Ob das Original Innozenz' II. überhaupt über Jerusalem und Akkon oder nicht unmittelbar nach Sizilien gekommen ist, bleibe offen. Als Ergebnis der Nachlese waren so achtzehn Stücke für die jerusalemitanische Abtei statt elf bekannt.

Für S. Maria Latina, für das vorher nur zwei Urkunden Hadrians IV. und Alexanders III. bekannt waren ${ }^{43}$, kam aus dem Archiv in Agira als älteste Papsturkunde für die Abtei ein Privileg Paschalis' II. hinzu ${ }^{44}$, das vor allem die innere Ordnung und den Ritus der Gemeinschaft und ihre Rechte regelt, aber nur allgemein den Besitz im Osten bestätigt, und eine Besitzbestätigung Coelestins III. für Kirchen in Sachsen und Acquapendente im nördlichen Latium ${ }^{45}$. Eine weitere Papsturkunde Alexanders III., als Regest in einem riesigen Inventar von Papsturkunden auf Malta (Vol. 1132) verzeichnet, war wohl im 13. Jahrhundert bei den Johannitern hinterlegt worden ${ }^{46}$. Hier hatte sich der Bestand an Papsturkunden für die älteste lateinische Abtei im Hl. Land so mehr als verdoppelt.

Auch für die Abtei auf dem Berge Thabor, für die bisher an Papsturkunden des 12. Jahrhunderts bisher nur zwei feierliche Privilegien Paschalis' II. und Eugens III. überliefert waren, ließen sich in Valletta zusätzliche Angaben zu einem verlorenen, auch historisch interessanten Privileg Alexanders III. gewinnen, von dem erst seit kurzem ein Regest aus einem Inventar von verlorenen Johanniterurkunden aus der Provence bekannt gewesen $\operatorname{war}^{47}$. Denn das gleiche

zum Fälschungskomplex von S. Maria de Valle Josaphat, in: DA 37 (1981) S. 140-161. Die insgesamt fünf Spuria sind in O 3 nicht neu ediert worden, weil ihre sich auf den Besitz im lateinischen Osten und die allgemeinen Rechte beziehenden Abschnitte wörtlich den entsprechenden Abschnitten in den echten Privilegien Paschalis' II. von 1113 Januar 2, ed. O 3 S. 117 Nr. 14, und Innozenz' II. von 1140 Mai 18, ed. O 3 S. $156 \mathrm{Nr}$. 44, entnommen sind.

41 Vgl. die Übersicht über die Überlieferung in O 3 S. 38-41.

42 O 3 S. 159 Nr. 45 und S. 199 Nr. 66.

43 Vgl. Anm. 24.

44 O 3 S. 112 Nr. 12.

45 O 3 S. 369 Nr. 184. Für eine Aufnahme in IP 2 kam auch das Regest bei Sinopoli (wie Anm. 35) S. 141 Nr. 6 zu spät, doch wäre es nach dem waltenden Prinzip höchstens zu einer Erwähnung in der Narratio gekommen, für GP 5/2 ist die Urkunde dagegen übersehen worden. Zum Vol. 1132 siehe unten S. 659-661.

46 Kenr, Papsturkunden in Italien (wie Anm. 5) 2 S. 122; O 3 S. 294 Nr. 120.

47 Joseph Delaville le Roulx : Inventaire de pièces de l'Ordre de l'Hôpital, in: Revue de l'Orient latin 3 (1895) S. 36-106, hier S. 55 Nr. 72; Ders.: Cartulaire (wie Anm. 10) 2 S. 904 Nr. XII zu (1159-1163). 
Inventar in Vol. 1132 auf Malta gab aus dem verlorenen Original das bisher unbekannte Datum von 1161 Januar $12^{48}$. Es zeigt die Abtei gleich nach dem Konzil von Nablus im Sommer 1160, das sich im Schisma für Alexander III. entschied, an der Kurie Roland Bandinellis, um eine neue Bestätigung ihrer Rechte zu erlangen ${ }^{49}$.

In der anderen Blickrichtung kamen für abendländische Institutionen, deren Kontakte mit dem Hl. Land bereits bekannt waren, neue Papsturkunden nur für die Kommune von Genua hinzu. Sie hatte ihren Besitz in Byblos in der Grafschaft Tripolis einem Hugo de Embriaco aus einer der führenden Familie der Stadt gegen einen Treueid und jährlichen Zins verpachtet. Doch seit den 1160 er Jahren trachteten die Embriaci, ihre Verpflichtungen gegenüber der Mutterstadt abzuschütteln. Ohne Möglichkeiten, direkt in Byblos einzugreifen, suchten die Genuesen daher neben den lokalen Mächten die Unterstützung des Papsttums, zuerst Alexanders III., dann Lucius' III., schließlich in den Jahre 1186-1187 Urbans III., um in einer konzertierten Einschüchterungsaktion, bei der es auch um weitere Konfliktpunkte ging, mit Hilfe des Grafen von Tripolis, der Patriarchen von Jerusalem und Antiochia und der Bischöfe von Byblos und Tripolis weltlichen und kirchlichen Druck auf den Rebellen auszuüben ${ }^{50}$. In der ältesten Handschrift des Liber iurium Genuensium, des offiziellen Urkundenbuches der Kommune, die damals noch in Paris lag, fand Léopold Delisle, der sie auf Bitten Kehrs durchsah, zu vier bereits bekannten päpstlichen Schreiben Urbans III. für die causa Embriaci noch zwei weitere. Da sie mehr Parallelurkunden zu den anderen darstellen, als zu den Rechten der Kommune Neues beitragen, waren sie vielleicht in den vorher allein zugänglichen Abschriften des

48 KeHr, Papsturkunden in Italien (wie Anm. 5) 2 S. 94 und Anm. 13.

49 O 3 S. 227 Nr. 84. Es war Schiaparelli noch entgangen, daß im Vol. 1132 ein ausführlicheres Regest über die Aufnahme in den päpstlichen Schutz, die Zehntenbefreiung, die Sepultur und die Exemtion, wenn auch leider ohne Besitzliste, nicht unter den Originalen Alexanders III., sondern unter einer langen Reihe von Transsumpten für die Abtei aus dem Jahre 1255 steht, vgl. jetzt O 3 S. 227 ff. Zum Bullarium Melitense des Sebastiano Paoli in der Biblioteca Governativa in Lucca, wo sich ein Auszug aus dem Transsumpt von 1255 findet, den Delaville, Cartulaire (wie Anm. 10) 2 S. 825 Nr. 2830 ediert hatte, vgl. unten. Die Abtei auf dem Thabor hatte zwar am Anfang des 12. Jahrhunderts Besitz in den Abruzzen erhalten, vgl. ebd. S. 899 Nr. V, doch war dieser anscheinend rasch verloren gegangen und erscheint schon in der Urkunde Eugens III. von 1146, ed. O 3 S. 187 Nr. 61 nicht mehr.

50 Vgl. auch Marie-Luise Favreau-Lilie: Die Italiener im Heiligen Land vom ersten Kreuzzug bis zum Tode Heinrichs von Champagne (1098-1197), Amsterdam 1989, S. 169-172, 226 f.; zum Stammvater der Embriaci, der schon 1100/1101 im Osten ist, auch Franco Cardini: Profilo di un crociato: Guglielmo Embriaco, in: Ders.: Studi sulla storia e sull'idea di Crociata, Rom 1993, S. 63-80. 
Liber iurium im Sinne rationeller Arbeitsweise als überflüssig weggelassen worden ${ }^{51}$.

Wenn die zwei Stücke für Byblos sachlich keine neuen Erkenntnisse vermittelten, nur durch den Textvergleich einen Einblick in die Arbeitsweise der Kanzlei bei einer Vielzahl von Parallelurkunden an verschiedene Empfänger gewähren, die im 13. Jahrhundert unter eodem modo in die Register eingetragen worden wären, also kanzleitechnisch von Interesse sind, so verhält es sich ganz anders mit den zwei letzten hier noch zu erwähnenden neu aufgefundenen Urkunden. Sie gehören nun wieder zur Diözesankirche des Ostens. Im Archiv von S. Paolo fuori begegnete Kehr der Kopie einer Verfügung Coelestins III. von 1193 September 26 zugunsten der Lazariter. Sie wurde vorerst nur in gekürzter Form ediert und trotz allgemeiner Adresse an den Meister des Leprosenhauses und die Brüder entgegen dem leitenden Prinzip in die „Italia Pontificia“ mit einem Regest unter einem Leprosenhaus in der Diözese Todi, S. Maria Maddalena de Monte Niblo, aufgenommen ${ }^{52}$. Einen Hinweis auf diese Zugehörigkeit gibt die Urkunde freilich nicht ${ }^{53}$. Der Inhalt mit der Bestätigung einer confraternitas ihrer Priester - nicht eine Aufnahme in den päpstlichen Schutz, wie sowohl in der Edition als auch im Regest in der „Italia Pontificia“ steht - stellt nichts außergewöhnliches dar. Doch erstens handelt es sich um die einzige im Volltext erhaltene Papsturkunde des 12. Jahrhunderts für die Lazariter überhaupt, und zweitens wirft die Überlieferung bisher nicht beachtete Probleme auf. Gegen eine angesichts der Überlieferung in S. Paolo fuori naheliegende Annahme schließt die Tatsache, daß sie - als fast einziges aller hier zu behandelnden Stücke - auch in den päpstlichen Registern und zwar in einer Urkunde Clemens' VII. von 1389 als Insert überliefert ist, de facto sowohl eine römische Niederlassung der Leprosen als auch die von Kehr angegebene in Umbrien als ursprüngliche Empfängerin aus, denn mit Clemens VII. war die Urkunde mitten im großen abendländischen Schisma einem avignonesischen Papst zur Inserierung vorgelegt worden ${ }^{54}$. Es ist daher nicht sicher, ob das Original an eine Niederlassung in Italien gegangen war oder ob die Kopie erst später nach Rom gekommen ist. In jedem Fall ist hinter die Aufnahme in die „Italia Pontificia“ ein Fragezeichen zu setzen.

Zum anderen brachte die Nachlese in Italien nebenbei einen Fund, der an Bedeutung für die Geschichte der Kreuzfahrerstaaten alle bisher genannten weit

51 Es könnte sich auch um einen Kopistenfehler gehandelt haben, der sich perpetuierte.

52 KeHr, Papsturkunden in Italien (wie Anm. 5) 2 S. 375 Nr. 43 (nur Auszug); dann in IP 4 S. 42 Nr. 1; der volle Text jetzt in O 3 S. 346 Nr. 168.

53 Dem Hinweis Kehrs, daß das Archiv der Leprosen sich in San Paolo befinde, müßte nochmals genau nachgegangen werden; einschlägig sind vor allem Vat. Lat. 7927 und 7932 und das Kopialbuch in S. Paolo fuori saec. XVIII, in dem auch die Urkunde Celestins III. enthalten ist. Zum Chartular für die Lazariter siehe oben.

54 Dies ist auch in O 3 S. 346 Nr. 168 nicht beachtet worden. 
übertrifft, ohne einen erkennbaren Zusammenhang mit den Beziehungen des Papsttums zu Italien und hier ohne zu einem Regest in der „Italia Pontificia“ zu führen. Es handelt sich um eines jener Nicht-Italica in den Papsturkunden in Italien, die wir zu Beginn erwähnt haben. Als Kehr im Jahre 1912 in der Ambrosiana in Mailand eine Nach-Nachlese für den Abschluß des Bandes 6/1 für die Lombardei hielt, stieß er auf ein feierliches Privileg Lucius' III. für das Bistum Beirut unter Bischof Odo von 1184 September 5, das sogleich in den Göttinger Nachrichten veröffentlicht wurde ${ }^{55}$. Es war ein schlagender Beleg, wie richtig die Entscheidung gewesen war, den Berichten den Titel „Papsturkunden in Italien“ und nicht etwa „Papsturkunden für Italien“ zu geben und jeweils alle neugefundenen Papsturkunden, nicht nur diejenigen für die „Italia Pontificia“ zugänglich zu machen. Weitere Urkunden für Beirut finden sich in der Ambrosiana nicht, was auch für die unbekannte Herkunftsinstitution gelten muß, aus der das Stück nach Mailand kam, denn schon im Mittelalter schrieb eine ordnende Hand auf die Rückseite knapp Nihil ad nos. Glücklicherweise blieb soviel Ehrfurcht vor dem prächtigen Exemplar eines feierlichen Privilegs mit Elongata, Rota, Benevalete und Kardinalsunterschriften, daß es nicht wie so manches „unnütze“ Pergament weggeworfen oder für andere Zwecke verwendet wurde. Weder Bischof Odo noch die namentlich erwähnten Kanoniker noch die angeführten Besitzungen, ausschließlich im Osten gelegen, haben etwas mit Oberitalien zu tun. Sollte es sich etwa um ein nachher nicht mehr ausgelöstes Depositum des vielleicht wegen seiner Reise an die Kurie in finanzielle Schwierigkeiten geratenen Bischofs handeln? ${ }^{56}$ Doch dies sind Spekulationen. In jedem Fall verdanken wir der auf vollständige Erfassung aller Überlieferungen von Papsturkunden für wen auch immer ausgerichteten „Nachlese“, ohne die es vielleicht noch lange unbemerkt geblieben wäre, das einzige erhaltene Original eines feierlichen Privilegs für ein Bistum der Kreuzfahrerstaaten von ihrer Gründung bis zum Untergang im Jahre 1291, das zudem neben der üblichen Besitzliste und der Aufzählung der Rechte wertvolle Angaben über die kirchenrechtlich heikle Zehntenregelung für die im Bistum lebenden Angehörigen der anderen christlichen Gemeinschaften, Maroniten und Griechen, brachte ${ }^{57}$.

Faßt man das Ergebnis der Archivforschungen in Italien im Blick auf die Kreuzfahrerkirche zusammen, so sind es in absoluten Zahlen nicht viele neue Stücke. Einschließlich der beiden Stücke für Byblos kamen 16 unbekannte

55 KeHr, Papsturkunden in Italien (wie Anm. 5) 5 S. 399 Nr. 24; O 3 S. 303 Nr. 127, vgl. O 3 S. $57 \mathrm{f}$.

56 Bischof Odo wird in der Totenliste der Belagerung von Akkon aufgeführt, vgl. Roger de Hovedene: Chronica, London 1868-1871 (Rolls Series 51), 3 S. 87; hier aus geht hervor, daß er in den Osten zurückgekehrt und nicht etwa unterwegs verstorben ist.

57 Vgl. Rudolf Hiestand: Die Integration der Maroniten in die römische Kirche. Zum ältesten Zeugnis der päpstlichen Kanzlei (12. Jh.), in: Orientalia christiana periodica 54 (1988) S. 119-152. 
Papsturkunden zum Vorschein. Schon die Gegenüberstellung zu den 63 vorher bekannten Stücken zeigt jedoch den sehr beträchtlichen Zugewinn, der von der sachlichen Bedeutung her noch bestätigt wird: non multa, sed multum. Er wird sich in seinem vollen Gewicht im künftigen Oriens Pontificius Latinus zeigen, in die „Italia Pontificia“ ist dagegen außer den beiden Stücken für Byblos und, vielleicht zu Unrecht, in jedem Fall gegen das sonst waltende Prinzip, dem Stück für die Lazariter keines als Regest eingegangen.

Von der Nachlese zu den Regestenbänden: Was trägt die „Italia Pontificia“ zur Geschichte der Kreuzfahrerkirche und der Kreuzfahrerstaaten bei? Noch einmal ist zu betonen, daß Papsturkunden für einen Empfänger außerhalb Italiens, auch wenn sie Besitz in Italien anführen, ja ggf. ausschließlich solchen betreffen, als Nicht-Italica galten. Für keine Diözesankirche oder Abtei des lateinischen Ostens findet sich daher in der „Italia Pontificia“ ein eigener Abschnitt. Erwähnt wurden sie, wenn sie nach 1291 ihren Sitz im Exil in Italien hatten oder in den Archiven ihrer abendländischen Niederlassungen Papsturkunden für die Institution als Ganzes aufbewahrt wurden, höchstens in den Narrationes. Dies war in größerem Umfang aus historischen Gründen fast nur für Süditalien der Fall ${ }^{58}$, und aus der wachsenden Erkenntnis, daß dem Benutzer sonst wesentliche Informationen entgehen, steigt mit dem Fortschreiten der "Italia Pontificia“ die Zahl solcher Hinweise. Dennoch wirkt sich der Nachteil dieses Vorgehens gerade bei der Frage nach den Beziehungen des Papsttums zum lateinischen Osten aus ${ }^{59}$. Denn noch immer müssen, um Niederlassungen und Archivreste zu erfassen, Band um Band, Narratio um Narratio einzeln durchgelesen werden, weil die Überschriften der einzelnen Abschnitte diese rechtlichen Bindungen nur selten ausweisen. Weder unter Agira, Monasterium s. Philippi noch unter Paternò, Ecclesiae s. Mariae virg. et s. Mariae Magdalenae oder Messina, Ecclesia s. Mariae Magdalenae ${ }^{60}$ ist ohne Vorkenntnis ersichtlich, daß es sich beim ersten um eine frühe Niederlassung, nach 1291 den Sitz von S. Maria Latina handelt, beim zweiten um Besitz von S. Maria im Tale Josaphat, ebenso beim dritten und zugleich den späteren Sitz dieser Abtei. Ähnlich findet sich nur in der Narratio zum Kapitelarchiv von Agrigento der Hinweis, daß S. Spirito in Caltanissetta eine Kopie eines verfälschten feierlichen Privileg Alexanders III. für die Abtei auf dem Berge Sion besaß ${ }^{61}$, in dem es als Besitz der Abtei in Jerusalem aufgeführt wurde, und erst auf dem Umweg über dessen in der „Italia Pontificia“ nicht erwähnte Edition in der Sicilia Sacra des Pirro ${ }^{62}$

58 Also die Bände IP 9 und IP 10; Band IP 8 erweist sich unergiebig.

59 Diese Fragestellung wurde auch für den Indexband Initien- und Empfängerverzeichnis zu IP 1-10 (wie Anm. 7) nur ansatzweise berücksichtigt.

60 IP 10 S. 294, 295 und 344.

61 Ebd. S. 262. Dort findet sich auch ein Hinweis auf Besitz von S. Maria Latina in der Diözese Agrigento.

62 Rocco Pirro: Sicilia Sacra, 2. Aufl., Panormi 1731, 2 S. 584. 
erfährt man, daß im 17. Jahrhundert das Original dieses Stückes in Messina lag. Alle Angaben über sizilischen Besitz transmariner Kirchen und deren Archive stehen zudem unter dem Vorbehalt, daß im 17. Jahrhundert riesige Urkundenbestände aus der Insel nach Spanien verschleppt wurden, deren Existenz im Archiv des Duque de Medinaceli in Sevilla unterdessen zwar bekannt ist, die Bestände selbst aber noch teils unerschlossen, teils unzugänglich sind. Man wird wohl eines Tages größere Abschnitte der Sicilia neu schreiben können bzw. müssen.

Bei der Suche nach dem Niederschlag solcher Beziehungen über das östliche Mittelmeer hinweg sei wieder getrennt zwischen Regesten für Niederlassungen transmariner Institutionen auf italienischem Boden, also im Blick von Osten nach Westen, und Regesten für Kirchen und Rechte italienischer Seestädte in Syrien, also im Blick von Westen nach Osten. Bei diesen handelt es sich um genuine Teile der „Italia Pontificia“63. Doch zahlenmäßig ist ihr Anteil an der „Italia Pontificia“ überraschend gering. Erstmals wird eine solche Urkunde unter Pisa verzeichnet, das sich angesichts des raschen Herrscherwechsels auf dem Thron von Jerusalem nach dem Zusammenbruch des Königreichs im Jahre 1187 die Freiheiten und Immunitäten, die ihm König Guido mit seiner Gattin Sybille, Richard Löwenherz und dann der ermordete Konrad von Montferrat gewährt hatten, im Jahre 1193 von Coelestin III. bestätigen ließ ${ }^{64}$. Sie bleibt aber zugleich die einzige erhaltene Urkunde für Pisas Stellung im Osten, denn weder die Kathedrale noch eine andere Kirche ließen sich im 12. Jahrhundert dortigen Besitz vom Papsttum bestätigen. Ohne eine solche Papsturkunde blieben Siena und Florenz, deren große Zeit erst im 13. Jahrhundert kam. Lucca, das am ersten Kreuzzug noch regen Anteil genommen hatte, erscheint in der Folge nicht mehr. Ob es für Ancona die historischen Fakten spiegelt oder nur eine Folge der Überlieferung ist, wenn man im 12. Jahrhundert nichts von transmarinem Besitz erfährt, muß offen bleiben ${ }^{65}$. Selbst für Venedig sind nur wenige Regesten für den lateinischen Osten zu finden, für S. Marco drei Besitzbestätigungen für Jerusalem, Tripolis, Antiochia, Cayphas und die Kirche S. Marco in Akkon ${ }^{66}$, und für S. Niccolò al Lido eine solche für seinen Besitz im

63 Vgl. generell Favreau-Lilie: Die Italiener (wie Anm. 50) und Dies.: Die italienischen Kirchen im heiligen Land 1098-1291, in: Studi veneziani n. s. 12 (1987) S. 15-101.

64 IP 3 S. 363 Nr. 46.

65 Noch im 13. Jahrhundert trägt eine paläographische Schwierigkeit dazu bei, daß es bei manchen Nachrichten unsicher bleibt, ob Acon oder mit einem Kürzungsstrich über dem a Ancon zu lesen ist.

66 Alexander III. von 1165 Mai 13; JL 11189; ed. O 3 S. 241 Nr. 89, vgl. IP 7/2 S. 147 Nr. 2, für den Procurator von S. Marco. Weiteres ist wohl durch den Verlust des Archivs bei einem Brand im Jahre 1232 verloren, aber vgl. Favreau-Lilie: Die Italiener (wie Anm. 50) S. 382 ff.; Dies.: Die italienischen Kirchen (wie Anm. 63). 
Königreich Jerusalem und in Akkon ${ }^{67}$. In Süditalien trat Amalfi, das im 10./ 11. Jahrhundert in den Beziehungen zum östlichen Mittelmeer eine wichtige Rolle gespielt hatte und dessen Kaufleuten die Gründung des Spitals in Jerusalem verdankt wurde, aus dem der Johanniterorden hervorging, bei allerdings desolaten Archivverhältnissen bereits völlig zurück, so daß bis zum Ende des 12 . Jahrhunderts keine erhaltene Papsturkunde für Besitz in Syrien überliefert ist.

In einem auffälligen Gegensatz zu dem dichten Netz von Besitzungen, die die jerusalemitanischen Abteien, das Hl. Grab, auch die Kirchen von Nazareth und Bethlehem in Süditalien hatten ${ }^{68}$, steht erstaunlicherweise ein völliges Fehlen an Zeugnissen trotz ihrer entscheidenden Rolle für den Transport von Leuten und Gütern für die apulischen und sizilischen Städte und Kirchen; für keine hört man etwas über Besitz in Syrien, selbst nicht für Bari und S. Nicola, ohne daß wir wissen, ob die normannischen Herrscher solche Verknüpfungen über das Mittelmeer hinweg bewußt verhinderten.

Ganz anders findet sich in der "Italia Pontificia“ dank der "offiziellen“ Stadtchronistik des Caffaro und seiner Fortsetzer, die zudem einzelne Papsturkunden im vollen Wortlaut anführen, und dank der reichen Bestände der Archive für das Erzbistum, für die Kathedrale und für die Civitas eine lange Reihe von Regesten. Sie beginnen mit einer Bestätigung der Rechte Genuas in Syrien (in partibus Syriae) durch Lucius II. im Jahre $1144^{69}$, der ältesten Papsturkunde dieser Art für alle italienischen Seestädte, denn eine päpstliche Bestätigung der bereits im Juli 1098, wenige Wochen nach der Eroberung Antiochias und dem Sieg über Kerbogha, von Bohemund verliehenen Rechte, der ersten in ganz Syrien von einem Kreuzfahrer ausgestellten Urkunde überhaupt ${ }^{70}$, ist nirgends bezeugt. Seit der Jahrhundertmitte führten Streitpunkte zwischen der ligurischen Metropole und den Kreuzfahrerstaaten immer wieder zur Einschaltung der Kurie und entsprechenden Papsturkunden. Von 74 Regesten für die Civitas Ianuensis aus den Jahren 1144 bis 1198 betreffen nicht weniger als 33, also fast die Hälfte, transmarine Angelegenheiten, einschließlich des dritten Kreuzzuges: die in den letzten Jahren viel diskutierte goldene Inschrift in der Grabeskirche, die Beschlagnahmung von Schiffen und Geld und vor allem der erwähnte politisch-feudale Streit mit den Herren von Byblos ${ }^{71}$. Über sie sind fast keine anderen Quellen, vor allem keine aus dem Osten erhalten, so daß ganze Kapitel der Geschichte der Kreuzfahrerstaaten nur dank der in der "Italia Pontificia“ verzeichneten Urkunden geschrieben werden können. Ein letztes Mal sieht man

67 Urban III., JL 15926, ed. (exc.) O 3 S. 394 Nr. 200, vgl. IP 7/2 S. 191 Nr. 7.

68 Vgl. dazu auch Bresc-Bautier: Les possessions (wie Anm. 33) mit instruktiven Karten.

69 IP 6/2 S. 326 Nr. * 18.

70 RRH Nr. 12 und Heinrich Hagenmeyer: Epistulae ad historiam primi belli sacri spectantes, Innsbruck 1901, S. 155 Nr. 13.

71 IP 6/2 S. 335 ff. Nr. 56-70 nicht weniger als 15 Mandate Urbans III. vom 11.-13. März 1186, vgl. auch Favreau-Lilie: Die Italiener (wie Anm. 53). 
Genua wegen seines Besitzes im lateinischen Osten im Kontakt mit der Kurie, als das Kapitel der Kathedrale im Jahre 1192 ähnlich wie die Pisaner im folgenden Jahr angesichts des rasch aufeinanderfolgenden Herrscherwechsels und einer dynastischen Spaltung des Königreichs Jerusalem in zwei Parteien den Papst um die Bestätigung einer ihm von Erzbischof Joscius von Tyrus geschenkten Kapelle bat ${ }^{72}$.

Hinzu kommt für Genua eine ganz andere Verknüpfung mit dem Papsttum und dem lateinischen Osten. Erstmalig am 25. April 1162 begegnet auch im Regest eines feierlichen Privilegs für den Erzbischof eine legatio transmarina als Dank für die Alexander III. in den ersten Jahren des Schismas gewährte Unterstützung ${ }^{73}$. Alle acht Jahre sollte der Erzbischof in partibus transmarinis zusammen mit einem Kardinal oder Bischof - gemeint ist wohl ein Kardinalbischof oder ein Kardinalpriester bzw. -diakon - die vices des Papstes wahrnehmen als eine frühe, unabhängig vom jeweiligen Titular nicht personal, sondern lokal an eine Kirche gebundene, ständige' Legation. Sie wurde im Abstand von ca. acht und einmal sechzehn Jahren bis ans Ende des Jahrhunderts immer von neuem bestätigt. So eindrucksvoll diese einmalige und für das 12. Jahrhundert einzigartige Verleihung sich ausmacht, muß gleich hinzugefügt werden, daß zwischen 1162 und 1198 kein einziger Fall zu belegen ist, wo sie eine praktische Umsetzung gefunden hätte. Weder ein Erzbischof von Genua noch ein von ihm Beauftragter noch ein Kardinal allein erscheinen in den folgenden 40 Jahren je im Osten, um dort eine Legation oder Visitation durchzuführen. Es bleibt bei einem Ehrenrecht des Erzbischofs von Genua ohne reale Wirkung, das nach 1191 ,einschläft'.

Neben diesen, letztlich doch an berechenbarer Stelle in die „Italia Pontificia“ eingebauten Regesten, die auch den lateinischen Osten betreffen, sind andere als zufällig zu bezeichnen. Im Regest eines Privilegs Paschalis' II. von 1113 Februar 13 für Montecassino folgt für das Eschatokoll in gewohnter Weise nach Datum und per manum-Vermerk die Erwähnung der eigenhändigen Unterschrift des Papstes, von drei Kardinälen und weiterer Prälaten, nämlich 10 Erzbischöfen und Bischöfen sowie des Abtes von S. Salvatore di Telese. Dann schließt sich jedoch an et Antiochenae eccl. legati ${ }^{74}$. Im Volltext der Urkunde lauten die beiden letzten Unterschriften Ego Rollandus Antiochenae ecclesiae legatus interfui et subscripsi und Ego Pontius Antiochenae ecclesiae legatus interfui et subscripsi. Zwar ist aus Wilhelm von Tyrus, aus einer Notiz im Chartular des Hl. Grabes und aus

72 IP 6/2 S. 291 Nr. 60.

73 Ebd. S. 268 Nr. 13; wiederholt in ebd. S. 271 Nr. ${ }^{*} 26$ und S. 272 Nr. 27 von 1179, S. 276 Nr. 46 von Clemens III. (1187-1188) und S. 277 Nr. *54 von Coelestin III. von 1192.

74 IP 8 S. 161 Nr. 174; JL 6340; ed. Migne, PL 163, 312 Nr. 356. Das Original befindet sich im Archiv von Montecassino. 
einer zweiten in einer kirchenrechtlichen Handschrift aus dem Hl. Land (Vat. Lat. 1345) bekannt, daß im Februar/März 1113 in Benevent vor Paschalis II. über die territoriale Abgrenzung der beiden Patriarchate Jerusalem und Antiochia und andere kirchenrechtliche Fragen verhandelt wurde, doch die Namen der antiochenischen Legaten, die im Auftrage des Fürsten und des Patriarchen in den Westen gereist waren, gibt allein die Papsturkunde für Montecassino. Rollandus und Pontius sind anderweitig im lateinischen Osten nicht nachzuweisen, den Namen nach zweifellos Lateiner, auch wenn sie, wie ein Augenzeuge hinzufügt, als Zeichen einer rasch erfolgten Akkulturation in östlichem Habitus mit wirrem Haupthaar und Bart aufgetreten sein sollen ${ }^{75}$. Mit Montecassino hatte ihre Gesandtschaft soweit wir wissen nichts zu tun, wie die Abtei auch nie Besitz oder abhängige Kirchen im Osten erhielt, sondern allein die zufällige zeitliche Koinzidenz mit der Anwesenheit syrischer Boten an der Kurie führte zu ihrer Unterschrift und so zu einer für die Prosopographie der lateinischen Kirche Antiochias wichtigen Nachricht.

Ganz ähnlich bringt eine am 3. April 1139 in Rom ausgestellte Urkunde einen Mosaikstein für die Biographie eines hochrangigen Mitglieds der Kreuzfahrerkirche. Als Abt Azo von S. Paolo fuori auf einer Sitzung des zweiten Laterankonzils Klage erhob gegen einige Mitglieder der gens Tebaldi wegen Besitzstreitigkeiten, wird als anwesend an dieser Verhandlung nach dem Papst und vor den Patriarchen von Aquileia und Grado der patriarcha Antiochenus angeführt ${ }^{76}$. Gemeint ist Radulf von Domfront, der Antiochia seine frühere Selbständigkeit im Sinne der Pentarchie wiedergeben wollte ${ }^{77}$. Ein besonderes Interesse an der Kreuzfahrerkirche bestand für den Urkundenschreiber evidenterweise nicht, noch für den Patriarchen an den Tebaldi, wohl aber an der Nennung hochgestellter Personen, wie sie Patriarchen darstellten, als Zeugen. Das Regest in der "Italia Pontificia“ 1 ist das erste für die „Italia Pontificia“ erstellte Regest überhaupt, das einen Bezug zur Kreuzzugsbewegung hat. Ihm verdanken wir so die sonst nirgends belegte Teilnahme des Leiters der lateinischen Kirche Nordsyriens am Konzil, dem sein Amtskollege aus Jerusalem fernblieb, ja die erste gesicherter Teilnahme eines Bischofs der Kreuzfahrerkirche

75 O 3 S. 119 Nr. 15: viri duo crinibus et barba concreti, calamistrati non ex industria, sed ut apparebat ex incuria.

76 IP 1 S. 169 Nr. 20, Capena municipio de Romani, ed. Pierluigi Gallettri, Rom 1756, S. 65 Nr. 3.

$77 \mathrm{Zu}$ ihm vgl. Bernard Hamilton: Ralph of Domfront, Patriarch of Antioch 1135-1140, in: Nottingham Medieval Studies 28 (1984) S. 1-21 und Rudolf Hiestand: Ein neuer Bericht zum Konzil von Antiochia 1140, in: Annuarium historiae Conciliorum 20 (1988) S. 314-350. 
an einem allgemeinen Konzil überhaupt ${ }^{78}$ und zugleich den Beleg, daß eine von Wilhelm von Tyrus dramaturgisch ausgestaltete Verhandlung gegen den Patriarchen wegen Mißachtung des päpstlichen Primatsanspruchs mit folgender Absolution wohl auch auf dem Konzil selbst stattgefunden hat ${ }^{79}$.

III.

An einer Scharnierstelle zwischen den Beziehungen des Papsttums zu den Kreuzfahrerstaaten, deren Niederschlag in der „Italia Pontificia“ hier untersucht werden soll, und den Kreuzzügen in den Osten stehen unter personellem Blick die päpstlichen Legaten ${ }^{80}$. Denn seit Clermont bis ans Ende des 12. Jahrhunderts wurde jeder Kreuzzug von Legaten begleitet und jede Legation für einen Kreuzzug in den Osten führte eo ipso auch zu Kontakten mit der Kreuzfahrerkirche auf syrischem Boden. Genuin gehörten wie die allgemeinen Kreuzzugsaufrufe auch die Legatenbestellungen für die Kreuzzüge als solche nicht in die „Italia Pontificia“. Gleich zu Beginn des Bandes für Rom hatte Kehr im Abschnitt „Cardinales SRE“ erklärt, deren Tätigkeit als Legaten außerhalb von Rom jeweils an der betreffenden Stelle behandeln zu wollen, d. h. hier im künftigen Oriens Pontificius, dagegen Urkunden, die sich auf einzelne Kardinäle beziehen, unter ihrem Bistum, ihrer Titelkirche oder ihrer Diakonie anzuführen $^{81}$. Nicht gemeint war damit, wie sich sogleich zeigt, die Einsetzung von Kardinälen als Legaten, auch wenn dafür schriftliche Zeugnisse, manchmal sogar eigentliche Bestellungsschreiben mit der Empfehlung an Personen des künftigen Wirkungskreises vorliegen. Doch auch die Ernennung von Angehörigen des Diözesanklerus zum Legaten erhielt weder ein eigenes Regest noch eine Erwähnung in den einleitenden Narrationes.

Es geht damit gerade für diesen Teil der Blick auf die Nachrichten, die sich in der "Italia Pontificia“ finden, einher mit der Gegenfrage, was fehlt. Die Lücken sind in der Tat beträchtlich. Für den ersten Kreuzzug ist sowohl die Bestellung von Erzbischof Daimbert von Pisa im Jahre 1097/1098 zum Legaten mindestens für die von ihm angeführte pisanische Flotte, wenn nicht zum

$78 \mathrm{Zu}$ den seit 1138 nachgewiesenen Templern auf dem Aventin, die zweifellos mit den stadtrömischen Äbten und Klerikern das Konzil aus der Nähe verfolgten, siehe unten. S. 657.

79 Wilhelm von Tyrus: Chronicon (wie Anm. 16) XV 12 S. 691.

80 Dieser Abschnitt stützt sich auf Rudolf Hiestand: Die päpstlichen Legaten auf den Kreuzzügen und in den Kreuzfahrerstaaten vom Konzil von Clermont (1095) bis zum vierten Kreuzzug, masch.schr. Habil., Kiel 1972. Künftig zum ganzen Problemkreis auch die Habilitationsschrift von Claudia ZeY, Die päpstliche Legatenpolitik im 11. und 12. Jahrhundert, masch.schr. Habil., München 2002.

81 IP 1 S. 5. 
Nachfolger des im Sommer 1098 in Antiochia verstorbenen Kreuzzugslegaten Adhemar von Le Puy ${ }^{82}$ als auch die Bestellung von Erzbischof Anselm von Mailand für den Kreuzzug der Lombarden im Jahre 1100/1101 ${ }^{83}$ und die erst sehr spät überlieferte, zweifelhafte Bestellung von Bischof Heinrich Contarini von Castello für das Unternehmen der Venezianer im Jahre $1100^{84}$ nicht aufgenommen. Ausdrücklich in ein Regest gefaßt wird dagegen die Bestellung Bohemunds vor seiner Reise nach Frankreich ${ }^{85}$.

Am Ende des 12. Jahrhunderts erhält die Bestellung von Erzbischof Gerhard von Ravenna im Jahre 1188 für die Kreuzzugspredigt (nicht aber diejenige für den dritten Kreuzzug selber ${ }^{86}$ und die in dieser Eigenschaft in Florenz durchgeführte Weihe von S. Donato a Torri ${ }^{87}$ ein Regest, ebenso die von Kehr als zweifelhaft bewertete chronikalische Nachricht über die Bestellung von Erzbischof Hubald von Pisa mit der gleichzeitigen Übergabe einer Petrusfahne, freilich nicht unter dem Erzbistum, sondern unter der Civitas ${ }^{88}$, weil er die pisanische Flotte in den Osten führen sollte, also nicht wegen der Person, sondern wegen der Sache ${ }^{89}$. Ein Regest für die Bestellung fehlt auch beim einzigen, nicht dem Kardinalkollegium angehörenden italienischen Legaten in die Kreuzfahrerstaaten außerhalb der Kreuzzüge, Abt Gaufried von Fossanova, unter dem Abschnitt für die in Latium gelegene Zisterzienserabtei zum Jahre

82 IP 3 S. 359 Nr. 23 gibt nur den auf Befehl Urbans II. erfolgten Aufbruch der pisanischen Flotte. Zu Daimbert vgl. jetzt vor allem Michael Matzke: Daibert von Pisa zwischen Pisa, Papst und Kreuzzug, Sigmaringen 1998 (Vorträge und Forschungen, Sonderband 44).

83 IP 6/1 S. 54 Nr. ${ }^{*} 122$ in ähnlicher Weise nur der Aufruf an Anselm, ein Heer zur Befreiung des Hl. Landes zu sammeln.

84 IP 7/2 S. 130 nach Nr. 4 einzufügen.

85 IP 9 S. 443 Nr. *6 unter dem Principatus Tarantinus mit einem terminus technicus: Paschalis I legat Bohemund in den Westen und setzt ihn zum signifer des exercitus Christi ein und gibt ihm das vexillum s. Petri. Die Einordnung wäre besser unter Bari (IP 9 S. 336 oder einem neuen Lemma ebd.) erfolgt.

86 IP 5 S. 72 Nr. 267. Zu Gerhard von Ravenna jetzt auch Karl Borchardt: Archbishop Gerard of Ravenna and Bishop John of Faenza, in: Proceedings of the Eighth International Congress of Medieval Canon Law, Città del Vaticano 1992, S. 574-592 und DBI 53 (1999) S. 543-545 (A. Ilari).

87 IP 3 S. 38 Nr. 2.

88 Ebd. S. 362 Nr. $\dagger^{*} 39$.

89 Die Angabe in der Narratio zum Bistum Verona IP 7/1 S. 217, daß Clemens III. Bischof Adelard als seinen Legaten zu Richard Löwenherz und Philipp II. August geschickt habe, ist unhaltbar. Die Gesandtschaft fällt wohl ins Jahr 1201, vgl. Edmond MARTĖNE/Ursin Durand: Thesaurus novus anecdotorum, Paris 1717, 3 S. 956. Zu Adelard vgl. auch Werner Maleczek: Papsttum und Kardinalkolleg im 12. Jahrhundert, Wien 1984 (Publikationen des Historischen Instituts beim Österreichischen Kulturinstitut in Rom 1), S. 68; Klaus Ganzer: Die Entwicklung des auswärtigen Kardinalats im hohen Mittelalter, Tübingen 1963 (Bibliothek des Deutschen Historischen Instituts in Rom 26), S. $137-140$. 
$1173^{90}$, dessen Legation auch in der Narratio nicht erwähnt wird. Neben ihrer Bedeutung für die Kreuzzugsbewegung im weiteren Sinne bilden Legatenernennungen ganz allgemein wichtige Nachrichten für das Verhältnis ihrer Herkunftskirche oder ihrer Person zum Papsttum und wären mit Gewinn an der jeweiligen Stelle einzuordnen.

Noch drei Regesten in der „Italia Pontificia“ sind zu erwähnen, deren Zusammenhang mit dem Kreuzzug und Kreuzzugslegationen vorerst überhaupt nicht erkennbar ist. Der Sache nach sind es Italica. Unter Genua findet sich aus einem Werk des 18. Jahrhunderts ein Regest für die Weihe der Kirche S. Teodoro und S. Salvatore in Fasiolo vor den Toren der Stadt am 20. Juli 1100 durch den Kardinal Mauritius von Porto, Legat Paschalis' II., und den Bischof Ayraldus von Genua. Gestützt wird die Nachricht durch eine Privaturkunde vom gleichen Tag, welche der Bischof und Mauritius de Portu Romano episcopus unterschreiben ${ }^{91}$. Dieser Bischof des suburbikarischen Porto und damit Mitglied des Kardinalkollegium scheint auf den ersten Blick auf dem Weg zu einer Legation in Frankreich zu sein, doch im November 1100 trifft er in Laodicea in Nordsyrien auf Balduin von Edessa, den Bruder des im Juli verstorbenen Gottfried von Bouillon, zieht mit ihm nach Süden und trägt die päpstliche Zustimmung zur Erhebung Jerusalems zum Königreich und zur Wahl eines lateinischen Patriarchen mit sich. Er war am 28. April 1100 den Kreuzfahrern im päpstlichen Glückwunschschreiben für die Eroberung Jerusalems als Legat angekündigt worden, um die neu entstandene Kreuzfahrerkirche den kanonischen Vorschriften entsprechend einzurichten ${ }^{92}$, und brach dann am 1. August, wie der Stadtchronist Caffaro überliefert, mit der zweiten genuesischen Flotte in den Osten auf ${ }^{93}$. Sein Legationsbereich wird in der genuesischen Urkunde und der Weihenotiz nicht erwähnt, doch durch Weihenotiz und Urkunde, beide in ein Regest in der „Italia Pontificia“ gefaßt, erhält man einen weiteren Hinweis auf den zeitlichen Ablauf seiner Legation.

Zwanzig Jahre später schreibt Calixt II. am 24. Juli 1121 aus Aversa an den Kleriker Markus in Venedig, der dem Hl. Petrus ein Grundstück aufgelassen hatte, um dort die künftige Kirche $S$. Maria della Carità zu bauen, er schicke ihm nun auf Bitte des clarissimus et venerabilis frater noster et legatus P. Portuensis

90 Einzureihen IP 2 S. 127 nach Nr. 4; zur Legation im Osten vgl. O 2 S. 230 ff. Nr. 21a und $21 \mathrm{~b}$.

91 IP 6 S. 314 Nr. 1; zu Mauritius vgl. Rudolf HüLs: Kardinäle, Klerus und Kirchen Roms 1049-1130, Tübingen 1977 (Bibliothek des Deutschen Historischen Instituts in Rom 48), S. 121 f., der aber die Urkunde aus Genua zu 1100 Januar 3 setzt und das Schreiben Paschalis' II. nicht erwähnt.

92 JL 5835 zu (1100) Mai 4, ed. O 3 S. 90 Nr. 4.

93 Caffaro: Annali Genovesi, ed. Luigi Tommaso Belgrano, Rom 1890 (Fonti per la Storia d'Italia 11), S. 51. 
episcopus einen Stein für die Grundsteinlegung des Gebäudes ${ }^{94}$. Wieder wäre aus dieser Erwähnung nicht zu erkennen, was Petrus von Porto, den Nachfolger des Mauritius und Senior des Kardinalkollegiums, in Wirklichkeit nach Venedig geführt hatte, wenn nicht vierzehn Tage zuvor am 8. Juli 1121 der Papst dem Erzbischof Ebremar von Caesarea, den übrigen Prälaten und König Balduin II. von Jerusalem ihn als seinen Legaten für das Hl. Land angekündigt hätte ${ }^{95}$. Ursprünglich hatte er mindestens die doppelte Aufgabe, dem neuen Patriarchen von Jerusalem Warmund von Picquigny (seit 1118) das Pallium zu überbringen, was nun auf anderem Wege erfolgen sollte, weil die Reise des Petrus sich verzögere, andererseits den Kreuzfahrern nach der vernichtenden Niederlage der Antiochener im Jahre 1119 mit einer venezianischen Flotte militärische Hilfe zuzuführen. Denn der zeitliche Ablauf legt nahe, daß Petrus der Überbringer einer aus der venezianischen Chronistik bekannten Aufforderung Calixts II. an den Dogen und die Venezianer zu solcher Unterstützung ${ }^{96}$ und einer Petrusfahne für den Dogen als äußeren Zeichens eines päpstlichen Auftrags war ${ }^{97}$, wie sie einst Urban II. dem Erzbischof Anselm von Mailand für den Kreuzzug von $1100 / 1101$ verliehen hatte ${ }^{98}$. Anders als für Mauritius, der wahrscheinlich im Osten gestorben ist, wissen wir nicht, ob Petrus in der Folge wirklich nach Syrien reiste. An der Kurie ist er erst während des ersten Laterankonzils, zwei Jahre nach seiner Abreise aus Rom, am 6. April 1123 wieder nachzuweisen ${ }^{99}$, doch aus dem Osten fehlt jedes urkundliche oder chronikalische Zeugnis.

Weder in Genua noch in Venedig hatte der Vorgang, der zur Ausstellung einer Urkunde führte, in der ein Legat für den Osten erschien, auch nur entfernt etwas mit dem Kreuzzug zu tun, dennoch verdanken wir jener ein weiteres Datum für die Reise des Legaten Mauritius von Porto, dieser einen weiteren Mosaikstein für die Legation des Petrus von Porto und ebenso einen zusätzlichen zeitlichen Anhaltspunkt, in beiden Fällen zugleich eine wertvolle Nachricht über die Kommunikationswege zwischen Papsttum und Hl. Land.

Wie diese Nachrichten aus der Frühphase der Kreuzzüge betrifft auch eines der letzten Zeugnisse in der „Italia Pontificia“ über die Kreuzzüge wieder einen Legaten, ohne ihn als solchen zu kennzeichnen. Unter S. Nicola in Bari wird eine Inschrift verzeichnet, wonach Bischof Konrad von Hildesheim und Kanzler

94 IP 7/2 S. 168 Nr. *1 und 2. Zu Petrus von Porto vgl. Hüls, Kardinäle (wie Anm. 91) S. 122-124. Beate Schilling: Guido von Vienne - Papst Calixt II., Hannover 1998 (Schriften der MGH 45) und Mary Stroll: Calixtus II (1119-1124): A Pope born to rule, Leiden 2004 (Studies in the history of Christian traditions 116) führen nicht über Hüls hinaus.

95 JL 6922, ed. O 3 S. 128 Nr. 22.

96 IP 7/2 S. 21 Nr. *38.

97 Ebd. S. 21 Nr. ${ }^{*} 39$.

98 IP 7/1 S. 54 Nr. *129 aus der Chronik Landulfs.

99 JL 7056 für die Kirche von Pisa. 
Kaiser Heinrichs VI. am 27. Juni 1197 in Gegenwart von fünf Erzbischöfen, 28 Bischöfen und sieben Äbten im Auftrage Coelestins III. die Kirche geweiht habe ${ }^{100}$. Damit sind wir im unmittelbaren Vorfeld des Kreuzzuges des Staufers. Konrad war mit den sich sammelnden Rittern nach Apulien gekommen, wo er längere Zeit in der Umgebung Heinrichs nachzuweisen ist. Damit erhält die Weihe von S. Nicola den Charakter einer Huldigung und Intervention beim Patron der Seefahrt vor der bevorstehenden Überfahrt nach Syrien, wie wir Eugen III. zu Beginn seiner Reise nach Frankreich in einer ähnlich symbolischen Handlung sehen werden. Konrad von Hildesheim ging dann mit Aufträgen des Kaisers und des Papstes in den Osten, wo er im Spätherbst 1197 dem Herrn von Zypern, Aimerich von Lusignan, die Königskrone überbrachte, wenn auch nicht sicher ist, wie weit dies auch im Namen des Papstes bzw. in Vertretung des anderen päpstlichen Legaten Erzbischof Konrad von Mainz erfolgte ${ }^{101}$.

\section{IV.}

Sieht man von dem feierlichen Privileg für Beirut und der Urkunde für die Lazariter ab, so war zweifellos von größerer Bedeutung als für die Kreuzfahrerstaaten die Nachlese für das eigentliche Kreuzzugs geschehen. Hier steht im zeitlichen Ablauf unter den Neufunden am Anfang ein Schreiben Urbans II. von 1096 Oktober 7 an die Mönche von Vallombrosa, das Wilhelm Wiederhold im Jahre 1901 aus einer Handschrift der Biblioteca Riccardiana in seinem Bericht über Papsturkunden in Florenz veröffentlichte ${ }^{102}$. Es tritt neben die beiden bekannten Schreiben des Kreuzzugspapstes, das erste vom Jahreswechsel 1095/1096 im Sinne des Aufrufs von Clermont um Beteiligung werbend an die Gläubigen in Flandern ${ }^{103}$, das andere aus dem Sommer 1096 eher eindämmend an die Bewohner von Bologna ${ }^{104}$, nachdem die Sprengkraft eines von Begeisterung getragenen Aufbruchs auf die bestehenden gesellschaftlichen Strukturen deutlich geworden war. Für Bologna legte der Papst fest, daß weder Kleriker noch Mönche ohne Erlaubnis ihres Bischofs oder Abtes aufbrechen dürften, ebenso wenig Männer im besten Alter (iuvenes) ohne die Zustimmung ihrer Frauen - in einer deutlichen Parallele zum Eintritt ins Kloster, der kirchenrechtlich ein beidseitiges Einverständnis erforderte, was die Nähe des

100 IP 9 S. 328 Nr. *4; jetzt auch GP 5/2 S. 57 Nr. 123.

101 GP 5/2 S. 57 Nr. *? 124.

102 Kehr, Papsturkunden in Italien (wie Anm. 5) 3 S. 216 Nr. 6; O 3 S. 88 Nr. 2.

103 JL 5608; ed. Hagenmeyer: Epistulae (wie Anm. 70) S. 136 Nr. 2.

104 JL 5670, ed. Hagenmeyer: Epistulae (wie Anm. 70) S. 137 Nr. 3. 
Kreuzzuges zu einer wandernden Klostergemeinschaft auf Zeit unterstreicht ${ }^{105}$. Das neue Schreiben, das dritte schriftliche Zeugnis des Papstes zum Kreuzzug aus der Zeit nach Clermont, schließt in seinem Tenor an das Schreiben nach Bologna an. Ging es dort um die Gesamtheit der städtischen Bevölkerung, vor allem auch der Laien, so richtete der Papst nun ein Verbot der Teilnahme an eine monastische Gemeinschaft, die wie ihre ganze Umwelt von der Kreuzzugsidee ergriffen worden war. Der Ruf von einem Plenarablaß, den man sich erwerben könne, hatte auch die Klostermauern durchdrungen. Ganz scharf wurde festgehalten, daß ein Mönch, sei es auch um des vom Papst initiierten Kreuzzuges willen, nur mit Erlaubnis seines Abtes das Kloster verlassen dürfe. Wie die Seelsorge durch eine Kreuzzugsteilnahme des Klerus und die Ehe durch einen „wilden“ Aufbruch gefährdet war, wenn der eine Partner ohne Rücksicht auf den anderen in den Osten zog, so erst recht die auf Gehorsam und Trennung von der Welt ausgerichtete klösterliche Gemeinschaft durch die Beteiligung an einem, wie der Papst noch einmal betonte, militärischen Unternehmen (armis Saracenorum feritatem debellare).

Wann genau die damit unübersehbare Abkehr von der uneingeschränkten Kreuzzugspropaganda des Jahres 1095/1096 eingetreten ist, läßt sich nicht mehr feststellen. Aus Frankreich werden in den Monaten nach Clermont trotz zahlreicher Nachrichten über die Kreuzzugswerbung des Papstes solche Töne nirgends laut, obwohl sich auch dort eine große Zahl nichtritterlicher Leute auf den Weg machte; nun schlägt die Haltung des Papstes um, kaum hatte er wieder italienischen Boden betreten, und er differenziert. Fügen wir hinzu, daß die Forschung den Fund Wiederholds, der in den Abschnitt über Vallombrosa in der „Italia Pontificia“ einging ${ }^{106}$, über ein halbes Jahrhundert de facto nicht rezipierte, auch weil er wieder wissenschaftsgeschichtlich aus chronologischen Gründen nicht in die als abschließend angesehene Ausgabe der Briefe zum ersten Kreuzzug von Heinrich Hagenmeyer aus dem gleichen Jahr 1901 aufgenommen worden war ${ }^{107}$. Dabei braucht die Bedeutung eines weiteren authentischen Schreibens des Papstes, das unmittelbar in die Zeit nach Clermont zurückging, als anders als nachher für die ex eventu schreibenden Kreuzzugschronisten der Erfolg des Unternehmens noch nicht abzusehen war, nicht betont zu werden. Es gewährt wie die beiden schon bekannten Schreiben Einblick in das Denken des Papstes nach dem auch für ihn unvorhergesehenen Erfolg des Aufrufes in Clermont.

105 Zum päpstlichen Widerstand gegen die Kreuzzugsteilnahme von Mönchen vgl. vor allem Giles Constable: Opposition to Pilgrimage in the Middle Ages, in: Studia Gratiana 19 (1976) S. 123-146.

106 IP 3 S. 89 Nr. 8.

107 Hagenmeyer: Epistulae (wie Anm. 70). Er fehlt daher auch bei Ursula Schwerin: Die Aufrufe der Päpste zur Befreiung des Heiligen Landes von den Anfängen bis zum Ausgang Innozenz' IV., Berlin 1937 (Historische Studien 301). 
Unter den neuen Schreiben für die Geschichte der Kreuzzüge schließt sich ein von Walther Holtzmann in einer Ivo-Handschrift in Lincoln entdeckter Brief Bohemunds von Antiochien an Paschalis II. vom Herbst 1106 an, also ein Nicht-Anglicum der dortigen Nachlese, das nicht völlig korrekt in den Abschnitt Regnum Normannorum aufgenommen wurde ${ }^{108}$. Verfaßt nach der Rückkehr aus Frankreich und unmittelbar vor dem Aufbruch über die Adria, bestätigt es einerseits Bohemunds Ernennung zum Legaten vor der Reise nach Frankreich als eines der ganz wenigen Beispiele von Laien als Legaten im 12. Jahrhundert, andererseits forderte der Normanne den Papst auf, unter Berufung auf einen entsprechenden Beschluß Urbans II. auf dem Konzil von Bari im Herbst 1098, dessen Umsetzung nur der Tod des Papstes verhindert habe, selber in den Osten zu ziehen oder wenigstens einen Legaten zu bestellen. Ausführlich legt es schließlich den Zwist mit dem Basileus dar, um den Zug gegen einen christlichen Herrscher zu rechtfertigen und wird daher auch in den Oriens graecus gehören. Zusammen mit der verfälschten Fassung des Briefes der Kreuzfahrer aus dem Lager bei Antiochia, im gleichen Abschnitt der „Italia Pontificia“ unter dem „Principatus Tarantinus“ eingereiht ${ }^{109}$, ist es zugleich ein wichtiges Zeugnis der sich nach dem ersten Kreuzzug ausbreitenden antibyzantinischen Stimmung.

Von allgemeiner Bedeutung für die Kreuzzugsgeschichte ist auch der dritte Neufund, der freilich im Gegensatz zu den Briefen Urbans II. und Bohemunds bisher keinen Niederschlag im Regestenwerk gefunden hat. In zwei Handschriften auf Malta stieß Luigi Schiaparelli auf einen Kreuzzugsaufruf Eugens III. von 1146 Oktober 5 Divini dispensatione consilii ${ }^{110}$. An die Geistlichkeit Italiens (prelatis per Italiam constitutis) gerichtet, belegt er zum ersten Mal eindeutig, daß die Konzeption Eugens III. sich nicht auf die Teilnahme des französischen Königs und dann eher widerwillig des deutschen Herrschers mit ihren Gefolgsleuten beschränkte, sondern schon vor dem Aufbruch nach Frankreich auch die Apenninenhalbinsel in die Werbung einbezog und damit den im berühmten Aufruf nach Frankreich Quantum praedecessores eher überraschend betonten Anteil der Italiener am ersten Kreuzzug (Francorum regni

108 IP 8 S. 27 Nr. 91; ed. O 3 S. 102 Nr. 7. Besser wäre die Einreihung unter Bari erfolgt, wie sich Bohemund stets als Barensis dominus bezeichnet, nie als Tarantinus princeps o. ä. wie üblicher-, aber fälschlicherweise angenommen wird.

109 Ed. Hagenmeyer: Epistulae (wie Anm. 70) S. 191 Nr. 15 und IP 9 S. 442 Nr. 4.

110 KeHr, Papsturkunden in Italien (wie Anm. 5) 2 S. 108 Nr. 3; ed. O 3 S. 193 Nr. 63. Er verdankt seine Überlieferung, wie die beiden Handschriften zeigen, offensichtlich der Zuschreibung an Eugen IV. In der Tabelle bei Schwerin, Aufrufe (wie Anm. 107) Nr. VI ist statt La Valletta vol. 1132 zu lesen vol. 1141. 
fortissimi et strenui bellatores et illi etiam de Italia) nicht nur als historische Reminiszenz, sondern auch als Projektion für die Gegenwart ansah ${ }^{111}$.

Im Text, der anscheinend eher als ein Begleitschreiben eines an weltliche Empfänger gerichteten eigentlichen Aufrufes anzusehen ist ${ }^{112}$, sind zwar längere Abschnitte über den Schutz der Kreuzfahrer, ihrer Familien und ihres Besitzes und über den Ablaß wörtlich aus den Aufrufen nach Frankreich vom 1. Dezember 1145 und 1. März $1146^{113}$ übernommen, doch anderes ist neu formuliert und bezieht sich gezielt auf die Empfängergruppe, wenn man in der Exhortatio liest: quoniam Italia viris potentibus et strenuis bellatoribus ... abundat. Allgemeiner gesprochen macht der nun mögliche Textvergleich mit den beiden Fassungen von Quantum praedecessores und mit dem Aufruf für den Wendenkreuzzug deutlich, wie sorgfältig der Papst und die Kanzlei empfängerbezogen formulierten. Vor allem der Abschnitt mit den Privilegia über das Schuldenmoratorium und die Mittelbeschaffung der Teilnehmer zeigt ein bewußtes Eingehen auf die anderen Rahmenbedingungen südlich der Alpen und die bereits weiter vorangeschrittene Geldwirtschaft ${ }^{114}$. Da der Aufruf nicht nur aus zwei Bullarien stammt, die, wie sich noch ergeben wird, auf süditalienische Ordensarchive zurückgehen ${ }^{115}$, sondern auch die Adresse ausdrücklich Italien nennt, gehört er ohne jeden Zweifel in die „Italia Pontificia“, wenn auch in den noch ausstehenden Band für allgemeine Stücke, wobei die archivalische Überlieferung hier im Gegensatz zum Schreiben Bohemunds eine zusätzliche Einordnung unter dem Regnum Normannorum rechtfertigen könnte. Auch dieses Schreiben ist lange weitgehend unbeachtet geblieben ${ }^{116}$ und zeigt fast exemplarisch den Nachteil einer auf einen Empfänger eingeschränkten Archivrecherche gegenüber einer umfassenden Zielsetzung, wie sie Kehr vor Augen stand. Denn Delaville le Roulx und Prutz hatten nachweislich die beiden Bände

111 JL 8796; ed. in: Otto von Freising: Gesta Frederici, ed. Adolf Schmidt und Franz-Josef Schmale, Darmstadt 1965 (Ausgewählte Quellen zur deutschen Geschichte des Mittelalters 17), hier I 37 (36) S. 200.

112 Vgl. Schwerin, Aufrufe (wie Anm. 107) S. 26 f.

113 JL 8876; ed. Peter Rassow in: Erich Caspar: Die Kreuzzugsbullen Eugens III. (11451153), in: NA 45 (1924) S. 283-305, hier S. 300; jetzt auch Rolf Grosse, Überlegungen zum Kreuzzugsaufruf Eugens III. von 1145/46. Mit einer Neuedition von JL 8876, in: Francia 18/1 (1991) S. 85-92, hier S. 90-92.

114 Zusatz zu den Vorurkunden nach Frankreich: si fideiussores etiam vel obsides dederunt... Si qui vero possessiones aliquorum in pignore vel pignora etiam pro pecunia uel pro alia re ab aliquibus receperint, nihilominus ... precipimus, ut receptis his tantum que susceptis pignoribus illis tradiderunt, in eadem specie, in auro videlicet sive argento vel aliis possessionibus, ipsas et pignora eis libere restituantur et nihil ab eis amplius exigant.

115 Siehe unten S. 662-664.

116 Die volle Rezeption setzt ein mit Schwerin, Aufrufe (wie Anm. 107) passim und Nr. VI, und Giles Constable: The Second Crusade as Seen by the Contemporaries, Traditio 9 (1953) S. 213-279. 
im Archiv in Valletta in der Hand gehalten, aber den Text, weil in ihm weder von Templern noch von Johannitern die Rede ist, nicht beachtet. Wie der Brief an Vallombrosa rückt er die Rolle Italiens in den Kreuzzugsplanungen stärker ins Blickfeld.

Diesen drei neuen päpstlichen Aufrufen gegenüber treten drei weitere, bei der Nachlese in Italien neugefundene Kreuzzugstexte deutlich zurück. In der zeitlichen Abfolge gehörte zwar zu den Papsturkunden in Italien, aber nicht in die "Italia Pontificia“ der in einer Orosius-Handschrift der Vatikana eingetragene Aufruf des päpstlichen Legaten Hyazinth von S. Maria in Cosmedin Vulgare proverbium est ${ }^{117}$. Wohl im Zusammenhang mit dem Konzil von Valladolid Anfang 1155 bat der spätere Papst Coelestin III. den Klerus Spaniens, für einen von ihm geplanten Feldzug gegen die Mauren multi saumarii et alia tante expeditionis necessaria zur Verfügung zu stellen, eine bisher in der Kreuzzugsgeschichte und der Geschichte der Reconquista ebenfalls wenig beachtete Episode $^{118}$, weil sie zu keinem erkennbaren Ergebnis geführt hat, aber sie zeugt von den Bemühungen, nach dem zweiten Kreuzzug den Kampf gegen die Mauren fortzuführen. Beachtung verdienen zwei Punkte: Einmal werden in der Adresse neben den Geistlichen, soweit ich sehe zum ersten Mal, auf gleicher Ebene die Templer und Johanniter angesprochen, was ihre auf dem zweiten Kreuzzug gewonnene Stellung spiegelt, zum anderen erklärt der Legat, auf Drängen der Könige und Fürsten, des Klerus und des Volkes selber das Kreuz genommen zu haben, und tritt als Organisator für ein Unternehmen unter seiner unmittelbaren Leitung auf, nicht nur begleitend und geistlich stützend, wie die Legaten auf dem ersten und dem zweiten Kreuzzug und wie es ebenso auf dem dritten Kreuzzug sein wird.

Wenig neue Ideen oder Fakten für die Kreuzzugspropaganda des 12. Jahrhunderts bringt ein bisher nicht in die "Italia Pontificia“ aufgenommener Kreuzzugsaufruf Lucius' III Cor nostrum von (1184) November/Dezember $10^{119}$ an die Könige, Herzöge, Fürsten, Grafen und alle Gläubigen. Er ging, wie ein

117 KeHr, Papsturkunden in Italien (wie Anm. 5) 4 S. 48 Nr. 12. Bei Kehr noch auf (11531155) datiert. Vgl. aber Carl Erdmann: Das Papsttum und Portugal im ersten Jahrhundert der portugiesischen Geschichte, Berlin 1928 (AAB, phil.-hist. Kl. 5), S. 37 Anm. 3 und Gerhard S̈̈векоw: Die päpstlichen Legationen nach Spanien und Portugal bis zum Ausgang des 12. Jahrhunderts, Diss. Berlin 1931, S. 50 Anm. 179, zu Anfang 1155; Stefan WeIss: Die Urkunden der päpstlichen Legaten von Leo IX. bis Coelestin III. (1049-1198), Köln/Wien 1995 (Forschungen zur Kaiser- und Papstgeschichte des Mittelalters. Beihefte zu J. F. Böhmer, RI 13), S. 176 Nr. 8 zu 1155 vor Februar 1.

118 Vgl. dazu Erdmann, Papsttum (wie Anm. 117) a.a.O.; S̈̈векow, Legationen (wie Anm. 117) a.a.O.

119 O I S. 352 Nr. 165, Schwerin, Aufrufe (wie Anm. 107) Nr. 8, B-B/S Nr. 1924. 
gleichzeitig nach England geschickter Aufruf Cum cuncti praedecessores ${ }^{120}$ aus den Beratungen von Kaiser und Papst mit dem Patriarchen Heraklius von Jerusalem und dem Johannitermeister Roger de Molinis in Verona hervor und folgt bis auf einen deutlich als Zusatz gekennzeichneten letzten Abschnitt mit der Absolution für Turnieropfer, die nach Kirchenrecht eo ipso der Exkommunikation verfallen waren, dem nur aus England überlieferten Aufruf Alexanders III. von 1181 Januar $16^{121}$.

Überliefert in drei Handschriften aus Palermo und Agrigento mit Urkunden zu den Beziehungen zwischen dem Papsttum und den Normannenherrschern und mit dem Hinweis, daß die Originale sich im Besitz von Antonino Amico befänden, muß der neue Aufruf Lucius' III. in das Normannenreich gegangen sein und könnte angesichts der zeitlichen Koinzidenz indirekt vielleicht ein Anstoß für die sizilische Flottenaktion gegen Thessalonike im Jahre 1185 geworden sein. Obwohl sich eine weitere Abschrift als die zeitlich älteste in einem Chartular des 16. Jahrhunderts aus Santo Crucifijo de Puente la Reina bei Pamplona findet ${ }^{122}$ und damit eine breite Streuung der Empfänger gegeben scheint, beruht dieses Bullar in Wirklichkeit auf den Beständen des Johanniterpriorats in Messina ${ }^{123}$. Auch wenn es weitere Ausfertigungen gab, wie die Adresse regibus, ducibus, principibus, comitibus et universis Christi fidelibus nahelegt, war mindestens die bisher allein nachweisbare Ausfertigung für Sizilien bestimmt und gehört damit auch zur „Italia Pontificia“, während eine textlich fast identische mit gleicher Adresse, wie die Überlieferungslage in diesem Falle ergibt, wenige Wochen später in der zweiten Januarhälfte 1185 nach Deutschland ging ${ }^{124}$. In einem größeren Rahmen werden einmal mehr die schon aus Handschriften in Barcelona, Inserten in englischen Chronisten und deutschen Johanniterchartularen erkennbaren Bemühungen des Papsttums nach dem dritten Laterankonzil in den Jahren 1181-1185 um breite Unterstützung für das zunehmend von Saladin bedrohte Königreich Jerusalem deutlich, vor allem aber rückt wie mit dem Kreuzzugsaufruf Eugens III. der Anteil Siziliens in der Kreuzzugspolitik des Papsttums in helleres Licht. Diese Linie fände geradlinig ihre Fortsetzung in einem Schreiben Clemens' III. an den Basileus Isaak II. Angelos von 1188 mit der Mitteilung, König Wilhelm II. werde die Kreuzfahrer mit Proviant und Waffen zum Kampf gegen Saladin unterstützen, wenn die

120 JL 15151, Gesta Henrici II, ed. William StubBs, London 1867 (Rolls Series 49), I S. 332; RI 4/4/2 1564 zu (1184 Nov.-1185 März); Schwerin, Aufrufe (wie Anm. 107) Nr. 7 zu 1184 (Nov.-Dez.).

121 JL 14360, Gesta Henrici II (wie Anm. 120) 1 S. 272; Schwerin, Aufrufe (wie Anm. 107) Nr. 6.

122 Vgl. die Vorbemerkung in O 1 S. 352 Nr. 165.

123 Ebd. S. $150 \mathrm{ff}$.

124 Ebd. S. 363 Nr. 175. 
modern anmutende, generalstabmäßig Plan und Durchführung umfassende Darlegung nicht ein Spurium, diesmal des 16. Jahrhunderts, wäre ${ }^{125}$.

Der letzte neue Text zu den eigentlichen Kreuzzügen ist ein Schreiben Clemens' III. von 1188 Juli 5 an die Gläubigen in der Toskana, die zwar das Kreuz genommen hatten, aber nun im Gegensatz zu den Pisanern den Aufbruch hinauszögerten ${ }^{126}$. Erst 1959 aus einer Handschrift der Vallicelliana in Rom bekannt geworden, konnte es nicht in die Nachlese und erst recht nicht in den Regestenband für die Toskana eingehen, sondern stellt gewissermaßen eine Additio Kehriana dar. Während jene für Frankreich zahlreichen Papsturkunden über eingegangene und nicht erfüllte oder aufgeschobene Kreuzzugsgelübde und über die Verletzung des Rechtsschutzes einzelner Kreuzfahrer und Pilger in der „Italia Pontificia“ völlig fehlen ${ }^{127}$, was, abgesehen vom zahlenmäßigen Unterschied in der Kreuzzugsbeteiligung diesseits und jenseits der Alpen, wohl auch die andere Struktur des städtischen Italiens spiegelt, wo sich die Probleme für einen Kreuzzugsteilnehmer anders stellten als für den kreuzfahrenden Ritter im agrarischen Frankreich, wird in der bisherigen Überlieferung für das 12. Jahrhundert einmalig ein scharfer Tadel an ein ganzes Kollektiv gerichtet, zugleich der terminus technicus der päpstlichen Kanzlei für die Kreuzfahrer, die signaculis crucis insigniti, verwendet.

Für das Verhältnis von Nachlese und Regestenwerk gingen in die „Italia Pontificia" von diesen Kreuzzugsschreiben, wie erwähnt, nur der Brief Urbans II. an Vallombrosa und das Schreiben Bohemunds ein, so daß sich erst recht die Frage stellt, was sie zur Geschichte der Kreuzzüge beiträgt und welches Bild der Kreuzzüge im Rahmen der Beziehungen des Papsttums zu Italien sich aus ihr ergibt. Da der Kreuzzug als solcher keinen eigenen Abschnitt bilden kann noch ein einzelnes Unternehmen, handelt es sich immer nur um vereinzelte, weit verstreute Nachrichten, die zusammenzufügen sind. Ein geschlosseneres Bild könnte sich höchstens eines Tages im ausstehenden allgemeinen Band ergeben.

Blickt man auf die großen Etappen der päpstliche Kreuzzugspolitik, so findet das Konzil von Piacenza, das mit der Gesandtschaft des Basileus und einem ersten, weitgehend ohne Echo bleibenden Aufruf des Papstes auf italie-

125 JL 16373, IP 8 S. 56 Nr. *223, Epistulae Turcicae, ed. Nicolaus Reusner, Frankfurt/ Main 1598, S. 16.

126 Ed. Mundò in: Rivista di storia della chiesa in Italia 13 (1959), vgl. O 3 S. 333 Nr. 155; einzuordnen in IP 3 S. 4 nach Nr. 15.

127 Die einzige derartige Urkunde in den „Papsturkunden in Italien“ stammt aus der Handschrift des damals noch ungedruckten Liber Censuum und betrifft die Festlegung eines Rekognitionszinses durch Coelestin III. von 1192 Aug. 13, ed. KeHr, Papsturkunden in Italien (wie Anm. 5) 2 S. 585 Nr. 25, jetzt Le Liber Censuum de l'Église romaine, ed. Louis Duchesne/Paul Fabre, Paris 1905, 2 S. 39 zu einem nach dem dritten Kreuzzug aus dem Heiligen Land zurückkehrenden französischen Kreuzfahrer, der der römischen Kirche seine Burg in der D. Périgueux aufgelassen hatte. 
nischem Boden vor Clermont am Anfang der Kreuzzugsbewegung steht, etwas überraschend selbst in der Narratio zum oberitalienischen Bistum keine Erwähnung ${ }^{128}$. Daß die Kreuzzugspredigt in Clermont nicht in die „Italia Pontificia" aufgenommen wurde, ist klar, doch für die nicht der Kurie angehörenden italienischen Teilnehmer wie die Erzbischöfe Daimbert von Pisa und Rangerius von Reggio di Calabria wäre nach der neueren Konzeption der Germania und der Gallia Pontificia ein Regest zu erstellen ${ }^{129}$.

Läßt man vorerst eine lange Serie von Spuria für einzelne Kreuzzugsteilnehmer beiseite, so bildet zeitlich das erste Regest in der „Italia Pontificia“ die Nachricht bei Caffaro, daß Urban II. nach dem Konzil von Clermont die Bischöfe Hugo von Grenoble und Wilhelm von Orange nach Genua geschickt habe, um die Genuesen zur Befreiung des Hl. Grabens anzustacheln ${ }^{130}$. Damit ist auch in der "Italia Pontificia“ die ligurische Hafenstadt als erste in die Kreuzzugsbewegung einbezogen, vor Pisa und vor Venedig und vor dem allgemeinen Aufbruch im Sommer 1096 und zwar in ihrer Kernfunktion für die künftige lateinische Herrschaft im Hl. Land als logistisches Zentrum für den Transport von Leuten und Material. Offensichtlich zögerten die Genuesen als vorsichtige Kaufleute jedoch, so daß von einer größeren Zahl von Kreuzfahrern, die 1096/1097 von Genua aus in den Osten gefahren wären, nichts verlautet, wenn auch einige genuesische Schiffe während der Belagerung von Antiochia im Winter 1097/1098 Proviant heranführten ${ }^{131}$. Selbst die Provenzalen, für die sich ein Weg zu See am ehesten angeboten hätte, waren am Ende des 11. Jahrhunderts noch ,Landratten' und nahmen lieber die Strapazen des Weges durch Dalmatien auf sich.

Ohne Erwähnung bleibt in der „Italia Pontificia“ aus dieser Frühphase des Kreuzzuges auch ein Vorfall, der den Kreuzzug und die päpstliche Herrschaft in Rom verband. Denn im Herbst 1096 geleiteten die französischen Kreuzfahrer, sozusagen als der erste Kreuzzug gegen einen innenpolitischen Gegner, Urban II. aus der Toskana in das in der Hand des Gegenpapstes befindliche Rom, wo sie als Pilger vor dem endgültigen Aufbruch in eine den meisten unbekannte Welt

128 Mindestens zu erwähnen in der Narratio IP 5 S. 442 f. Das Konzil erscheint genannt als Hintergrund für die Nachricht, daß Urban II. im März 1095 der Kirche von S. Maria de Campagnola einen Ablaß von so vielen Jahren zugesprochen habe, wie der jeweilige Gläubige Sandkörner in seiner Hand halten könne, vgl. IP 5 S. 487 Nr. $\dagger 1$.

129 Für die Konzilsteilnehmer siehe Robert Somerville: The Council of Clermont and Christian Society, in: Archivum Historiae Pontificiae 12 (1974) S. 55-90, hier S. 73. Er nennt außer Daimbert und Rangerius noch die suburbikarischen Bischöfe Walter von Albano, Johannes von Porto, Bruno von Segni. Zu ihnen vgl. HüLs, Kardinäle (wie Anm. 91) passim.

130 Caffaro: Annali (wie Anm. 93) 1 S. 101; IP 6/2 S. 323 Nr. *5.

131 Erwähnt werden u. a. bei Baudri de Dol: Historia Hierosolymitana, Paris 1879 (Recueil des Historiens des Croisades, Historiens Occidentaux 4), hier 1 8, S. 18. 
mit einer gefährlichen Reise über das Meer die Apostelgräber aufsuchen wollten. In St. Peter erwartete sie allerdings die böse Überraschung, daß die Anhänger Clemens' III. während ihres Gebetes auf das Dach stiegen, Ziegel abdeckten und die unten im Kirchenschiff betenden Kreuzfahrer mit Steinen bewarfen ${ }^{132}$ - eine Nachricht, die unter den seither geänderten Maßstäben zweifellos in einen Regestenband aufzunehmen wäre.

Nur fragmentarisch finden sich in der "Italia Pontificia“ Regesten über die Unternehmen, die noch mit dem ersten Kreuzzug verbunden sind oder unmittelbar an ihn anschließen: Unter Lucca wird der Brief seines Klerus an die Gläubigen über einen auf dem Konzil von Bari im Herbst 1098 von Urban II. beschlossenen eigenen Aufbruch cum multis terrae senatoribus nach Jerusalem ${ }^{133}$ nicht aufgenommen, auch nicht als Kommentar oder in der Narratio, sondern erscheint erst im Kommentar zum Brief Bohemunds und der anderen Kreuzzugsführer an Urban II. aus Antiochia von 1098 unter dem Principatus Tarantinus ${ }^{134}$. Der Aufbruch der Pisaner auf Befehl Urbans II. im Jahre 1098 wird unter Pisa, Civitas, erwähnt, nicht aber wie gesagt die Bestellung ihres Erzbischofs Daimberts zum Legaten ${ }^{135}$ noch die venezianische Expedition des Jahres 1100/1101. Nur nebenbei erfährt man wie erwähnt vom Aufenthalt des Legaten Mauritius von Porto in Genua ${ }^{136}$, dagegen erhält die Aufforderung an Erzbischof Anselm von Mailand zur Hilfe für das Hl. Land ein volles Regest ${ }^{137}$. Daß dies in den späten Bänden der "Italia Pontificia“ auch für die Bestellung Bohemunds zum Legaten für seine Werbereise nach Frankreich ${ }^{138}$ und, unter dem Regnum Normannorum, wo er eben eigentlich fehl am Platz ist ${ }^{139}$, für seinen Brief an Paschalis II. nach der Rückkehr aus Frankreich und vor seinem Aufbruch zum Kreuzzug gegen Byzanz ${ }^{140}$ erfolgt, zeigt die sich ausweitende Konzeption.

Für die Kreuzzugsbeteiligung erfährt man im Gegensatz zu der nicht erwähnten Anwesenheit italienischer Prälaten in Clermont und auf den folgenden Versammlungen in Frankreich wieder in den späten Bänden der „Italia Ponti-

132 Fulcher von Chartres: Historia Hierosolymitana, ed. Heinrich HagenmeYer, Heidelberg 1913, hier 1 7, 1-2, S. 163-166.

133 disponens ad Ierusalem profecto tendere.

134 IP 9 S. 442 Nr. 4. Zur Einordnung vgl. Anm. 108.

135 IP 3 S. 359 Nr. *23.

136 Siehe oben S. 635.

137 IP 6/1 S. 54 Nr. *129.

138 IP 9 S. 443 Nr. *6. Das Regest ist nicht ganz korrekt, denn nach dem päpstlichen Auftrag soll er in Frankreich nicht gegen Alexius werben, sondern für das Hl. Land. Jenes ist dann Bohemunds eigene Interpretation und Umsetzung, so daß er nachher wohlweislich einer Begegnung mit dem Papst aus dem Wege geht und sich aufs Briefeschreiben verlegt.

139 IP 8 S. 27 Nr. 91.

140 Wie Anm. 108. 
ficia“, ausgehend von dem Bemühen, die Bischofslisten zu ergänzen, unter Ariano Irpino im Samnium, daß der dortige Bischof Gerard am ersten Kreuzzug teilgenommen habe ${ }^{141}$, unter Martirano in Kalabrien von der Anwesenheit des Bischofs Arnulf bei der Eroberung von Jerusalem, nicht aber von seinen Aspirationen auf das Bistum Bethlehem ${ }^{142}$, während unter Adria im Podelta noch übergangen worden war, daß auch sein Bischof auf dem ersten Kreuzzug gewesen sein soll.

Als nächste und für Jahrzehnte einzige Regesten für den Kreuzzug folgen für 1121/1122 die Entsendung von Boten Calixts II. nach Venedig, um dort zur Hilfe für das Hl. Land aufzufordern, und die Übersendung der Petrusfahne an den Dogen ${ }^{143}$, jedoch ohne den Zusammenhang mit der Intervention des Legaten Bischof Petrus von Porto zugunsten von S. Maria della Carità herzustellen ${ }^{144}$. Mit dem venezianischen Unternehmen der Jahre 1122-1124 bricht in der „Italia Pontificia“ wegen der noch nicht rezipierten Aufrufe Eugens III. und Lucius' III., jener für den künftigen allgemeinen Band ein ,Muß', dieser wegen der durch die Überlieferung gesicherten Adressaten mindestens ein ,Soll', für Jahrzehnte ein völliges Schweigen über die Kreuzzugsbewegung herein. Erst die auf die Nachricht von Hattin und des Falls von Jerusalem am 2. Oktober 1187 folgenden Bemühungen Gregors VIII. und Clemens' III. und der Legaten Petrus von S. Cecilia und Soffred von S. Maria in Via lata ${ }^{145}$ um Hilfe für die bedrohten Kreuzfahrerstaaten und im Vorfeld um einen Friedensschluß zwischen den beiden tyrrhenischen Seestädten, erhalten unter Pisa mit fast einem Dutzend Regesten breiten Raum. Freilich wird eine chronikalische Nachricht, daß der Papst den Pisanern und ihrem Erzbischof Hubald, als dem Fahnenträger des Heeres und aller Christen und Legat des apostolischen Stuhls für alle Christen bei der Rückgewinnung Jerusalems, eine Petrusfahne übergeben habe, zu Recht mit einem Fragezeichen versehen ${ }^{146}$. Ein Teil dieser Regesten findet sich entsprechend unter Genua wieder, mit teilweise leicht abweichenden zeitlichen Einordnungen, die den Forschungsfortschritt spiegeln ${ }^{147}$.

141 IP 9 S. 137.

142 IP 10 S. 118.

143 IP 7/2 S. 91 Nr. *38 und *39; vgl. auch unten. Die auch in diesem Zusammenhang wichtige Chronik des Martino da Canal wird aber nicht herangezogen. Zum Unternehmen von 1122-1124, vgl. Jonathan Riley-Smith: The Venetian Crusade of $1122-$ 1124, in: I comuni italiani nel regno crociato di Gerusalemme, hg. v. Gabriella Arraldi/ Benjamin Z. Kedar, Genua 1986, S. 339-350 und Stroll, Calixtus II (wie Anm. 94) S. $451 \mathrm{ff}$.

144 Siehe Anm. 106.

145 IP 3 S. 362 f. Nr. $38, * 40-44$.

146 IP 3 S. 362 Nr. $\dagger^{*} 39$.

147 IP 6/2 S. 338 ff. Nr. 71 ff. Wieder Fälschungen sind zwei Schreiben Gregors VIII. an die Kanoniker und das Kapitel der Kathedrale von Pisa, die Herzen der Pisaner zum Kreuzzug anzuspornen, IP 3 S. 345 Nr. †72, und Clemens' III., eine Versammlung der 
Chronologisch reihen sich an die bereits erwähnte Bestellung von oberitalienischen Legaten der 1959 aufgefundene Brief Clemens' III. an die Kreuzzugsteilnehmer in der Toskana ein wie auch der wohl aus der Überlieferungssituation nur für Genua in einer eigenen Ausfertigung von 1188 Mai 27 erhaltene, aber sonst weit gestreute Kreuzzugsaufruf Clemens' III. Quam grave $e^{148}$. $\mathrm{Da}$ er mindestens auch nach Pisa geschickt wurde, darf man annehmen, ob auch nach Venedig, ist weniger sicher. Denn für die Hafenstadt an der Adria erscheint zu keinem der drei großen Kreuzzüge ein Regest, bis Coelestin III. dem Dogen im Jahre 1192 befiehlt, dem päpstlichen Legaten, dem Subdiakon N., Rektor von Massa, Getreide für die Christen im Hl. Land zur Verfügung zu stellen, zusammen mit einem Lastschiff für solche Transporte, das einst schon auf Betreiben des Kardinals und Legaten Rufinus bereitgestellt worden sei ${ }^{149}$. Wenn zudem bereits nach dem dritten Laterankonzil die Ausfuhr von Waffen, Eisen und Holz aus Venedig in die islamischen Gebiete unterbunden werden sollte ${ }^{150}$, zeigt beides die dominierende logistische Funktion für den Nachschub in die Kreuzfahrerstaaten, aber auch den Papst nicht auf einen Anstoß von außen reagierend, sondern selber aktiv eingreifend, wie der Kreuzzug seit 1095 zunehmend zum eigentlichen Handlungsraum und zur primären Aufgabe des Papsttums an der Spitze der Christianitas geworden war.

Wie angedeutet spielt in der „Italia Pontificia“ eine Reihe von S p u ri a für die Kreuzzüge, insbesondere für die Kreuzzugsbeteiligung, eine große Rolle, wie überhaupt in ihr unter den Spuria des 12. Jahrhunderts der Anteil solcher, die den Kreuzzug betreffen, überproportional hoch ist. Sie sollen hier zusammenfassend untersucht werden. Ganz offenkundig regte auch in Italien der Kreuzzug Fälscher an, wie dies aus dem neuzeitlichen Frankreich mit der berühmten Collection Courtois bekannt ist. Dabei läßt erst die zusammenfassende Betrachtung der einzelnen Nachrichten ihre Bedeutung erfassen. Die meisten hängen mit dem ersten Kreuzzug zusammen. Doch auf dieser Ebene beginnt der Beitrag der „Italia Pontificia“ lange vor 1095. Unter „Civitas Ianuensis“ erscheint als erstes Regest überhaupt der berühmte Brief auf den Namen Papst Sergius' IV. mit dem Versprechen aller Bürger Italiens (d.h. der Poebene), Venetiens und Genuas, tausend Schiffe auszurüsten, um das von den Agareni zerstörte Grab Christi zu rächen ${ }^{151}$. Entgegen der heute mehrheitlich vertretenen

Suffraganbischöfe und anderer tuszischen Prälaten, der Grafen und Markgrafen, Ritter usw. in der Kathedrale für die Wiedergewinnung des Hl. Landes einzuberufen, IP 3 S. 345 Nr. $† 74$.

148 IP 6/2 S. 290 Nr. 55, ed. O 3 S. 332 Nr. 154.

149 IP $7 / 2$ S. 26 Nr. 63.

150 IP $7 / 2$ S. 25 Nr. ${ }^{*} 60$ zu $(1179-1181)$, ebd. Nr. 61.

151 IP 6/2 S. 322 Nr. ${ }^{*} 1$. 
Auffassung, daß es sich um eine Fälschung handle ${ }^{152}$, sah Kehr den Fälschungsverdacht nulla ratione begründet und wiederholte das Regest dem Text entsprechend ohne Crux unter Venetien, behielt aber die dritte Erwähnung für „Italien“ dem allgemeinen Band vor.

Es folgt unter Civitas Ianuensis auf der nächsten Seite das Regest einer vom 1. Mai 1094 (!), also über ein Jahr vor Clermont, datierten littera Urbans II. an alle Christen von Osten nach Westen und von Süden nach Norden mit der Aufforderung, den genuesischen Brüdern Jakob und Ottobonus Belmusto, den Söhnen des Roger Belmusto, der unter Robert Guiscard Krieg führe, und den sie begleitenden 300 Rittern bei ihrem Durchzug zum großen Herzog Buglioni (!) Hilfe zu gewähren. Als Belohnung sollte den Wohltätern ein Plenarablaß in der Form eines Anno Santo winken ${ }^{153}$. Daß es sich um eine Fälschung handelt, braucht kaum betont zu werden. Aus derselben Werkstatt stammt auch ein von Kehr erstmals ediertes Privileg Urbans II. von 1097 aus einer anderen vatikanischen Handschrift für die edlen Brüder Spinelli aus Neapel, ebenfalls mit dem Ablaß eines Jubeljahres ${ }^{154}$. Zeitlich nochmals ein Jahr vor dem Brief für die Belmusti soll ein drittes dieser päpstlichen Schreiben am 24. Februar 1093 dem populus libertatis von Bisantium, gemeint mit antikisierendem Namen Prato, unter dem Fischerring (!) auf Bitte Peters des Einsiedlers befohlen haben, binnen Jahresfrist 30 Adlige für den Kreuzzug auszurüsten ${ }^{155}$. Bezieht man entsprechende Nachrichten in italienischen Stadtchroniken und -geschichten des 15.-17. Jahrhundert ein, ließe sich die Zahl leicht vermehren. So berichtet die venezianische Cronaca Navagera des 16. Jahrhunderts von einer Aufforderung Urbans II. auf dem Konzil von Clermont in Cilicia (!) an die Venezianer zur Teilnahme am Kreuzzug und von der Übertragung einer Kreuzzugslegation an den Bischof Heinrich Contarini von Castello für die venezianische Flotte in mari, wie sie Adhemar von Puy in terra erhalten habe ${ }^{156}$. Beides wurde nicht in die „Italia Pontificia“ aufgenommen.

Was für die Belmusto, die Spinelli usw., isoliert gesehen, als phantasievolle Kuriositäten abgetan werden könnte, bildete in Wirklichkeit Teil eines weit

152 JL $† 3972$; vgl. jetzt auch RI 2/5 Nr. †1049 und Papsturkunden 896-1046, hg. v. Harald Zimmermann, 3 Bde., 2. Aufl., Wien 1988-1989, hier 2 S. 845 Nr. 445.

153 IP 6/2 S. 323 Nr. †4.

154 KeHR, Papsturkunden in Italien (wie Anm. 5) 5 S. 6 Nr. †2, IP 8 S. 465 Nr. †1, O 3 S. 89 Nr. $† 3$ mit dem Hinweis auf ein Privileg Kaiser Heinrichs VI. für einen Rupert Belmosto (Stumpf 5078).

155 IP 3 S. 142 Nr. †1, ed. Kenr, Papsturkunden in Italien (wie Anm. 5) 5 S. 6 Nr. $\nmid 2$; O 3 S. $391 \mathrm{Nr}+1196$.

156 Andreas Naugerius: Historia Veneta (Cronaca Navagera), ed. Ludovico Antonio Muratori, Mailand 1723 (Rerum Italicarum Scriptores 23), S. 962; vgl. Fortunatus Olmus: Historia translationis s. Nicolai, Venedig 1626, S. 32. Regest einzureihen in IP 7/2 S. 20 nach Nr. 36. 
verbreiteten Bestrebens, sich als Individuum, als Familie oder als staatlichkommunales Kollektiv einen Platz in dem ruhmbringenden Kreuzzugsgeschehen zu sichern. Die Absicht, das im 11. Jahrhundert noch unbedeutende Prato oder das erst um 1100 in den Kreuzzug eingreifende Venedig schon in Clermont oder gar zuvor als beteiligt darzustellen, ist evident, und die abwegigen Datierungen sollen Italien gegenüber der im allgemeinen Bewußtsein dominierenden Stellung Frankreichs eine Art Erstgeburtsrecht am Kreuzzug verschaffen.

$\mathrm{Zu}$ diesen Bemühungen gehört auch eine lange Reihe von Fälschungen, die den Anteil Pisas am Kreuzzug glorifizieren und keinen geringen Teil der Regesten für die „Civitas Pisana“ ausmachen. Darunter befindet sich ein seit dem 17. Jahrhundert als eine Zimelie der pisanischen Geschichte verehrter Brief Paschalis' II. an die pisanischen Konsuln Gloria in altissimis, mit dem er für ihre Hilfe beim ersten Kreuzzug dankt und verspricht, er werde ihren Erzbischof Daimbert, jetzt Patriarch von Jerusalem, an Gottfried von Bouillon und die anderen Kreuzzugsführer in Syrien empfehlen. Jaffé wie die ganze Kreuzzugsforschung hatte ihn ohne jedes Bedenken rezipiert, weil er scheinbar präzise Angaben über die Überlieferung macht, doch Kehr wies nun nach, daß auch er ein Machwerk des 17. Jahrhunderts darstellt ${ }^{157}$. Aus der gleichen Quelle stammt eine nicht minder falsche littera Calixts II., die den in Jerusalem weilenden pisanischen Kanonikern P. und C. außer der ihnen vom Patriarchat gewährten Unterstützung den Ertrag ihrer Pfründen und die übrigen Zuwendungen der Kirche von Pisa zubilligt, als ob sie anwesend wären ${ }^{158}$. Es folgt immer gleicher Herkunft eine Befreiung der Kathedrale von Pisa von Kreuzzugssteuern durch Innozenz II. im Jahre 1138, ein Aufruf Gregors VIII. und ein solcher Clemens' III. zur Hilfe für das Hl. Land ${ }^{159}$. Die große Zahl solcher Spuria aus Pisa ist kein Zufall, sondern diente offensichtlich dazu, durch angebliche Papsturkunden „Lücken“ in der historischen Überlieferung über die eigene Beteiligung an den Kreuzzügen insbesondere gegenüber dem konkurrierenden Genua zu überbrücken.

\section{V.}

In mancher Hinsicht in einer Art Zwischenstellung zwischen der Diözesanorganisation und den Ritterorden, denen der letzte Abschnitt gelten wird, steht das Kapitel des Hl. Grabes. Dabei ist zu beachten, daß wie in Frankreich und England keineswegs alle Kirchen Italiens mit diesem Patrozinium

157 IP 3 S. 359 Nr. $† 24$.

158 IP 3 S. 360 Nr. $† 30$.

159 IP 3 S. 345 Nr. $† 72$ und $\dagger^{*} 39$. Ein zweiter, von Kehr verworfener, chronikalisch überlieferter Aufruf, mit dem Erzbischof Hubald zum Legaten für das ganze Kreuzzugsheer ernannt wird, ist dagegen höchstens verfälscht, vgl. IP 3 S. 345 Nr. †*74. 
auch institutionell zur Grabeskirche in Jerusalem gehörten. Papsturkunden etwa für S. Sepolcro in Piacenza ${ }^{160}$ sind daher nicht dem lateinischen Osten zuzurechnen. Andererseits hatte die Grabeskirche in Jerusalem schon lange vor den Kreuzzügen Besitz in Italien, Südfrankreich und Spanien und scheint mit regelmäßigen Botenreisen die ihr zustehenden Abgaben und gleichzeitig Almosen eingesammelt zu haben ${ }^{161}$, was es dem Kapitel nach 1291 erlaubte, zeitweise seinen Sitz in Perugia zu nehmen, wo auch noch lange Archivteile aufbewahrt worden sein sollen ${ }^{162}$. Ältere Papsturkunden für die Grabeskirche in Jerusalem sind freilich bei der Nachlese für die „Italia Pontificia“ nicht zum Vorschein gekommen. Es bleibt bei der Erwähnung von einzelnen Niederlassungen.

Auf diese Beziehungen verweist in der „Italia Pontificia“ zuerst der - sit venia verbo - etwas chaotische Abschnitt über die Abtei S. Sepolcro in Acquapendente im nördlichen Latium ${ }^{163}$. Wenig klar erwähnt die Narratio, die zwölf Regesten vorausgeht, die Abtei sei eine Niederlassung der Zisterzienser und ein Haus der Templer gewesen, aber auch Acquapendente gehöre zum Hl. Grab, sei jedoch von Innozenz III. als Eigentum der römischen Kirche angesehen worden, das er den Vallombrosanern zur Reform übergeben habe. Damit läßt sich freilich das einzige feierliche Privileg des 12. Jahrhundert von Lucius II. von 1144 Mai $21^{164}$ nur schwer verbinden, das den Ort in den apostolischen Schutz aufnimmt, ohne die Templer oder die Zisterzienser oder das Hl. Grab zu erwähnen, während in der von Holtzmann in Agira neugefundenen Urkunde von 1196 die Kirche S. Sepolcro in Acquapendente der Abtei S. Maria Latina in Jerusalem, nicht dem Hl. Grab, als Besitz bestätigt wird ${ }^{165}$. Ebenso unklar bleibt, wie in diesen Ablauf die wohl nicht rein zufällige Weihe der Kirche durch Eugen III. im Januar 1147, d.h. bereits auf seiner Reise nach Norden, um jenseits der Alpen die Kreuzzugsvorbereitungen zu fördern, einzureihen sei ${ }^{166}$. Mit ihr scheint der Papst ein symbolisches Zeichen für seine Bemühungen um Hilfe für das Hl. Land gesetzt zu haben, was aber nur Sinn macht, wenn Acquapendente schon damals einer Kirche in Syrien gehörte.

Als Besitz der Grabeskanoniker wird in der „Italia Pontificia“ ferner ein Hospital des Hl. Grabes vor der Porta S. Pietro in Perugia erwähnt, das Lucius

160 IP 5 S. $504 \mathrm{f}$.

161 Vgl. Paul Riant: Inventaire des lettres historiques des croisades, in: Archives de l'Orient latin 1 (1881) S. 1-224. Einige Angaben bei Johannes Pahlitzsch: Graeci und Suriani im Palästina der Kreuzfahrerzeit, Berlin 1998 (Berliner historische Studien 33, Ordensstudien 15), S. 40-52.

162 In IP 4 nicht erwähnt. Vgl. Riant: Inventaire (wie Anm. 161).

163 IP 2 S. $227-229$.

164 JL 8618, ed. Codice diplomatico della città di Orvieto, ed. Luigi Fumi, Florenz 1884 (Documenti di storia italiana VIII), S. 109 zu Nr. 169.

165 Holtzmann, Papsturkunden (wie Anm. 35) S. 63 Nr. 4.

166 IP 2 S. 229 Nr. ${ }^{*} 12$. 
II. aufgrund einer gefälschten Urkunde Calixts II. der dortigen Abtei S. Pietro übertrug, Eugen III. jedoch wieder absprach ${ }^{167}$. Ein Hospital und die Kirche des Hl. Grabes in Jerusalem in Nervi bei Genua wird dagegen nur unter der dortigen Pfarrkirche S. Siro angeführt, mit der die Kanoniker einen längeren Streit austrugen, den der Kardinalpriester Petrus von S. Cecilia mit folgender Bestätigung durch Coelestin III. beilegte ${ }^{168}$. Dies alles sind übliche Konflikte, die nur zeigen, daß die Niederlassungen des Hl. Grabes wegen der großen Distanz zum Mutterhaus oft gefährdet waren, in anderen Fällen wie in Nervi jedoch gestützt auf ihre Privilegien durchaus aggressiv gegen Konkurrenten vorgingen.

Ohne folgende Regesten erscheint unter Barletta neben den Templern und Johannitern die Kirche S. Sepolcro ${ }^{169}$ und unter dem Erzbistum Brindisi ein dort gelegenes Priorat ${ }^{170}$. Ebenso wird für Rom nur in der Narratio zu S. Egidio im Borgo Angelico erwähnt, daß Alexander III. während seines ersten Aufenthaltes in der Stadt nach der Rückkehr aus Frankreich im Jahre 1166/1167 die Kirche dem Prior und den Brüdern des Hl. Grabes zur inneren Reform und personalen Erneuerung durch erfahrene Leute geschenkt habe ${ }^{171}$, doch erscheint dieses im Titel des Abschnittes nicht, so daß die Zugehörigkeit zu einer Kirche des Hl. Landes erst bei genauer Lektüre erkennbar wird. Auffälligerweise fehlt auch jeder Hinweis auf die bereits von Coelestin II. 1144 erfolgte Schenkung einer von ihm ohne Patrozinium genannten Kirche in Rom ${ }^{172}$. Diese scheint in der Zwischenzeit verloren gegangen zu sein, wenn es sich unter Alexander III. nicht um eine Neuschenkung bzw. unter Auflagen ausgesprochene Bestätigung der in der Zwischenzeit heruntergekommenen - oder etwa in die Hand der Anhänger des Gegenpapstes geratenen? - Kirche handelt, auf die die Kanoniker ihre Rechte verwirkt hatten. Auch die von Coelestin II. hervorgehobene Zweckbestimmung als Unterkunft für die in Geschäften des Hl. Grabes an die Kurie kommenden Brüder aus dem Hl. Land, wird 1166/1167 nicht wiederholt ${ }^{173}$. Sie stellte jedoch die Niederlassung in einen direkten Bezug zum Papsttum und hätte daher eigentlich unter 1144 zu einem eigenen Regest führen müssen. Von Bedeutung ist sie als Beleg für eine bereits kurz nach dem zweiten

167 IP 4 S. $71 \mathrm{f}$.

168 IP 6/2 S. 344 Nr. 1-3. In der Edition von Pflugk-Harttung, Acta (wie Anm. 19) 2 S. 398 Nr. 454 wird sie fälschlich den Johannitern zugeschrieben.

169 IP 9 S. 302.

170 Ebd. S. 385.

171 IP 1 S. 153 f., JL 13184, ed. O 3 S. 176 Nr. 54; ed. BresC-Bautier: Le cartulaire (wie Anm. 19) S. 273 Nr. 140.

172 JL 8482, ed. O 3 S. 176 Nr. 54; ed. Bresc-Bautier (wie Anm. 19) S. 58 Nr. 13.

173 In qua Domino serviatis et cum pro negociis ecclesie vestre ad curiam veneritis, honestum hospicium habeatis. 
Laterankonzil institutionell verankerte Präsenz der Grabeskirche in Rom bzw. an der Kurie ${ }^{174}$.

Am wichtigsten für das Verhältnis des Hl. Grabes zum Papsttum und Italien im 12. Jahrhundert ist freilich jenes in der Narratio zu Barletta erwähnte, weil dort als Original aufbewahrte feierliche Privileg Lucius' III. ${ }^{175}$. Es ist nicht in den Chartularen des Kapitels enthalten und stellt daher wohl im angedeuteten Sinn eine spezielle Ausfertigung für die apulischen Niederlassungen dar, die eine Art Generalpriorat mit Sitz in Barletta gebildet haben könnten. In Erweiterung der Vorurkunden enthält es neben der allgemeinen Bestätigung von Besitz in Sizilien, Kalabrien und Apulien, Rom und Toskana eine nur hier überlieferte Liste von zwölf einzeln aufgeführten Kirchen in Apulien und der Basilicata, über die wir sonst meist nichts wissen und die in der nächsten, wieder an das Mutterhaus gegangenen Bestätigung durch Coelestin III. am Ende des Jahrhunderts wegfallen ${ }^{176}$.

\section{VI.}

Weitgehend übergangen wurden bisher die großen Ritterorden der Te m ple r und Joh an nit e r ${ }^{177}$. Dabei ist stets zu beachten, daß als Folge der Aufhebung des Templerordens auf dem Konzil von Vienne und der Integration seiner Güter in den Johanniterorden in der Regel auch die Urkunden an die neuen Eigentümer übergingen, so daß sich heute außer auf der Iberischen Halbinsel, wo eine andere Lösung für den Ordensbesitz erfolgte, im Prinzip überall in den Archiven der Johanniter auch Urkunden für die Templer finden ${ }^{178}$. Weil durch die beiden großen Urkundenbücher von Delaville le Roulx und d'Albon ${ }^{179}$ umfassende Vorarbeiten geleistet worden sind, sei hier mit dem Bild begonnen, das sich aus den Bänden der „Italia Pontificia“ ergibt und dann erst die Frage nach der Nachlese gestellt.

Wie für die großen Abteien von S. Maria Latina, S. Maria im Tale Josaphat, S. Maria auf dem Berge Sion lag für beide Orden das Haupthaus bis zur Krise des Jahres 1187 in Jerusalem, nach 1191 in Akkon. Doch ihr Besitz im Westen wuchs im Laufe des 12. Jahrhunderts fast explosionsartig und übertraf rasch

174 Für die Niederlassungen der Templer, der Johanniter und des Hl. Grabes in Rom vgl. künftig meinen Beitrag „Esser presente alla curia“.

175 Siehe oben S. 619 Anm 19.

176 O 3 S. 298 Nr. 125. Vgl. dazu auch Bresc-Bautier: Les possessions (wie Anm. 33).

177 Auf den deutschen Orden wird hier nicht besonders eingegangen, da er an anderer Stelle behandelt wird.

178 Vgl. die Übersicht über die Aufbewahrungsorte der Johanniterurkunden in Delaville LE Roulx: Cartulaire (wie Anm. 10).

179 Siehe oben Anm. 10 und 18. 
auch denjenigen des Hl. Grabes bei weitem. Sie wurden zu ,internationalen Orden, die überall präsent waren und über eine Fülle von Privilegien verfügten, was zu einer Vielzahl von Konflikten mit der Diözesangeistlichkeit führte, gegen die sie ihre Privilegien bald offensiv und oft rücksichtslos ausspielten, bald auch angegriffen verteidigen mußten. Dies führte zu einem zunehmend komplexeren hierarchischen Aufbau von einzelnen Häusern und Kommenden über sogenannte Bailliages und (Groß-)Priorate zu Provinzen und Zungen und einer Zentrale mit dem Konvent am Sitz des (Groß-)Meisters, was freilich erst am Ende des 13. Jahrhunderts voll ausgebildet war ${ }^{180}$.

Auch auf der Apenninenhalbinsel war der Besitz der Templer und Johanniter beträchtlich. Als Folge bildete sich anscheinend weitgehend parallel eine Reihe von Ordensprovinzen heraus, die zum Teil durch die politische Struktur vorgegeben waren, denn der Besitz im normannischen Süditalien, im Kirchenstaat und im kleinräumiger gegliederten Oberitalien konnte nicht von einer für die ganze Halbinsel zuständigen Instanz geleitet werden. Daß es sich gerade in Süditalien um umfangreichen Besitz handelte, zeigt die Einrichtung von drei Johanniter-Großprioraten in Messina, Barletta und Capua, die den drei Teilen des normannisch-staufischen Königreichs entsprachen, während für die Mitte und den Norden vier weitere in Rom, Pisa, Venedig und in der Lombardei zuständig waren ${ }^{181}$. Welche Befugnisse und welchen Amtsbezirk der magister Italiae hatte, der am Ende des 12. Jahrhunderts bei den Templern begegnet, ist noch nicht abschließend geklärt ${ }^{182}$. In der "Italia Pontificia“ hatten weder die Ordenszentralen noch die Orden als Ganzes Platz, die in den Oriens Pontificius Latinus gehören. Doch die nachgeordneten Verwaltungseinheiten mußten neben den Besitztiteln für den lokalen Besitz aus logistischen Gründen auch an Ort und Stelle über die dem Orden verliehenen allgemeinen Rechtstitel verfügen und erhielten daher im eingangs erwähnten Sinne nicht nur Kopien von Privilegien aus dem Mutterhaus, sondern auch Originalausfertigungen aus der päpstlichen Kanzlei, die aber in der Adresse oder im Kontext fast immer den Orden allgemein, nicht eine nachgeordnete Organisationsebene oder einen Raum nennen. Daher standen auch die einzelnen Häuser und vor allem die zusammenfassenden Organisationseinheiten der Orden in unmittelbarem Kontakt mit der Kurie. Es sind allein die Überlieferung und die Kommuni-

180 Für die Templer vgl. Malcolm BARBER: The New Knighthood. A history of the order of the Temple, Cambridge 1994, und Alain Demurger: Les Templiers. Une chevalerie chrétienne au Moyen Âge, 2. Aufl., Paris 1993; für die Johanniter Jonathan RiLEYSмiтн: The Knights of St. John in Jerusalem and Cyprus (c. 1050-1310), London 1967.

181 Vgl. für die Johanniter Delaville le Roulx: Cartulaire (wie Anm. 10) 1 S. CXICXXXV.

182 Vgl. Fulvio Bramato: Storia dell'Ordine dei Templari in Italia, 2 Bde., Rom 1994, hier 1 S. 153-159. 
kationswege von der Kanzlei zum heutigen Aufbewahrungsort, die über die Zuordnung für eine vom Empfängerprinzip her konzipierte Zusammenstellung entscheiden, so daß selbst von zwei völlig identischen Ausfertigungen eines feierlichen Privilegs oder eines Mandats beide an die Zentrale oder beide an dieselbe nachgeordnete Instanz oder die eine an die Zentrale und die andere an eine nachgeordnetete Instanz gegangen sein können und dementsprechend im Regestenwerk an verschiedenen Stellen einen Haupteintrag erhalten.

Dennoch bleibt die Zahl der Regesten für die beiden großen Ritterorden in der „Italia Pontificia“ gering und ihre Organisationsstruktur kommt selbst in den Narrationes nur ganz undeutlich zum Ausdruck. Die Großpriorate und Ordensprovinzen spielen keine Rolle als Überlieferungsträger, denn ihre Archive sind, soweit es um ältere Bestände und insbesondere um ältere Papsturkunden geht, im Laufe der Jahrhunderte anscheinend fast restlos verloren gegangen, was auch dazu beiträgt, daß es bis heute keine umfassende Darstellung der Geschichte der Johanniter in Italien gibt, während Fulvio Bramato in zwei Bänden eine Geschichte der Templer in Italien vorgelegt hat, deren zweiter Band 647 Regesten von 1130 bis 1394 enthält ${ }^{183}$, davon 19 für Papst- und Legatenurkunden bis 1198.

Entsprechend klein ist in der „Italia Pontificia“ die Zahl der selbständigen Abschnitte für Templer- und Johanniterniederlassungen. Da diese zudem häufig aus Schenkungen bereits bestehender Kirchen herrührten, wurden sie meist mit Einschluß der vorangehenden Zeit unter dem ursprünglichen Patrozinium behandelt, wie auch die anschließenden Regesten sich oft nicht auf die Ordenszeit beziehen, so daß erst aus der Narratio die Zugehörigkeit zu einem der beiden Orden ersichtlich wird. Nur vereinzelt wird als Untertitel etwa Mansio Templariorum $^{184}$ oder Domus Hospitalariorum ${ }^{185}$ hinzugefügt, wie es auch nie ein Ziel der „Italia Pontificia“ war, einen Gesamtblick auf den Ordensbesitz, seien es die Ritterorden oder die großen Reformorden, zu vermitteln. Häufig finden sich daher Erwähnungen von Templern und Johannitern unter den Regesten für

183 Ebd. 2 S. 71-235. Papst- und Legatenurkunden werden erwähnt bis 1198 in 19 Regesten, einem Fünftel von 85: S. 77 Nr. 2 für Lucca, S. 82 Nr. 25 für Sizilien, S. 83 Nr. 30 für Capitanata, Apulien und Kalabrien, S. 84 Nr. 35 für Reggio Emilia, S. 85 Nr. 41 für Ceprano, S. 86 Nr. 45 und 46 für Termoli/Tremiti, S. 87 Nr. 50 für Principato, Capitanata, Apulien und Kalabrien, S. 88 Nr. 52 für San Germano bei Montecassino, S. 89 Nr. 56 für Verona und Nr. 58 für Ceprano, S. 90 Nr. 61 für Verona und Nr. 64 für Acqui, S. 90 Nr. 65 und S. 91 Nr. 66 Legaten für Verona mit päpstlicher Bestätigung, S. 92 Nr. 72 für Zara und Nr. 74 für Apulien, Kalabrien und Sizilien, S. 93 Nr. 79 päpstliche Legaten für Moncalieri, S. 94 Nr. 84 für Fermo. Die Liste bei Bramato ist unvollständig, so fehlt z. B. Clemens III. für die Crociferi und Zara.

184 IP 3 S. 215 Nr. *1 für Siena.

185 Siehe unten Anm. 209. 
andere Kirchen, vor allem wenn es um Besitzstreitigkeiten oder Auseinandersetzungen über die Sonderrechte der Orden ging.

Es kann nicht darum gehen, jeden einzelnen Beleg in einer Narratio, einem Regest oder einem Kommentar in der „Italia Pontificia“, der auf Templer und Johanniter weist, zu erörtern. Nur die lokale Verteilung der Niederlassungen mit der Zahl der ihnen zugeordneten Regesten sei genannt. Auf der Ebene der Großpriorate hat nur Barletta für die Johanniter einen eigenen Abschnitt mit vier Regesten ${ }^{186}$, während in den Narrationes zum Erzbistum dasjenige für Messina $^{187}$, als einfache Domus hospitalis jenes für Capua erwähnt wird, im Band für Rom S. Maria auf dem Aventin den Untertitel S. Maria del Priorato erhält. Unter Pisa, Venedig und für die Lombardei sucht man vergeblich nach einem entsprechenden Abschnitt, für die Templer entfällt überhaupt jeder Hinweis auf die höheren Verwaltungseinheiten, obwohl Schiaparelli in seinem Bericht über Sizilien ausdrücklich festgehalten hatte, einzelne Abschriften in Palermo seien dem Tabularium domus Templi nobilis civitatis Messanae entnommen ${ }^{188}$.

Auf der Ebene der Kommenden weist die „Italia Pontificia“ für die Templer nur wenige nach, die im Laufe des 12. Jahrhunderts in Kontakt mit dem Papsttum getreten sind. Sie folgen hier in der Abfolge der Bände der „Italia Pontificia": Ceprano für S. Paterniano mit Erwähnung in der Narratio und zwei Regesten ${ }^{189}$, und das bereits bei den Kanonikern des Hl. Grabes erörterte Acquapendente als Templariorum militum domicilium in der Narratio ${ }^{190}$, Lucca mit der Bestätigung einer Schenkung durch Innozenz II. von 1138 Dezember 2 als der ältesten Papsturkunde für die italienischen Niederlassungen (ein Regest) ${ }^{191}$ und als erstes eigenes Lemma die Mansio Templariorum in Siena (ein Regest) ${ }^{192}$, Fermo in einer Verfügung Coelestins III. zugunsten des Bischofs ${ }^{193}$, ReggioEmilia für S. Stefano mit dem Untertitel Domus templariorum und einem Re-

186 IP 9 S. 305.

187 IP 10 S. 322.

188 Kehr, Papsturkunden in Italien (wie Anm. 5) 2 S. 45 zu Cod. Qq. H. 12.

189 IP 2 S. 173; die Kirche S. Paterniano wird 1173 von Alexander III. den Templern gegeben; JL 2 S. 263; IP 2 S. 173 Nr. * 4 aus der Chronik von Fossanova. 1181 wird eine weitere Schenkung des Bischofs von Veroli durch Alexander III. bestätigt, JL -; KEHR, Papsturkunden in Italien (wie Anm. 5) 2 S. 503 Nr. 22. Im Kommentar wird erwähnt, daß schon Bf. Faramundus von Veroli den Templern die Kirche geben wollte auf Intervention von Franco, dem Kämmerer Alexanders III. (Archiv von Veroli Nr. 656). Dieser Franco war jedoch selber ein Templer, vgl. O 2 S. 235 Nr. $24 \mathrm{~b}$ und Marie Luise Bulst-Thiele: Templer in königlichen und päpstlichen Diensten, in: Festschrift Percy Ernst Schramm, hg.v. Peter Classen, 2 Bde., Wiesbaden 1964, 1 S. 289-308, S. 301.

190 IP 2 S. 227.

191 IP 3 S. 448 und 449 Nr. 1; JL 7916.

192 IP 3 S. 204 Nr. 37 an den Bischof von Siena = S. 215 Nr. ${ }^{*} 1$ an die Templer.

193 IP 4 S. 138 Nr. ${ }^{*} 18$. 
gest ${ }^{194}$, Moncalieri in Piemont für S. Egidio als Templerbesitz mit einem Regest $^{195}$, ferner in Acqui die Ecclesia s. Margaritae Templariorum mit einem Regest ${ }^{196}$, Verona mit der Ecclesia s. Vitalis Templariorum mit fünf Regesten ${ }^{197}$. Es folgen im Süden in San Germano zu Füßen von Montecassino eine Domus Templariorum mit zwei Regesten ${ }^{198}$ und schließlich ein Haus in der Capitanata mit drei Regesten, wohl identisch mit der in der Narratio zu einer Domus misericordiae apud Foiam sita (kein Regest) erwähnten Niederlassung oder der mit der Abtei auf den Isole di Tremiti prozessierenden Templer (zwei Regesten $)^{199}$ und zuletzt Barletta unter der Narratio ohne Regest ${ }^{200}$. Sizilien bleibt ein weißer Fleck.

Nicht besser ist es mit den Johannitern bestellt. Zwar ist hier neben den bereits erwähnten Großprioraten Capua, Barletta und Messina in Asti eine domus hospitalis iuxta civitatem belegt, bei der es sich um das schon 1113 erwähnte Hospital handeln könnte, wenn auch der Bischof von Asti sie 1182 als Gründung eines Petrus Fantinus und eines Soldanus dem Meister und dem praeceptor Hospitalariorum de Lombardia verleiht ${ }^{201}$. Weitere Häuser erhalten z.T. einen eigenen Abschnitt wie Imola mit einer Domus fratrum hospitalis Hierosolymitani mit einem Regest ${ }^{202}$, Foggia dagegen nur in der Narratio der Domus misericordiae ohne Regest ${ }^{203}$, daneben nur vier weitere Orte, wo sich aus Rechtsstreitigkeiten Regesten ergeben, die die Existenz von Ordensniederlassungen belegen: Fermo mit der schon bei den Templern erwähnten Verfügung

194 IP 5 S. 325 Nr. 8 = S. 377 Nr. 1. Eine erste Nachricht über ein Haus in Mussadella stammt von 1144 .

195 IP 6/2 S. 92 Nr. 1; Bramato, Storia (wie Anm. 182) 2 S. 93 Nr. 79, dessen Regest aber fälschlich den Legaten statt des Bischofs von Turin als Schenkenden ausweist, der auf Bitten des Legaten handelt.

196 IP 6/2 S. 195. Frühere Nachrichten über ein Templerhaus in Acqui sind nicht bekannt. 197 IP $7 / 1$ S. 265 f.

198 IP 8 S. 194 f. Nr. 1 und 2, zuerst Alexander III. bestätigt Kirche S. Angelo von Abt von Montecassino geschenkt und dann kurz darauf Spezifizierung mit Schutz von Montecassino, daß sie keine Kirche bauen und Montecassino nicht schädigen sollen (ed. JL - , KeHr, Papsturkunden in Italien [wie Anm. 5] 2 S. 81 Nr. 33 und JL 13590). Für die jeweilige Zahl der Regesten wird hier nicht geschieden zwischen Hauptregest und Nebenregesten für Papsturkunden an andere Empfänger, die auch einen der beiden Orden betreffen, und ebenfalls nicht zwischen Papsturkunden, Legatenurkunden und anderen Urkunden, die zu der betreffenden Niederlassung gehören.

199 IP 9 S. 144. Es dürfte sich dabei um das in IP 9 S. 226 unter der Domus misericordiae bei Foggia genannte Templerhaus handeln oder die mit dem Abt von Tremiti einen Konflikt austragenden Templer vgl. IP 9 S. 185 Nr. * 12 und 13.

200 IP 9 S. 302.

201 IP 6/2 S. 180 Narratio ohne Regest.

202 IP 5 S. 171.

203 IP 9 S. 226. 
Coelestins III. zugunsten des Bischofs als einzigem Beleg ${ }^{204}$, Acqui für die Ecclesia s. Caloceri Hospitalariorum mit einem Regest ${ }^{205}$, Tortona für die Domus Hospitalariorum s. Crucis mit einem Regest ${ }^{206}$, und Genua unter Ecclesia s. Fidis nur in der Narratio ohne Regest ${ }^{207}$. Nur in einem Kommentar kommt schließlich im äußersten Süden des Festlandes Cosenza hinzu ${ }^{208}$. Diese Liste ist von den genannten Niederlassungen her zweifellos wesentlich repräsentativer, wenn man bedenkt, daß im ersten feierlichen Privileg Paschalis' II. im Jahre 1113 Asti, Pisa, Bari, Otranto, Taranto und Messina als nachgeordnete Häuser des Hospitals in Jerusalem genannt werden ${ }^{209}$, doch zahlenmäßig mit acht Regesten (und einem räumlich definierten) gegen 21 (und drei räumlich definierten) für die Templer noch kläglicher sind ${ }^{210}$.

Unter archivalischem Gesichtswinkel lassen sich in Italien in chronologischer Abfolge für das feierliche Privileg der Johanniter Christianae fidei religio Originale oder alte Kopien nachweisen aus Barletta für 1154 Oktober 21, in Messina von 1167 Juni 23, in Assisi von 1180 Januar 26 von unbekannter Herkunft $^{211}$, aus Capua Kopie von 1304 des feierlichen Privilegs Urbans III. (JL 15551) jetzt in Montecassino ${ }^{212}$, und wieder für Barletta von 1186 März $14^{213}$, dagegen auf der ganzen Apenninenhalbinsel kein Exemplar des Templerprivilegs Omne datum optimum, sei es als Original oder als Kopie. Weil diese Ausfertigungen stets an den Meister des Hauses in Jerusalem gerichtet sind, erhielten sie dem gewählten Prinzip folgend, wenn auch unberechtigterweise, nie ein eigenes Regest, obwohl sie in Wirklichkeit, wie heute feststeht, für die entsprechenden Priorate ausgestellt worden waren.

204 IP 4 S. 138 Nr. * 18.

205 IP 6/2 S. 195.

206 Ebd. S. 228.

207 Ebd. S. 303.

208 IP 10 S. 114 Nr. 8, Kommentar erwähnt zu Erzbischof Sanctus Alexander III. (11791181) November 27, ed. KeHr, Papsturkunden in Italien (wie Anm. 5) 2 S. 76 Nr. 12.

209 Diese Liste ist in den letzten Jahren heftig umstritten, nachdem Michael Matzke darin nicht den Niederschlag realer Gegebenheiten, sondern m.E. völlig mittelalterfremd, einen groß angelegten Plan künftiger Besitzerwerbungen zu erkennen glaubte, der nachher nicht habe verwirklicht werden können. Vgl. Ders.: De Origine Hospitalariorum Hierosolymitanorum - Vom klösterlichen Pilgerhospital zur internationalen Organisation, in: Journal of Medieval History 22 (1996) S. 1-23.

210 Templer auf Sizilien, Kenr, Papsturkunden in Italien (wie Anm. 5) 2 S. 63 Nr. 4 und S. 121 Nr. 33, Templer in Prinzipat, Kapitanat, Apulien und Kalabrien, ebd. S. 435 Nr. 15 und Johanniter in Sizilien/Kalabrien, ebd. S. 70 Nr. 14.

211 Die handschriftlichen Aufzeichnungen Kehrs führten nicht weiter, weil ihm abgesehen von der Unterschriftenliste das Stück als uninteressant galt. Es konnte daher auch nicht für die Entwicklung des Formulars verwendet werden, vgl. O 2 S. 108-135.

212 Kehr, Papsturkunden in Italien (wie Anm. 5) 2 S. 142. Das ist ein drittes Original. 213 Vgl. Delaville le Roulx: Cartulaire (wie Anm. 10) passim und O 2 S. 108 f. 
Wie sehr sich die restriktive Auswahl von Nachrichten bei der Erstellung von Regesten auf das Bild auswirkt, das die „Italia Pontificia“ von den Beziehungen der beiden Orden zum Papsttum entwirft, zeigen am deutlichsten die römischen Niederlassungen, was schon für das Hl. Grab galt. Weder ein Abschnitt für die Johanniter noch für die Templer wird offen ausgewiesen. Vergeblich sucht man daher die brisante Nachricht, daß der Meister des Templerhauses auf dem Aventin mit seinen Brüdern im Jahre 1159 dem frisch gewählten Papst Viktor IV. die Obödienz erwies. Sie steht nicht an abgelegener Stelle, sondern in Rahewins Bericht über die Untersuchung des Wahlvorgangs auf dem Konzil von Pavia, wo unter den Anhängern Viktors IV. der magister fratrum templi Hierosolimitani in monte Aventino cum suis (fratribus) genannt wird $^{214}$, was eine direkte Beziehung der lokalen Templer zur Person des Papstes dokumentiert und ein eigenes Regest hätte erhalten müssen, nun aber dem Benutzer der „Italia Pontificia“ entgeht. Mindestens in einem Kommentar wäre schon für 1138 das Templerhaus als Ausstellungsort einer im Rahmen eines kurialen Prozesses ausgestellten Urkunde für St-Florent in Saumur zu erwähnen, die beweist, daß sich der erste abendländische Ritterorden ganz früh in der Nähe des Papsttums niederließ und eine wichtige Funktion auch für andere Bittsteller an der Kurie zu spielen begann ${ }^{215}$. In der Narratio zum alten Kloster S. Maria in monte Aventino, dessen Abschnitt als Untertitel den modernen, für Eingeweihte in die richtige Richtung weisenden Namen S. Maria del Priorato erhielt, liest man, daß im 13. (!) Jahrhundert die Templer dieses zu ihrer Prioratskirche gewordene Kloster besiedelten und der Besitz dann an die Johanniter überging, die bis heute dort seien ${ }^{216}$. Im 12. Jahrhundert scheinen so für den Benutzer der „Italia Pontificia“ beide Orden in Rom nicht präsent zu sein.

Auf einer anderen Ebene bringen Regesten für Urkunden anderer Empfänger beiläufig wertvolle prosopographische Hinweise für die Geschichte der Orden in Italien ${ }^{217}$. Wie schon nur aus dem Prozeß um die in Nervi errichtete Kirche der Name des Priors Nikolaus des Hl. Grabes für die Lombardei am Ende des 12. Jahrhunderts und damit zugleich die Existenz einer größeren Zahl

214 Rahewin: Gesta Frederici (wie Anm. 111) IV 77 S. 674.

215 Cartulaire d'argent de Saint-Florent de Saumur saec. XII f. 86, Angers, Archives départementales, H 3714. - Copia saec. XVIII, Paris, Bibl. nat. de France, Collection de Touraine IV 1606 fol. 317. Teiledition in D’Albon, Cartulaire du Temple (wie Anm. 18) S. 107 Nr. 153.

216 IP 1 S. 116 und S. 117 Nr. *1. Bramato, Storia (wie Anm. 182) 1 S. 112-114, ohne die Nachricht zu 1138. Auch Barber, Knighthood (wie Anm. 180) S. 385 Anm. 167 führt sie nicht an, betont aber 1159 .

217 Für diesen Aspekt der Italia, wo vor allem die beiden letzten Bände der Italia den Bischofslisten erhöhte Aufmerksamkeit schenkten vgl. jetzt Dieter Girgensohn: Miscellanea Italiae Pontificiae 1, Göttingen 1974, S. 135 f.; für das ausgehende 12. Jahrhundert jetzt die ausführlichen Zusammenstellungen in Norbert Kaмp: Kirche und Monarchie im staufischen Königreich Sizilien 1-4, Münster 1973-1982. 
von Häusern in Oberitalien bekannt ist, wird für die Johanniter mit einem Fulco im Jahre 1179 gegenüber den früheren Annahmen sechzig Jahre früher ein Prior in Capua greifbar ${ }^{218}$, ein Templermeister der Lombardei namens Bonifatius bereits $1169^{219}$, und für den Templermeister der Lombardei (?) Albert ist eine Legatenurkunde von 1196 für die Templer in Moncalieri die einzige Nachricht ${ }^{220}$. Die Ordensforschung hat diesen Zugang, der auch für die Organisation des Ordensbesitzes von großer Bedeutung ist, bis heute kaum wahrgenommen, weil er nicht aus den Ordensarchiven allein gewonnen werden kann.

Wichtiger und weit über den engen Raum hinaus weisen freilich für die Geschichte der Orden auf der Apenninenhalbinsel die Ergebnisse für die Geschichte der Archive. Die spärliche Überlieferung von Papsturkunden als Originale oder Kopien aus den lokalen Ordensarchiven ließ sich auch durch die Nachlese nicht wesentlich verbessern. Die genannten Zahlen von Templer- und Johanniterregesten in der „Italia Pontificia“ sprechen für sich. Es kam kein von Delaville le Roulx oder Prutz übersehener Ordensfonds zum Vorschein, sondern außer in Valletta und Palermo nur neun neue Stücke mit einer örtlichen $\mathrm{Zu}$ weisung $^{221}$ und ein allgemeines Stück aus den päpstlichen Registern ${ }^{222}$.

Dennoch kann das bisherige Bild einer tiefgreifenden Revision unterzogen werden, wenn auch auf einem Umweg. Zwar hatte Delaville le Roulx feststellen müssen, daß die ehemaligen Archive der Großpriorate der Johanniter in Messina, Capua, Brindisi wie auch in Roma, Pisa, Venedig und Mailand im Laufe der Jahrhunderte verloren gegangen waren und für das 12. Jahrhundert, soweit es Papsturkunden betrifft, im Wesentlichen nur späte Abschriftensammlungen des 17. und 18. Jahrhunderts zur Verfügung stehen. Unter ihnen stützte sich das Bullarium Melitense von Sebastiano Paoli aus Lucca zum ersten Mal auf die Originalurkunden aus der syrischen Zeit im Ordenszentralarchiv in Valletta und eine Reihe heute z.T. verlorener Bullarien und war von Delaville le Roulx ausgiebig ausgewertet worden ${ }^{223}$. Kehr ließ es daher beiseite.

Doch das Archiv auf Malta und zwei Handschriften in der Biblioteca Comunale in Palermo erwiesen sich für die Nachlese als unerwartet ergiebig ${ }^{224}$. Es bewährte sich, auch von früheren Forschern benutzte Archivalien noch

218 IP 8 S. 236 Nr. 1 = S. 359 Nr. 48. Das Stück fehlt bei Delaville Le Roulx: Cartulaire (wie Anm. 10), der S. CXXXIf. das Haus in Capua erst seit 1237 nachweist.

219 IP 5 S. 325 Nr. $8=$ S. 377 Nr. 1.

220 Vgl. oben Anm. 195.

221 Ein Stück aus dem Staatsarchiv in Neapel, KeHR, Papsturkunden in Italien (wie Anm. 5) 2 S. 435 Nr. 15, ist im Zweiten Weltkrieg vernichtet worden.

222 Sie sind in die Untersuchung aufgenommen und erscheinen meist als Nebenregest in der Italia Pontificia.

223 Vgl. die genaue Übersicht über die dort kopierten Stücke in O 1 S. 175-182.

224 Kenr, Papsturkunden in Italien (wie Anm. 5) 2 S. 89-129 und S. 44-47, 60-87. 
einmal genau durchzusehen. Auf Malta verzeichnete Schiaparelli insgesamt 21 Originale, 16 Kopien und 161 Abschriften in Bullarien. Sie waren alle von Delaville le Roulx erfaßt und, soweit sie die Johanniter betrafen, in das Cartulaire aufgenommen worden. Doch in archivalischer Vorgehensweise, entdeckte' Schiaparelli ein riesiges, zweibändiges Inventar der Papsturkunden des Ordensarchivs, den bereits für die Kreuzfahrerkirche wegen der darin verzeichneten Urkunden für S. Maria Latina und die Abtei auf dem Berge Thabor erwähnten Vol. 1132, mit weit über tausend Regesten für Papsturkunden von den Anfängen bis 1700, die für jede einzelne Urkunde Aussteller, Initium, Datum und den Überlieferungsort im Archiv nennen. Es führt dabei auch heute verlorene Originale und Bullarien an, die sich so recht genau rekonstruieren lassen. Dadurch kamen für das 12. Jahrhundert noch einmal 73 Originale, worunter sich einige frühe Kopien befinden können, und 142 kopiale Abschriften aus fünf verlorenen Bullarien hinzu. Aus diesen 413 Texten $^{225}$, darunter fünf für die Abtei auf dem Berge Thabor mit dem feierlichen Privileg Alexanders III. ${ }^{226}$, dem Regest eines feierlichen Privilegs des gleichen Papstes für S. Maria Latina ${ }^{227}$ und dem Kreuzzugsaufruf Eugens III. ${ }^{228}$, die alle bereits erörtert worden sind, wurden $51 \mathrm{im}$ Volltext oder als Regest überlieferte unbekannte Urkunden für Templer und Johanniter ediert. Aus Sizilien kamen aus zwei Handschriften in der Biblioteca comunale weitere 18 für die beiden Orden hinzu $^{229}$, zusammen also 69 neue Stücke. Jene stellen in der Nachlese aus Italien, sieht man von den päpstlichen Registern mit ihren über 300 Inserten ab, bei weitem den größten geschlossenen Überlieferungsblock überhaupt dar, diese den zweitgrößten. Anders als für Sizilien mit 15 Johanniter- und drei Templerstücken betraf der Neugewinn auf Malta die beiden Orden zu etwa gleichen Teilen $^{230}$. Über 150 weitere, bei JL auch nicht verzeichnete Texte für die Johanniter, die jedoch Delaville le Roulx eben erstmals ediert hatte, und ein halbes Dutzend solcher für die Templer, die bei Prutz standen, wurden nicht mehr neu ediert $^{231}$. Von den zehn an verstreuter Stelle gefundenen Stücken war schon die Rede, so daß 89 unbekannte Texte ediert und insgesamt fast 250 unbekannte Texte für die beiden Ritterorden erschlossen wurden.

225 Dabei sind die zahlreichen Mehrfachüberlieferungen eingerechnet.

226 Siehe oben Anm. 49.

227 Siehe oben Anm. 46.

228 Siehe oben Anm. 110.

229 KeHr, Papsturkunden in Italien (wie Anm. 5) 2 S. 92-107.

230 Mindestens einmal, KeHr, Papsturkunden in Italien (wie Anm. 5) 2 S. 112 Nr. 10, hat der Regestator freilich ein Stück durch Flüchtigkeitsfehler statt den Templern den Johannitern zugeschrieben. Das kann auch für andere Stücke, für die eine Parallelüberlieferung fehlt, nicht völlig ausgeschlossen werden.

231 Die Zahl neuer Stücke wäre erheblich kleiner, weil das gleiche Stück z.T. mehrfach überliefert ist. 
Daß die für die Nachlese in den abendländischen Reichen zum Teil sehr ergiebigen päpstlichen Register wie für die Diözesankirche des Hl. Landes auch für die Ritterorden (fast) nichts beitrugen, ergibt sich aus der rechtlichen Lage der Orden. Sie hatten längst durch Tausende von Papsturkunden sich die Fülle ihrer Rechte immer wieder bestätigen lassen, und diese waren seit dem 12. Jahrhundert ständig fortentwickelt und in der Kanonistik festgeschrieben worden, so daß sich ein Rückgriff auf ältere Papsturkunden in der Regel erübrigte. Die Templer fielen zudem nach dem Jahre 1312 als mögliche Petenten für eine Bestätigung und Inserierung ihrer Urkunden in eine neue Papsturkunde weg. Die einzige Ausnahme eines Inserts in die Register bildet eine Ausfertigung einer vielfach wiederholten Verfügung Alexanders III. zum Schutz der Personen und Güter der Johanniter Quanto maior ab, die während des Schismas dem avignonesischen Papst zur Bestätigung vorgelegt wurde ${ }^{232}$. Was zu diesem sachlich ungewöhnlichen Schritt veranlaßt haben könnte ist nicht ersichtlich. Ein zweites Insert in den Registern sei noch erwähnt, obwohl es nicht zu den bisher unbekannten Urkunden zählt. Wie die Zisterzienser und die Karthäuser zu Beginn des 14. Jahrhunderts bis heute in vielen Exemplaren überlieferte Sammeltranssumpte erstellen ließen, mit denen die einzelnen Niederlassungen die Rechtstitel für Prozesse zur Verfügung hatten, wurden in einem parallelen Vorgang im Jahre 1454 an der Kurie von einem päpstlichen Notar und Richter, dem Auditor der Audientia litterarum contradictarum Andreas de Viterbo, große Sammlungen niedergeschrieben, beglaubigt und dann von Calixt III. mit einer Mantelurkunde versehen und später von Sixtus IV. und anderen Päpsten ihrerseits bestätigt ${ }^{233}$. Die beiden einzigen darin enthaltenen Papsturkunden des 12. Jahrhunderts, Lucius III. (JL 14989; RI 4/4/4/1 971) und Urban III. (JL 15896), sind daher, vom Rechtsinhalt nichts Außergewöhnliches, die vielleicht am häufigsten überlieferten Papsturkunden für den Orden geworden.

Freilich bleibt die Frage, woher die Originale und Kopien auf Malta und die Vorlagen für die dort aufbewahrten Bullarien und die Vorlagen für die zwei Abschriftensammlungen in Palermo des Antonino Amico aus dem 17. Jahrhundert (Ms. Qq. H. 12) ${ }^{234}$ und eines Anonymus aus dem 18. Jahrhundert (Ms. Qq. H. 203) ${ }^{235}$ stammen. Zwar steht heute fest, daß große Teile der Originale und Kopien der älteren Papsturkunden auf Malta aus dem einstigen Ordenszentralarchiv über die Provence dorthin $\operatorname{kamen}^{236}$, daneben mindestens einige

232 KeHr, Papsturkunden in Italien (wie Anm. 5) 3 S. 435 Nr. 6.

$233 \mathrm{Zu}$ diesen Bullarien vgl. O 1 S. 133 ff. und O 2 S. 163-192.

234 KeHr, Papsturkunden in Italien (wie Anm. 5) 2 S. $44 \mathrm{f}$.

235 Ebd. S. 46 f. Diese Handschrift ordnet die ältere Sammlung Amicos mehr oder weniger chronologisch, fügt aber eine Reihe von Stücken anderer Herkunft hinzu, die u.a. auf das Großprioratsarchiv Böhmen zurückgehen.

236 Vgl. O 1 S. 22 f. 
Kopien des 14. Jahrhunderts aus dem englischen Großpriorat ${ }^{237}$. Alle 18 bisher unbekannten Stücke aus Sizilien stammen aus der Sammlung Amicos, der nach eigenen Aussagen Vorlagen aus dem Archiv des Großpriorats in Messina hatte, so daß auch seine Abschriften mit einer allgemeinen Adresse oder Bestimmung unmittelbar an das Großpriorat Messina gegangen sein dürften ${ }^{238}$. Den Beweis liefert das bereits für den Kreuzzugsaufruf Lucius' III. erwähnte Chartular aus Santo Crucifijo in Puente la Reina im Archiv von Pamplona. Trotz seines heutigen Lagerortes stammen seine Texte, wie die erste kopierte Urkunde Clemens' V. Ad providam von 1312 in der an die Prälaten von Trinacriba (sic) gerichteten Ausfertigung, und die fast völlige Übereinstimmung mit den Kopien Amicos zeigen, aus dem Archiv des Großpriorats Messina.

Damit sind als Ergebnis unter Messina zwei neue Abschnitte für die Großpriorate der beiden Ritterorden mit etwa 30 Regesten für die Johanniter ${ }^{239}$ und drei für die Templer einzufügen. Die Ergebnisse gehen freilich weiter, denn aus einer Verfügung Alexanders III. zugunsten der Kollektensammlungen für die Johanniter ergibt sich, daß bei ihnen Kalabrien organisatorisch zu Sizilien gehörte ${ }^{240}$, während nach einer anderen Verfügung des gleichen Papstes bei den Templern anscheinend die Straße von Messina die Verwaltungsgrenze bildete ${ }^{241}$.

Es bleiben die Bullarien im Archiv von Valletta. Wie das Chartular in Pamplona begann das verlorene, aber nun dank Vol. 1132 rekonstruierbare Bullarium B quintum, das 30 Papsturkunden des 12. Jahrhunderts für die Johanniter und acht für die Templer enthält, von denen nur fünf bereits bei Jaffé verzeichnet sind, mit Clemens' V. „Ad providam“, hier freilich an die Erzbischöfe von Bari und Brindisi und den Bischof von Canosa di Puglia gerichtet. Auch weitere Stücke des 12. Jahrhunderts im Bullarium B betreffen Apulien ${ }^{242}$, keines eine andere Region. Als Basis diente damit offensichtlich das Archiv in Barletta, so daß dort der bereits vorhandene Abschnitt für das Großpriorat der Johanniter mit 28 Regesten für allgemeine Verfügungen und einem neuen

237 So z. B. eine an die Johanniter in Schottland gerichtete Verfügung Urbans III. Sicut evangelica veritate über die Entgegennahme von testamentarischen Verfügungen in einer Sammelkopie von 1326, ed. KeHr, Papsturkunden in Italien (wie Anm. 5) 2 S. 126 Nr. 47. Dadurch steht auch für Alexander III. Commissi nobis offici von 1177 April 7, ed. ebd. S. 113 Nr. 13 und Lucius III. Dilecti filii von (1182) August 13, ed. ebd. S. 122 Nr. 37 die Herkunft aus dem englischen Ordensarchiv fest. So ergibt die Nachlese in Italien auch einen Beitrag für die Anglia Pontificia.

238 Die meisten finden sich auch in der Sammlung des 18. Jahrhunderts (Qq. H. 203), die auch Texte aus anderen Archiven zur Verfügung hatte, aber keines ist nur dort überliefert.

239 Die Zahl steht wegen Doppelungen und einem leicht abweichenden Bestand im Bullarium von Pamplona noch nicht fest.

240 Alexander III. Quanta religione dilecti von (1179-1181) Februar 15, ed. KeHR, Papsturkunden in Italien (wie Anm. 5) 2 S. 70 Nr. 14.

241 Alexander III. Quanto maiora von (1166-1178) Juli 4, ed. ebd. S. 435 Nr. 15.

242 Vgl. IP 9 S. 306 Nr. 3 und 4 zu (1186-1187) Juli 18. 
Abschnitt für das Großpriorat der Templer mit acht Regesten erweitert werden kann.

Offen bleibt die Herkunft des verlorenen Bullarium A quartum und des erhaltenen Bullarium C sextum. Jenes stammt, wie eine Reihe von Stücken zeigt, die entweder das nördliche Gebiet des Normannenreiches oder Verfügungen König Rogers II. nennen, ebenfalls aus dem festländischen Süditalien, könnte aber Material aus Capua und aus Barletta enthalten, dieses, ein mixtum compositum, enthält Urkunden aus Rom und Mittelitalien. Für eine sichere Zuweisung ist es freilich noch zu früh.

Doch die genaue Untersuchung von Bullarium B und Bullarium A werfen ein historisches Problem auf. Beide enthalten eine Ausfertigung des kleinen Privileg für die Johanniter Quam amabilis deo mit der Ablaßzusage für Wohltäter des Ordens durch Viktor IV. vom Herbst 1159, obwohl sie in einem Gebiet entstanden sind, das nach allgemeiner Auffassung zur Oboedienz Alexanders III. gehörte. Selbst wenn man daraus schließen muß, daß die süditalienischen Johanniter wie nachweislich die Templer des Hauses auf dem Aventin und anfangs die Kirche der Kreuzfahrerstaaten auf der Seite Viktors IV. gestanden hatten und sich von ihm Urkunden ausstellen ließen, so wird doch auffälligerweise noch im 15. Jahrhundert eine Urkunde des Gegenpapstes, die mit Leichtigkeit gegen eine gleichlautende eines anderen ,rechtgläubigen' Papstes hätte ausgetauscht werden können, in eine offizielle Sammlung von Ordensurkunden aufgenommen und selbst an der Kurie anstandslos von einem höchsten päpstlichen Beamten beglaubigt ${ }^{243}$.

Als Ergebnis läßt sich festhalten, daß für die Templer und Johanniter neben dem erheblichen Zuwachs an bisher unbekannten Stücken durch die Nachlese mit dem Auffinden von Vol. 1132 in Valletta und später durch die Nachlese für den Oriens Pontificius in Spanien die Überlieferungswege der Papsturkunden in den erhaltenen und den verlorenen Bullarien erfaßbar geworden sind. Auf diese Weise lassen sich nun dank dieses methodischen Ansatzes viele Stücke trotz allgemeiner Adresse einem bestimmten Raum bzw. einem bestimmten Archiv auf der mittleren Ebene der Ordenshierarchie, hier den Großprioraten Messina und Barletta, weniger eindeutig denjenigen von Capua und Rom zuordnen. Wenigstens deren einstige Bestände an originalen Papsturkunden des 12.-15. Jahrhunderts können teilweise rekonstruiert und der „Italia Pontificia“ zugewiesen werden. Auf dem gleichen methodischen Wege lassen sich andere Stücke

243 Es sei daran erinnert, daß das berühmte Privileg Paschalis’ II. nicht nur nachträgliche Unterschriften Calixts II. und einiger Kardinäle und Bischöfe aus seinem Pontifikat aufweist, sondern zwei Nachzeichnungen des 17. Jahrhunderts aus dem Großpriorat Navarra anstelle von anno quarto der Datierung für Calixt II. noch als Ansatz zu einer dritten Papstunterschrift ein Ego Vict. folgen lassen, was kaum auf jemand anderen als Viktor IV. bezogen werden kann, vgl. O 2 S. 194 f. Nr. 1, hier S. 195. 
des Archivs in Valletta dem englischen Ordensarchiv zuweisen. Dies zeigt aber auch, wie entscheidend für ,internationale' Orden, hier die Templer und Johanniter, für ,internationale' Bewegungen, hier den Kreuzzug und erst recht für das ,internationale‘ Wirken des Papsttums und der päpstlichen Kanzlei das den einzelnen Raum übergreifende Zusammenwirken der Forschung ist.

Zum anderen wird durch die Überlieferung von zwei neuen Kreuzzugsaufrufen in Handschriften in Malta und in Palermo, aber auch in dem zuerst so fern scheinenden Navarra mitten unter Papsturkunden für die Ritterorden einerseits der Anteil Italiens an den Kreuzzügen deutlicher, andererseits die bisher weitgehend übersehene Rolle der Ritterorden für die Verbreitung der päpstlichen Kreuzzugsaufrufe ins Licht gerückt. Dies kann nur auf einen ganz gezielten Einsatz der zentralistisch-hierarchischen Ordensstruktur durch die päpstliche Kanzlei zurückgeführt werden ${ }^{244}$.

\section{VII.}

Faßt man die Ergebnisse zusammen, so hat die Nachlese in den italienischen Archiven und Bibliotheken nicht viel an neuen Texten, aber einiges sehr Wichtiges für die Geschichte der Kreuzfahrerkirche und der Kreuzzüge ergeben ${ }^{245}$, allerdings nur sehr weniges für die abendländischen Niederlassungen im lateinischen Osten. Noch einmal hervorgehoben seien das Original des feierlichen Privilegs für Beirut als Unikat aus der ganzen Kreuzzugszeit und die Kopie einer Verfügung Coelestins III. für die Lazariter. Sie öffnen je ein neues Feld für den künftigen Oriens Pontificius latinus, wie zahlenmäßig die 26 neuen Papsturkunden für die Diözesankirchen aus italienischen Überlieferungen angesichts der kläglichen Überlieferung an Papsturkunden aus dem Hl. Land eine beträchtliche Vermehrung der Quellenbasis darstellen. Für die beiden großen Ritterorden brachte die Arbeit an der „Italia Pontificia“ insgesamt 79 neue Stücke ${ }^{246}$, prozentual sicher weniger, doch hier gelingt es, mit den Ergebnissen der Nachlese für den Oriens die Archivgeschichte auf eine neue Grundlage zu stellen. Dies zeigt, wie viel die Kreuzzugsforschung der Nachlese Kehrs in Italien und dem Papsturkundenunternehmen schuldet. Es wäre zu wünschen, daß sie sich dessen stärker bewußt wird.

Andererseits verdankt man von der „Italia Pontificia“ her den Papsturkunden des 12. Jahrhunderts für Institutionen des Hl. Landes Nachrichten über

244 Vgl. dazu meinen Beitrag "The Military Orders and Papal Crusading Propaganda“, in: The Military Orders, Volume 3: History and Heritage, hg. v. Victor Mallia-Milanes, Aldershot 2008, S. 155-165.

245 Siehe die Einzelnachweise oben.

246 Diese Zahl wie erwähnt ohne die von Delaville zwischen dem Erscheinen der zweiten Auflage des Jaffé und dem Beginn der Nachlese neu zugänglich gemachten Stücke. 
Dutzende von Kirchen und Klöstern auf italienischem Boden von Agrigento bis Varazze, die dem Hl. Grab, den Abteien S. Maria Latina, S. Maria im Tale Josaphat und S. Maria auf dem Sionsberg gehörten und ohne entsprechende lokale Überlieferung nur auf diesem Umweg ins Bewußtsein der Kurie gebracht wurden. Ihre Auswertung ist noch keineswegs abgeschlossen.

Es bleibt freilich auch die andere Seite. Mehrfach wurde von der Kreuzzugsforschung her auf Lücken in der "Italia Pontificia“ hingewiesen, die über einzelne Fakten hinaus methodische Fragen aufwarfen und auch für die künftige Arbeit an anderen Pontificiae gelten, zum Teil dort schon Beachtung gefunden haben. Sie schmälern nicht die Bewunderung für die Leistung Kehrs, der in den acht Jahren von 1906 bis 1914 sieben Bände der „Italia Pontificia“ vorlegte, bis der erste Weltkrieg und die neuen Aufgaben in Berlin nur noch beschränkt Zeit für die „Italia Pontificia“ ließen. Sie wirkten sich auf allen drei Feldern, vor allem auf das Bild der Kreuzzüge aus und gehen zu einem erheblichen Teil auf die restriktive Konzeption zurück, die Kehr in den ersten Bänden leitete und bis zum Band X in hohem Maße von jenem Ziel der urkundlichen Archivgeschichte als Vorbereitung der künftigen Edition bestimmt war. So blieben anfänglich Nachrichten über Beziehungen, die mehr die Person als die jeweilige Kirche betrafen, wie die Einsetzung von Bischöfen, Äbten usw. als Legaten und delegierte Richter, aber auch Vorgänge außerhalb Roms unter Mitwirkung der Päpste unberücksichtigt. Für das Verhältnis von Papsttum und Kreuzzug beginnt dies schon mit dem Konzil von Piacenza von 1095 und dem berühmten Hilferuf des Basileus Alexios I. Komnenos, die nicht einmal in der Narratio zu Piacenza erwähnt wurden ${ }^{247}$ und schließt die nicht aufgenommene Bestellung von italienischen Geistlichen zu Legaten als Vertretern des Papstes auf den Kreuzzügen und im lateinischen Osten ein.

Neben diesen personenbezogenen Nachrichten läßt sich strukturell bedingt aus der „Italia Pontificia“ nicht erkennen, wo überall, wie nochmals wiederholt sei, auf der Apenninenhalbinsel und Sizilien die Kirchen des Hl. Landes vom Papsttum bestätigten Besitz hatten, wie solcher selbst, wo er erwähnt wird, oft nur versteckt in den Narrationes begegnet. Komplexer ist diese Frage bei den Ritterorden. Feierliche Privilegien für die Templer und die Johanniter mit Besitzlisten für Italien besitzen wir anders als für die Kanoniker der Grabeskirche nicht. Doch übersehen worden sind auch, wohl aus der Geschichte des Unternehmens, das erst nach dem Abschluß von Mittel- und Norditalien (IP 1 -7) sich der Nachlese auf der Iberischen Halbinsel zuwandte, der Besitz des kurzlebigen Ordens vom Mons Gaudii, der Santiagoritter, des Ordens von Calatrava und auch der Kathedrale von Santiago de Compostela in Oberitalien, den sie sich von der Kurie ausdrücklich bestätigen ließen. Ähnliches gilt für den südlich der Alpen gelegenen Besitz großer französischer Abteien, was alles Aufgaben für

$247 \mathrm{Zu}$ erwähnen in IP 5. 
die künftige Arbeit an den Regesta Pontificum Romanorum aufzeigt. Das Bild des Kreuzzuges und des Anteils des Papsttums an ihm bleibt in der „Italia Pontificia" wie nicht anders zu erwarten ein Mosaik mit vielen Lücken, doch die Nachlese Kehrs und seiner Mitarbeiter hat diesem Mosaik nicht wenige neue Steine hinzufügen können.

\section{Riassunto}

Nella storia delle crociate l'Italia, a parte il papato, non gioca un ruolo preponderante se non come terra di passaggio per l'Oriente e per i quartieri delle città marinare sulla costa siriana. In più, quando il Kehr cominciò la revisione degli archivi, la ricerca sulla crociata aveva raggiunto un primo apogeo coll'edizione delle fonti documentarie grazie ai Röhricht, Delaville le Roulx, Prutz ecc. Perciò non erano da aspettarsi nuovi fondi sconosciuti per le istituzioni ecclesiastiche o secolari dell'Oriente, tratti in salvo dopo il 1187 o il 1291, mentre in Oriente Turchi e Mamlucchi avevano fatto tabula rasa.

Malgrado ciò la „vendemmia“ ha dato frutti molto importanti aumentando la documentazione pontificia per la chiesa diocesana in Oriente di un quarto come p. es. un privilegio di Lucio III per la chiesa di Beirut, singolare per l'Oriente latino. Ma sia le ricerche archivistiche del Kehr che l'Italia Pontificia sono stato per lungo tempo tralasciate dagli storici delle crociate. Ancora più rilevante si rivelò un gruppo d'appelli papali a partire d'Urbano II per i monaci di Vallombrosa fino a Clemente III per i crociati toscani, mettendo l'Italia nella propaganda papale accanto alla Francia ecc. che fin'oggi a torto domina il quadro generale. Particolarmente importanti furono inoltre le nuove bolle per gli ordini militari, Templari e Ospedalieri, conservatici in manoscritti a Palermo e Malta, il cui valore era sfuggito al Delaville, in modo minore tali per i canonici del S. Sepolcro ed i lebbrosi di San Lazzaro. In quanto ai dieci volumi dell'Italia un numero non esiguo di regesti riguarda le crociate che non entravano originariamente nel progetto, come tante notizie tralasciatevi saranno da riassumere in un volume di additamenta.

Per tale rivalutazione segue una lista di 57 nuove bolle per il movimento crociato nel senso largo che serviranno a future ricerche. 


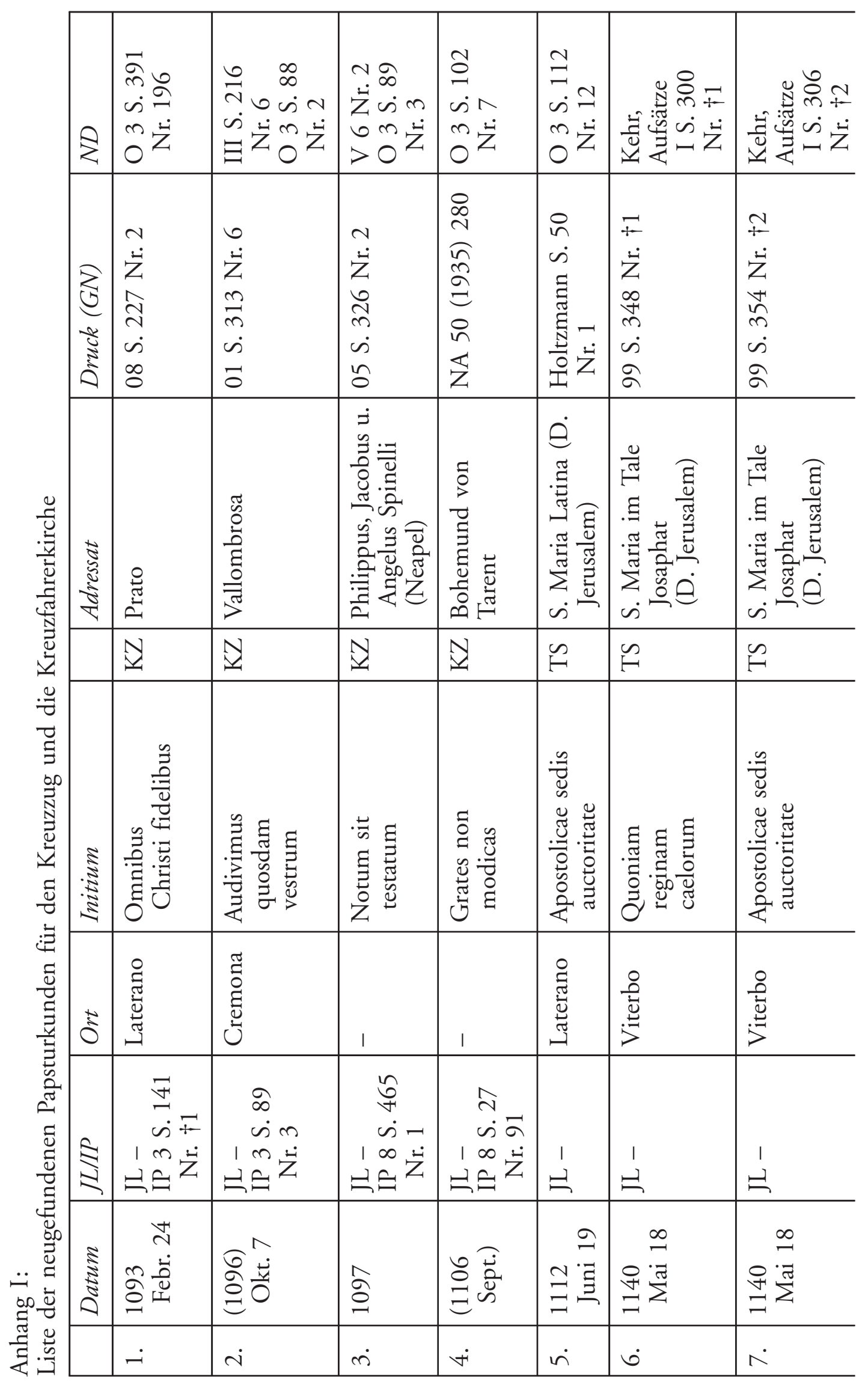




\begin{tabular}{|c|c|c|c|c|c|}
\hline & 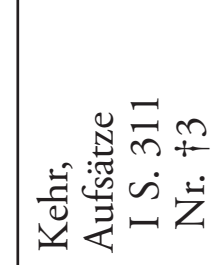 & 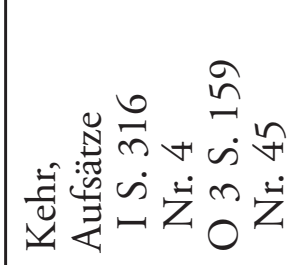 & 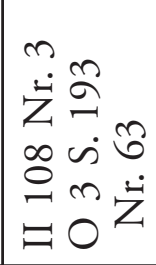 & 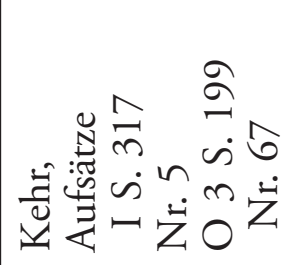 & $\begin{array}{l}\sim \\
\cdots \\
\dot{z} \\
\infty \\
\infty \\
+1 \\
z\end{array}$ \\
\hline & $\begin{array}{l}m \\
\dot{n} \\
\dot{z} \\
\hat{n} \\
\tilde{n} \\
\dot{a} \\
\hat{a}\end{array}$ & $\begin{array}{l}+ \\
\dot{z} \\
\dot{n} \\
\stackrel{n}{n} \\
\dot{n} \\
\grave{a}\end{array}$ & $\begin{array}{l}n \\
\dot{z} \\
\infty \\
\infty \\
\dot{m} \\
\dot{n} \\
\check{\sigma}\end{array}$ & $\begin{array}{l}n \\
\dot{z} \\
\tilde{n} \\
\dot{n} \\
\dot{n} \\
\tilde{a}\end{array}$ & 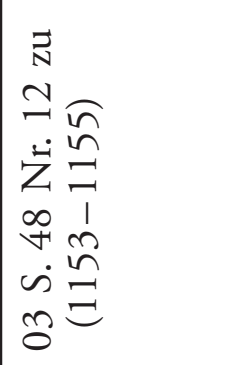 \\
\hline & 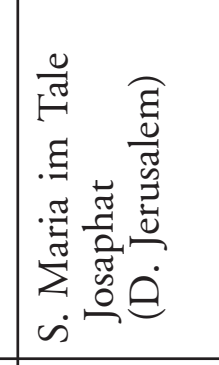 & 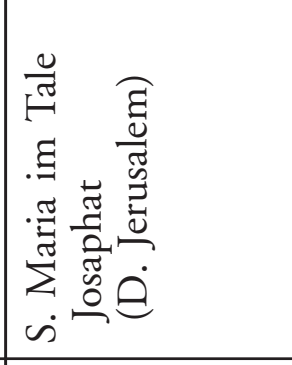 & 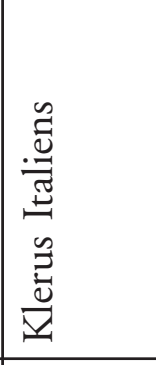 & 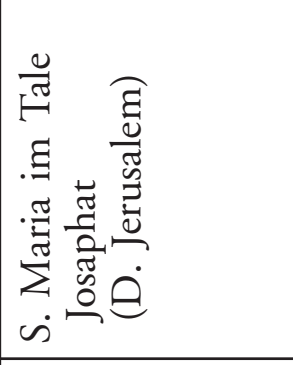 & 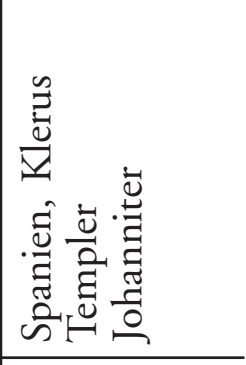 \\
\hline & $\mathscr{H}$ & $\mathscr{H}$ & 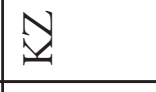 & $\mathscr{H}$ & \pm \\
\hline & 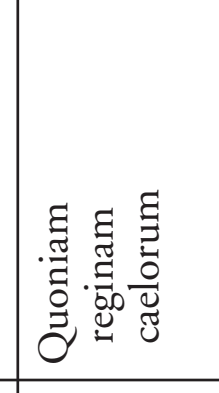 & 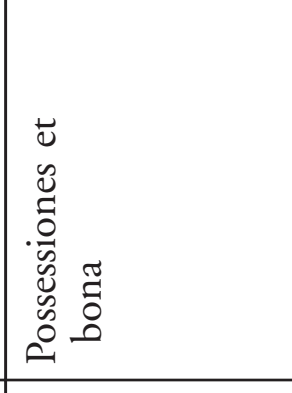 & 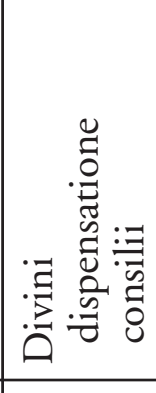 & 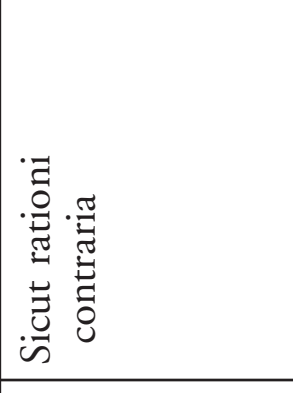 & 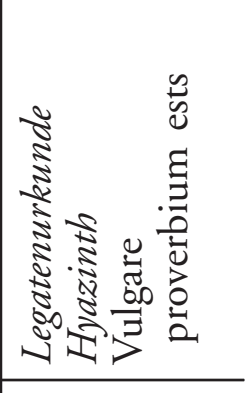 \\
\hline & 意 & 莺 & 离 & 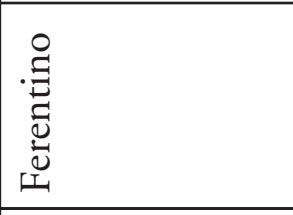 & \\
\hline & $\stackrel{1}{\varrho}$ & $\stackrel{1}{\doteq}$ & 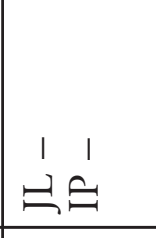 & $\stackrel{1}{\varrho}$ & 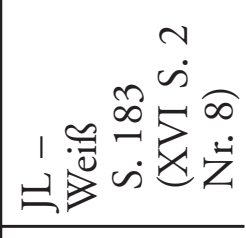 \\
\hline & $\begin{array}{l}\sum_{i}^{\pi} \\
0 \\
\stackrel{+}{*} \infty \\
=\end{array}$ & 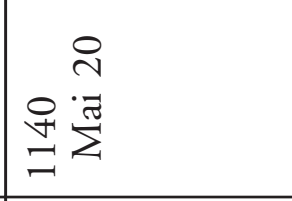 & $\begin{array}{l}\sigma_{0}^{n} \\
\stackrel{\dot{y}}{0} \\
\underbrace{0}\end{array}$ & 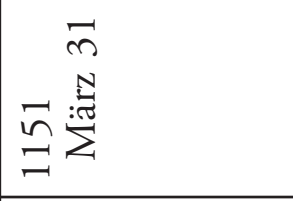 & 点 \\
\hline & $\infty$ & $\dot{a}$ & $\stackrel{0}{0}$ & $\doteq$ & $\stackrel{i}{i}$ \\
\hline
\end{tabular}




\begin{tabular}{|c|c|c|c|c|c|c|c|}
\hline$\xi$ & 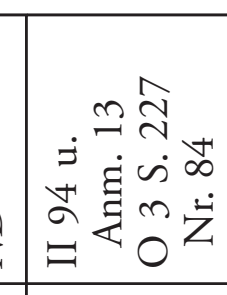 & 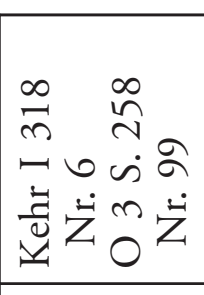 & 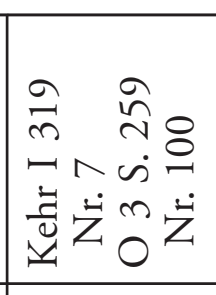 & 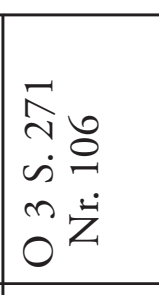 & 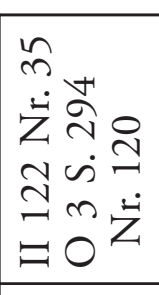 & 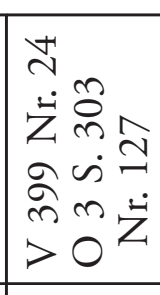 & 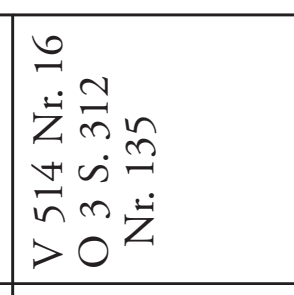 \\
\hline కְ & 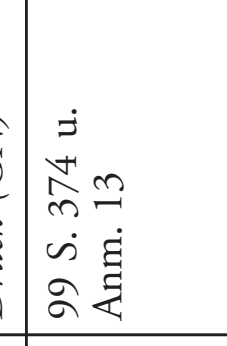 & $\begin{array}{l}0 \\
\dot{z} \\
0 \\
0 \\
0 \\
\dot{n} \\
\sigma \\
\sigma \\
\end{array}$ & $\begin{array}{l}n \\
\dot{z} \\
\hat{\sigma} \\
\dot{\omega} \\
\dot{\omega} \\
\alpha \\
\sigma\end{array}$ & 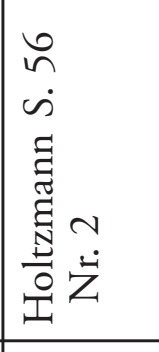 & 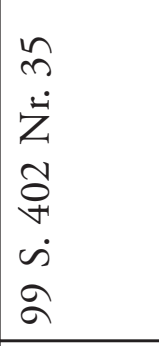 & 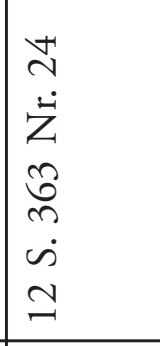 & 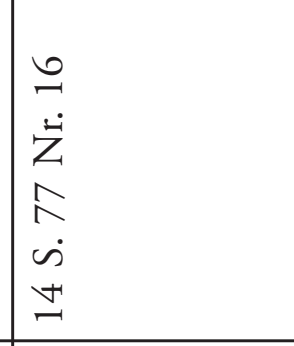 \\
\hline 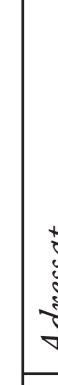 & 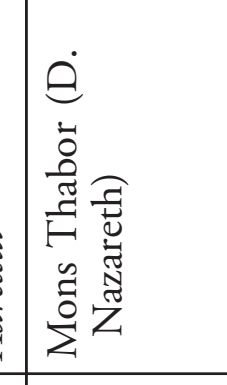 & 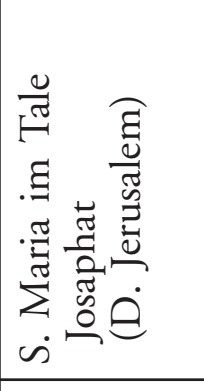 & 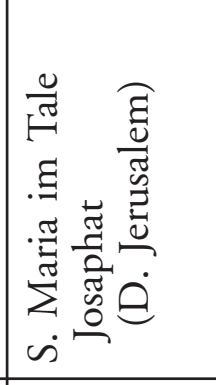 & 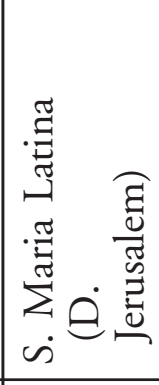 & 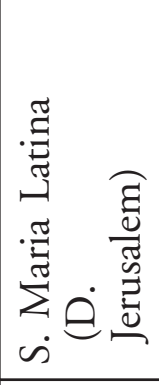 & 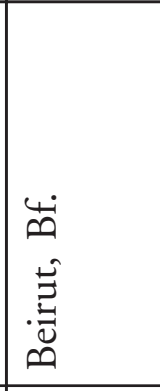 & 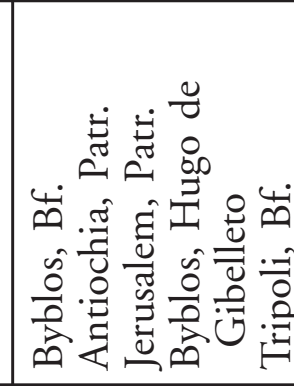 \\
\hline & $\mathscr{n}$ & $\stackrel{n}{\mu}$ & $\tilde{H}$ & $\mathscr{H}$ & 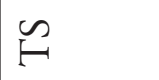 & $\tilde{H}$ & $n$ \\
\hline 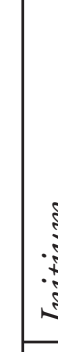 & 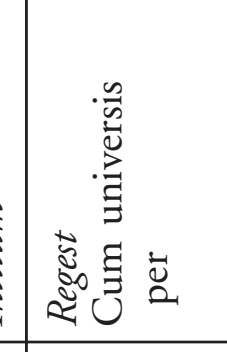 & 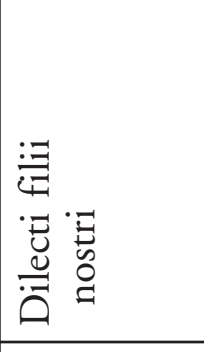 & 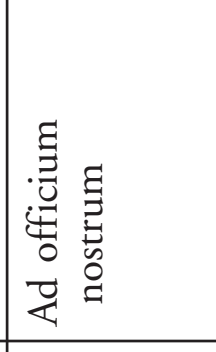 & 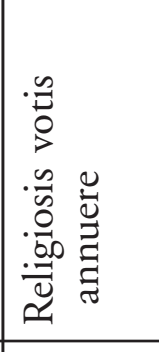 & 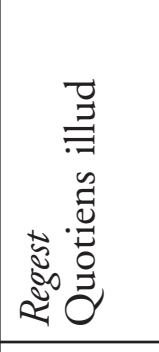 & 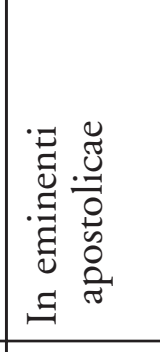 & 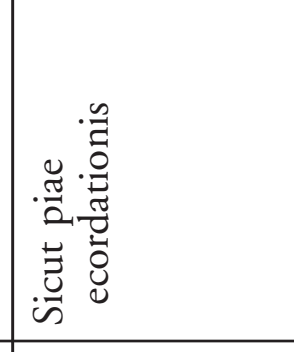 \\
\hline 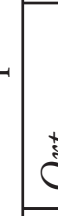 & 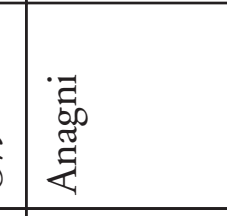 & 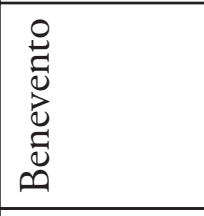 & 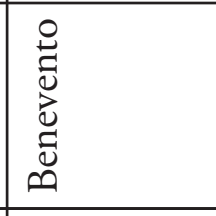 & 苑 & 1 & 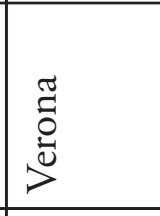 & 竞 \\
\hline & $\stackrel{1}{=}$ & $\stackrel{!}{\lrcorner}$ & $\stackrel{1}{g}$ & $\stackrel{1}{=}$ & $\stackrel{1}{\lrcorner}$ & $\begin{array}{l}1 \\
= \\
\end{array}$ & 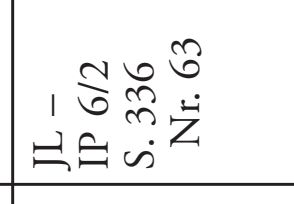 \\
\hline 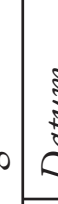 & 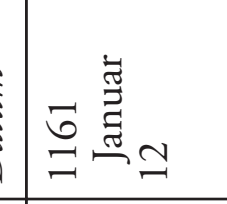 & 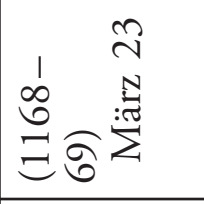 & 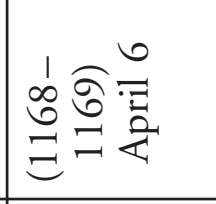 & 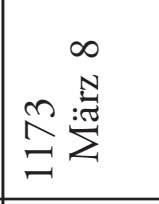 & 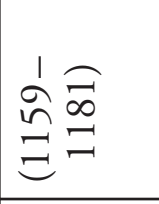 & 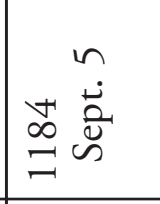 & 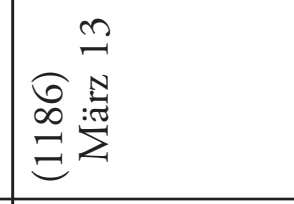 \\
\hline & $\dot{9}$ & $\stackrel{ \pm}{ \pm}$ & $\dot{n}$ & $\stackrel{\circ}{-}$ & 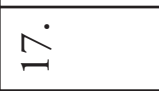 & $\stackrel{\infty}{\rightarrow}$ & $\stackrel{2}{2}$ \\
\hline
\end{tabular}




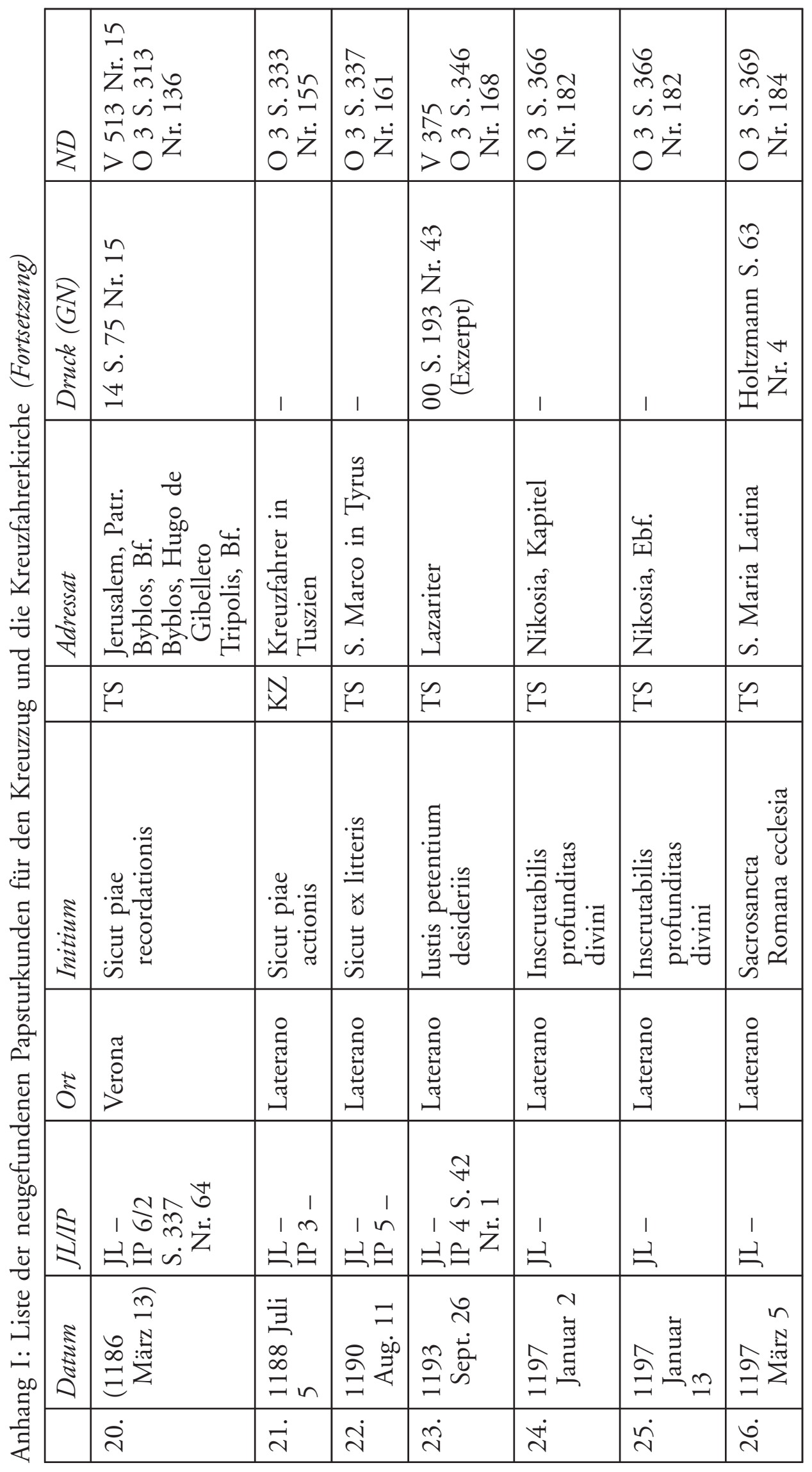




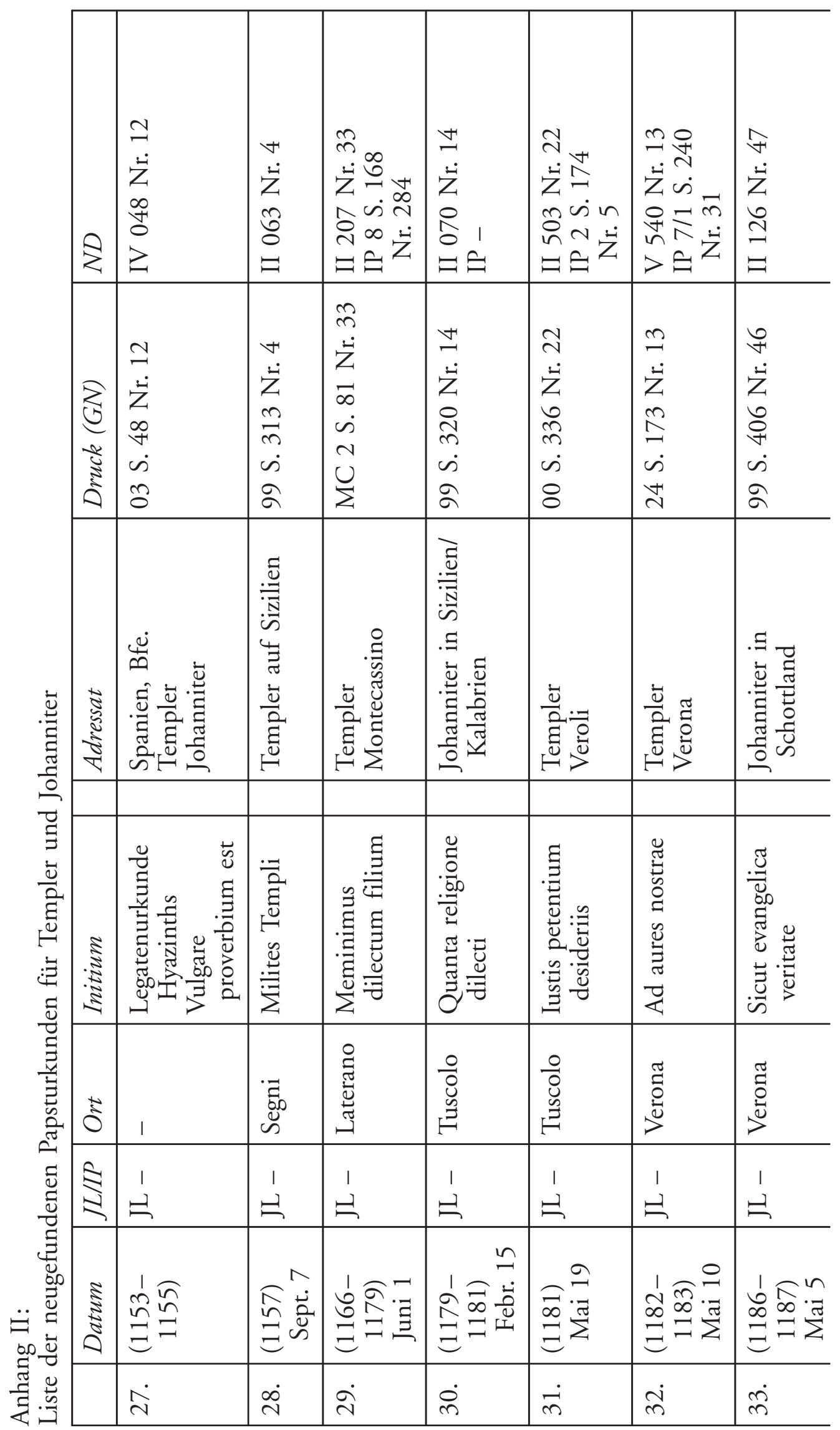




\begin{tabular}{|c|c|c|c|c|c|}
\hline & $\underset{z}{2}$ & 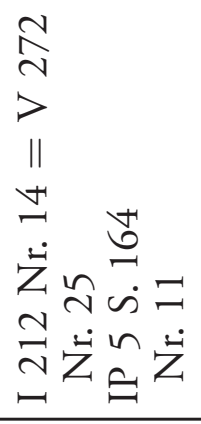 & $\begin{array}{l}\hat{\lambda} \\
\dot{\vec{z}} \\
\ddot{2} \\
\stackrel{i}{a} \\
>\end{array}$ & 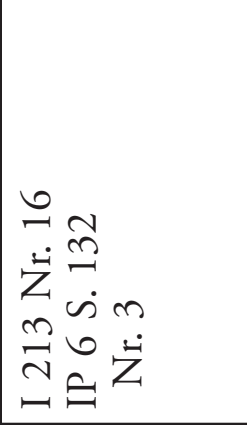 & 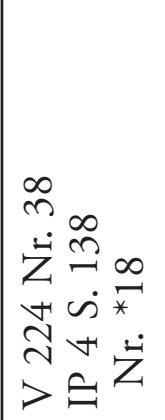 \\
\hline & 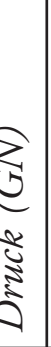 & 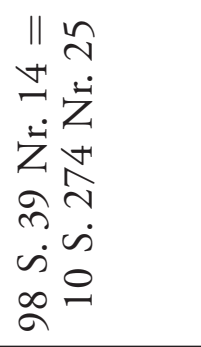 & 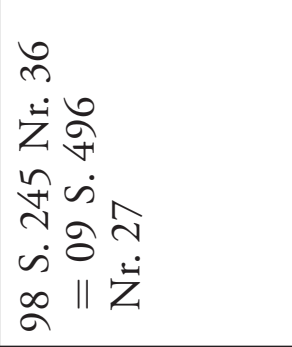 & $\begin{array}{l}\stackrel{\vartheta}{Z} \\
\dot{\vec{z}} \\
o \\
+ \\
\dot{\infty} \\
\infty \\
a\end{array}$ & $\begin{array}{l}\infty \\
i \\
\dot{z} \\
o \\
\dot{n} \\
\dot{n} \\
\dot{0}\end{array}$ \\
\hline & हैं & 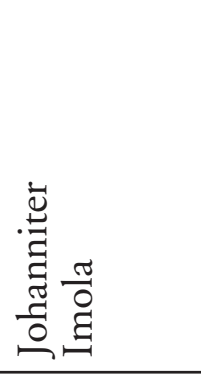 & 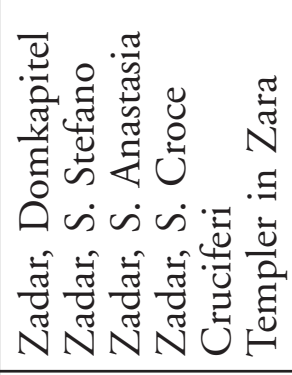 & 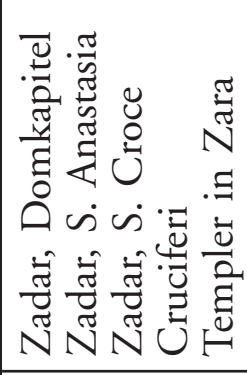 & 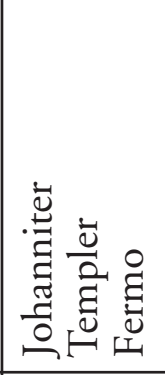 \\
\hline & & & & & \\
\hline & $\begin{array}{l}5 \\
\text { है } \\
\text { ह }\end{array}$ & 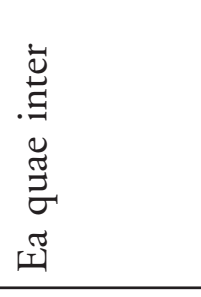 & 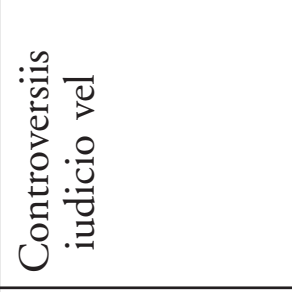 & 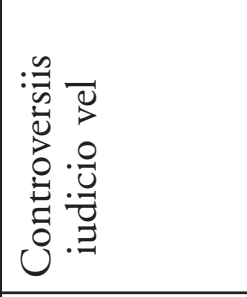 & 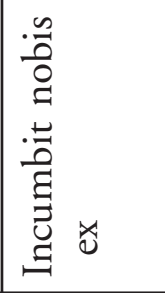 \\
\hline & $\Xi$ & 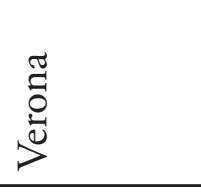 & 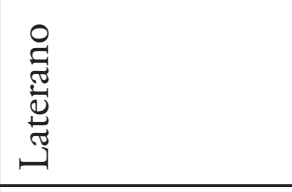 & 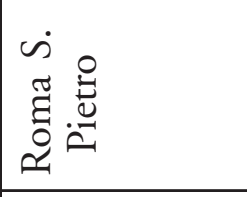 & 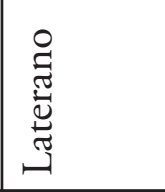 \\
\hline & $\$$ & $\stackrel{1}{\Perp}$ & $\stackrel{1}{\varrho}$ & $\stackrel{1}{=}$ & $\stackrel{1}{\varrho}$ \\
\hline & $\begin{array}{c}\tilde{5} \\
\mathbf{5}\end{array}$ & 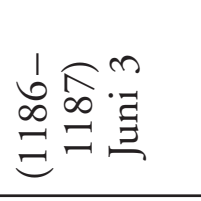 & 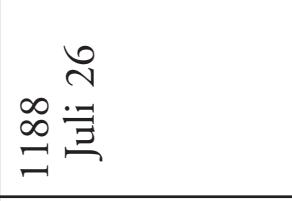 & $\begin{aligned} & \vec{\lambda} \\
& \vec{\Xi} \vec{\Xi} \\
& \vec{\Xi}\end{aligned}$ & 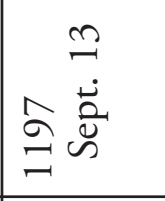 \\
\hline & & 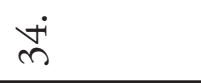 & $\ddot{n}$ & $\dot{n}$ & m \\
\hline
\end{tabular}

